An Experimental Study of Heavy-Mineral Segregation Under Alluvial-Flow Conditions

GEOLOGICALSURVEY PROFESSIONAL PAPER $562-\mathrm{K}$ 


\section{An Experimental Study of Heavy-Mineral Segregation Under Alluvial-Flow Conditions}

By LAWRENCE L. BRADY and HARVEY E. JOBSON

SEDIMENT TRANSPORT IN ALLUVIAL CHANNELS

GEOLOGICAL SURVEY PROFESSIONAL PAPER $562-\mathrm{K}$

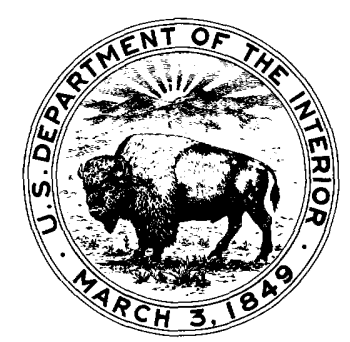

UNITED STATES GOVERNMENT PRINTING OFFICE, WASHINGTON : 1973 


\section{UNITED STATES DEPARTMENT OF THE INTERIOR \\ ROGERS C. B. MORTON, Secretary}

GEOLOGICAL SURVEY

V. E. McKelvey, Director

Library of Congress catalog-card No. 73-600017 


\section{CONTENTS}

Abstract

Introduction

Theoretical considerations

Relative velocities of water-transported particles with differing densities

Shear stress as a density-segregation parameter

Bed forms produced by flow in an alluvial channel

Relation of grain entrainment to turbulence ...Summary

Experimental runs and results of sediment analysis..

Hydraulic measurements

Sediment analysis

Sediment characteristics

Size analyses - total bed material ...........

Size analyses-suspended sediment

Size analyses-core samples

Experimental results

Summary of bed form and opaque-heavy-

mineral segregating characteristics

Dune bed forms (run 1)

Dune bed forms (run 2)

Transition bed forms (run 3)
Experimental results-Continued

Summary of bed form and opaque-heavymineral segregating characteristics-Con.

Bed forms of moving flat-bed

Relation of fall velocities of dark opaque

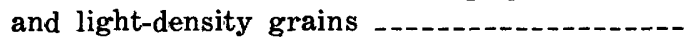

Relation of grain entrainment to critical shear stress and grain size

Heavy-mineral transport and deposition

in a flat-bed flow

Discussion of data

Relations among sediment samples -..........

Bed forms and hydraulic variables -........-..Conclusions

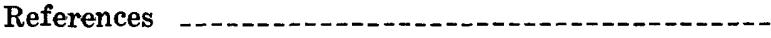
Appendix:

A. Symbols and nomenclature -...-

B. Grain-mount preparation and relationship of direct grain measurements to sieve-size equivalents

C. Analyses of opaque-heavy-mineral grains and light-mineral grains from core samples (runs 2-4)

D. Sediment concentration and size analyses of suspended-sediment samples --
Page K17

25

25

27

29

\section{ILLUSTRATIONS}

Figure 1. Graph showing resistance of a particle to motion as a function of the ratio of its size to the size of the bed material

2. Schematic diagram of forces acting on a discrete moving particle in a fluid

3-4. Graph showing-

3. Velocity ratios for spheres of equal size but of different densities

4. Velocity ratios of spheres that have equal submerged weight but different densities

5. Shields diagram showing sediment entrainment as a function of the particle Reynolds number ...-

6. Idealized diagram of bed forms in an alluvial channel

7. Dune profile showing dune terminology

8. Schematic diagram of the flume used in the four experimental runs

9. Size distribution curves for sand used in the flume

10-12. Photographs:

10. Dune bed configuration and opaque-heavy-mineral accumulations at the bed surface following run 1

11. Dune bed configuration of run 2

12. Accumulations of dark opaque heavy minerals on the upstream sides of dunes (run 2) 
FIGURE 13. Sketch of a dune showing structures and locations of different types of opaque-heavy-mineral accumulations

14-19. Photographs:

14. Opaque-heavy-mineral accumulations in foreset and topset beds of dunes formed in run 2 .-

15. Bed configuration and opaque-heavy-mineral accumulation at the bed surface formed during run 3

16. Accumulations of opaque heavy minerals formed along the crestal region of a dune (run 3) -

17. Opaque-heavy-mineral accumulations formed in topset and foresetbeds during run 3 .....

18. Flat-bed surface formed by run 4

19. Profile of flat-bed flow deposits showing opaque-heavy-mineral layers within the flat-lying beds

20-23. Graph showing-

20. Fall-velocity relationship of light-mineral grains to opaque-heavy-mineral grains obtained from the bed-material sample and core samples of runs 2, 3, and 4

21. Plot of median fall velocities of opaque-heavy-mineral grains and light-mineral grains

22. Critical shear relationship of light minerals to opaque heavy minerals for the bed material and core samples

23. Relation of magnetite in transport to time in $20-\mathrm{cm}$ flume and under flat-bed conditions

24. Photograph of sections of core samples showing opaque-heavy-mineral beds

\section{TABLES}

2. Hydraulic variables and parameters of runs.

3. Mean dune size (with standard deviations) measured by sonic sounder

4. Results of a resistance-to-motion experiment using a poorly sorted quartz bed material .......

5. Size analyses of opaque heavy minerals from core samples

6. Size analyses of light minerals associated with opaque heavy minerals in the core samples

7. Size analyses and concentration of suspended-sediment samples 


\title{
AN EXPERIMENTAL STUDY OF HEAVY-MINERAL SEGREGATION UNDER ALLUVIAL-FLOW CONDITIONS
}

\author{
By Lawrence L. Brady and Harvey E. Jobson
}

\begin{abstract}
Segregation of opaque minerals (mainly ilmenite and magnetite) from the light minerals in a natural sand was observed in a large $(61 \times 2.44 \times 1.22$ meters $)$ recirculating watersediment flume. Bed material (median size 0.286 millimeter) used in the study was taken from the Rio Grande near Bernardo, N. Mex. Opaque heavy minerals (median size 0.144 millimeter) amounted to 0.38 percent of the bed-material volume. Significant hydraulic variables and the sorting and bedding patterns of the bed material were observed for four different bed configurations: a flat bed (upper flow regime), a transition bed, and two different dune beds (lower flow regime).

Accumulations of opaque heavy minerals were formed as three basic types:

1. Thin accumulations of small extent that were associated with the upstream or stoss slopes of dunes;

2. Accumulations associated with the topset deposits of large dunes and with dunes formed in the transition flow;

3. Accumulations associated with the flat-bed condition.

The most important factors influencing the type and amount of accumulation of opaque heavy minerals are bed configuration and grain density. The most widespread deposits were the segregations of heavy minerals associated with the base of the flat beds. The thickest deposits of opaque-heavy-mineral grains were associated with topset deposits of dune beds, but local conditions must be optimum for thick accumulations to occur. The importance of a mineral's density to segregation is shown by considering theoretically the forces necessary to move grains of two different densities and by analyzing the size distribution of light and heavy minerals in the bed-material and core samples of the laboratory experiments using a Shields' type criteria for initiation of motion.

Sediment size, sorting, and shape were determined for each mineral group from core samples taken from the bed. The sorting of the opaque heavy minerals for the flat-bed run was significantly different from the sorting of these minerals for the other runs.

Median sizes of the light minerals which were obtained from laminae adjacent to or within the heavy-mineral laminae also showed a significant variation among runs. Fall velocities of the grains of the two different mineral groups were found to have little importance as local segregating mechanisms.
\end{abstract}

\section{INTRODUCTION}

In an alluvial channel, bedding patterns produced in sediment are responses to the hydraulic variables of flow. Variations in sorting as well as the segregation of materials according to shape and density are important elements in the production of bedding structures and in recognition of the structures in sediments and sedimentary rocks.

Relatively little is understood about the local hydraulic conditions or the sediment responses to these conditions that are responsible for sorting of sediments. The relative densities of particles and the streamflow characteristics have long been assumed to be important factors in sorting, but their relative contributions to the sorting process have not been well understood.

The relationship of heavy minerals to the more common low-density minerals was first described in relation to given hydraulic conditions by Rubey (1933). Fall velocity was considered by Rubey to be the most important segregating mechanism accounting for the close association of small highdensity grains with low-density but larger mineral grains in a sediment. Other factors considered important by Rubey $(1933$, p. 3) were density and hardness of the minerals, differences in original sizes of the grains in the source rock, amount of abrasion during transport, and degree of sorting at the site of deposition.

Rittenhouse (1943) used the concept of hydraulic equivalence to explain mineral relations in sands of the Rio Grande in New Mexico. He described hydraulic equivalence (p. 1749) as "whatever the hydraulic conditions may be that permit the deposition of a grain of particular physical properties, these conditions will also permit deposition of other grains of equivalent value." The distribution of heavy minerals in the streambed was considered by 
Rittenhouse (1943, p. 1742-1743) to be caused by varying hydraulic conditions at the time and place of deposition, equivalent hydraulic size of each of the heavy minerals, availability of the minerals, and unknown factors.

Studies on sorting of minerals with different densities were conducted simultaneously with studies of turbulence, bed resistance, and sediment transport at the Engineering Research Center at Colorado State University. Experiments were conducted in a large recirculating sediment flume using natural sand from the Rio Grande south of Albuquerque, N. Mex. This research was undertaken in an effort to find what sediment properties and hydraulic variables are responsible for the rapid segregation of certain heavy minerals during movement and deposition of a sediment load.

Four flow conditions were studied at near equilibrium conditions. Observations were made of the significant hydraulic variables, sediment transport rate, sediment segregation, and the physical characteristics of the sediments entrained by each flow to obtain information necessary to explain the sorting process.

This study contributes to the understanding of local segregation processes that affect grains of different densities. Techniques used and results obtained can be applied to studies of bedding in modern sediments and to the interpretation of bedding in ancient deposits. Further, observations made in these flume studies of modes of segregation, transport, and accumulation of heavy minerals should help in future research on and exploration for economically valuable placer deposits.

This program was completed under a cooperative arrangement between the U.S. Geological Survey, University of Kansas, and Colorado State University. The data contained herein are essentially the same as those contained in a dissertation by Brady (1971). The data were collected under the general supervision of the second author.

Special thanks are due the dissertation committee members, W. M. Merrill, E. C. Pogge, M. E. Bickford, A. J. Powell, and J. D. Winslow, of the University of Kansas, for advice and counsel during the research.

\section{THEORETICAL CONSIDERATIONS}

\section{RELATIVE VELOCITIES OF WATER-TRANSPORTED} PARTICLES WITH DIFFERING DENSITIES

An analysis of the forces acting on discrete particles in a few idealized situations can provide the basis for estimates of their effects in the natural environment. Actual values for the velocities and forces involved in the grain movement would be very difficult to determine experimentally. By making certain assumptions to allow for direct comparisons between grains with different densities, however, approximations of the relative velocities of grains can be developed.

For immersed particles moving along a bed, the five principal forces important in determining the movement of the particle are the (1) gravity forces related to the immersed weight of the particle, the (2) drag and (3) lift forces that result from pressure and frictional effects of the fluid on the particle, (4) frictional forces that result from contact between the grain and bed, and (5) forces resulting from interaction of moving grains.

If one assumes an individual sphere moves without interference from adjacent moving grains, four principal forces can be defined. The gravity force, $F_{G}$, is the resultant force acting on the particle that is dependent on the immersed weight of the particle and the gravitational constant, $g$. The gravity force is defined as

$$
F_{G}=\frac{\pi d^{3}}{6}\left(\rho_{s}-\rho\right) g
$$

where $d=$ diameter of the particle, $\rho_{s}=$ mass density of the particle, and $\rho=$ mass density of the fluid. (All symbols used in the text are listed in appendix A.)

The hydrodynamic forces acting on a body are discussed in any standard fluid mechanics text, as for example that of Daily and Harleman (1966, p. 376-394). The hydrodynamic drag force, $F_{D}$, that acts on a particle is dependent on the frictional drag resulting from surface shear between the grain and the fluid and on the form resistance that is related to shape of the grain and results from pressure drag on the particle. It is customary to define a total drag coefficient, $C_{D}$, to include both frictional and form drag. Some researchers have directly measured the drag and lift forces acting on regular shaped objects such as spheres (Watters and Rao, 1971; Coleman, 1967; and Ippen and Verma, 1955) and hemispheres (El-Sammi, 1949) in laboratory flumes.

The drag force is defined as

$$
F_{D}=C_{D} A_{s} \rho \frac{V_{0}^{2}}{2}=C_{D} \frac{\pi d^{2}}{8} \rho\left(V_{f}-V_{s}\right)^{2}
$$

where $A_{s}=$ projected area of the sphere, $V_{0}=$ 
relative velocity of the flow past the sphere, $V_{f}=$ velocity of the flow at some representative distance above the bed, and $V_{s}=$ velocity of translation of the particle.

Lift forces on the body are due to a difference in pressure between the upper and lower sides of the particle. The increased velocity resulting from fluid acceleration around the upper side of a particle causes a local reduction in pressure, while the pressure on the lower side of the grain surface at or near the bed approaches the static pressure of the fluid. The lift force, $F_{L}$, is defined as

$$
F_{L}=C_{L} A_{8} \rho \frac{V_{0}^{2}}{2}=C_{L} \frac{\pi d^{2}}{8} \rho\left(V_{f}-V_{s}\right)^{2}
$$

where $C_{L}=$ coefficient of lift.

The frictional force acting on a moving particle is difficult to determine. The frictional force is discussed in most basic physics or mechanics texts, such as that of Sears and Zemansky (1963, p. 35). Ippen and Verma (1955, p. 921-937) have also discussed the frictional force. Bagnold $(1966, p$. 5) states that the friction coefficient for grains is of the same order as the static coefficient, not only when the grains are at rest but also when they are in motion. For the purposes of this study, the frictional force was assumed to be equal to the coefficient of kinetic friction, $C_{F}$, times the normal force between the particle and the bed, $F_{N}$. The frictional force, $F_{F}$, is defined as

$$
F_{F}=C_{F} F_{N}=C_{F}\left(F_{G} \cos \theta-F_{L}\right)
$$

where $\theta=$ angle between the bed surface and horizontal. A positive value of $\theta$ indicates that the bed surface is rising in a downstream direction, as the surface does on the stoss slope of a ripple or dune.

Although the coefficient of kinetic friction for sediment particles is very difficult to determine, one would suspect that it is closely related to the coefficient of static resistance, $C_{R}$, of a particular particle resting on a given bed configuration. For a rigid spherical particle of diameter $d_{m}$ resting on a bed of rigid spherical particles of diameter $d_{B}$ arranged in a prescribed manner, it is a simple matter to determine the coefficient of static resistance, $C_{R}$.

For example, if the bed spheres are arranged in a close packed rectangular pattern and are resting on a horizontal plane, it can be easily shown that the centrally applied horizontal force required to move a sphere of diameter $d_{m}$ in the direction of least resistance is $C_{R} F_{N}$, where $C_{R}$ is given by the relation

$$
C_{R}=\frac{1}{\sqrt{k^{2}+2 k-1}}
$$

and $k$ is defined as the ratio of $d_{m}$ to $d_{B}$. Likewise, if the bed spheres are arranged in a rhombic pattern, the value of $C_{R}$ corresponding to movement in the direction of least resistance is given by

$$
C_{R}=\frac{1}{2 \sqrt{k^{2}+2 k-(1 / 3)}}
$$

It is seen that the resistance of a particle to motion is a function of both the size of the moving particle and the size of the bed particles.

In order to determine the effect of particle size on the resistance to motion, the resistance ratio is defined as the ratio of $C_{R}$ at any value of $k$ to the value of $C_{R}$ with $k=1$. The relation of the resistance ratio to $k$ is shown in figure 1 . The curves approach infinity at a value of $k$ for which a small moving particle could fall between the interstices of the larger bed particles. Figure 1 illustrates that the resistance to motion of a small particle resting on

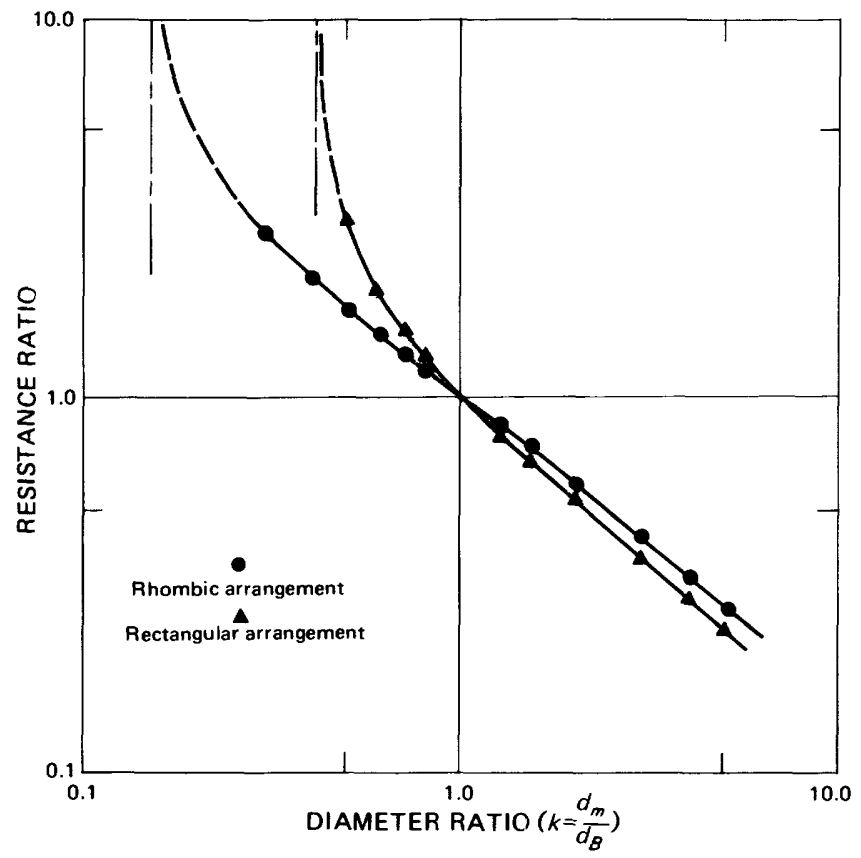

Figure 1.-Resistance of a particle to motion as a function of the ratio of its size to the size of the bed material. 
a bed of large particles can be quite large. It is not presumed that the values given in figure 1 can be applied directly to field situations; however it is suggested that the trend is qualitatively correct.

The four forces as they are applied to a spherical particle are shown schematically in figure 2. The gravitational force can either oppose or supplement the drag force depending on the sine of $\theta$.

By use of the four fundamental equations 1-4, a general equation of motion for particles can be derived. Direct comparisons between grains of different densities can then be made by establishing ratios of the translating motion of the grain of greater density to that of the grain of lesser density and reducing the equations to a form that expresses the relative difference in the velocities of the two grain types for the same flow conditions.

For a particle moving at a uniform velocity, the general translation-motion equation for the particle can be expressed as

$$
F_{F}=F_{D}-F_{G} \sin \theta
$$

By dividing the frictional force on one particle by the frictional force on a particle of different density, the following ratio can be established using equations 4 and 7 :

$$
\frac{F_{F^{\prime}}}{F_{F_{1}}}=\frac{F_{D}-F_{G} \sin \theta}{F_{b_{1}}-F_{G_{1}} \sin \theta}=\frac{C_{F}\left(F_{G} \cos \theta-F_{L}\right)}{C_{F_{1}}\left(F_{G_{1}} \cos \theta-F_{L_{1}}\right)} .
$$

The subscript 1 is used to denote the forces and coefficients affecting the sphere of the lower density.

By substituting equations 1,2 , and 3 into equa-

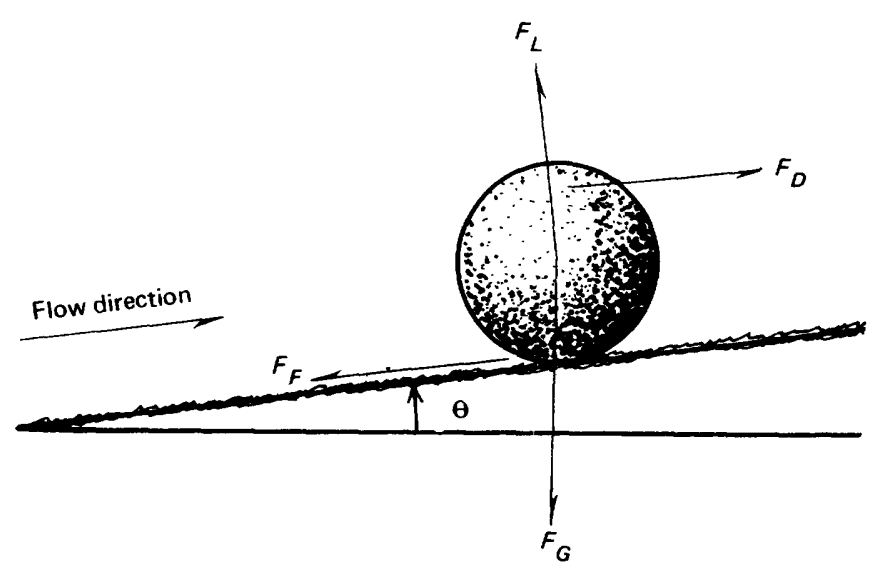

Figure 2.-Schematic diagram of forces acting on a discrete moving particle in a fluid. tion 8 , and simplifying terms, the following equation can be developed:

$$
\begin{aligned}
& \frac{3 \rho C_{D}\left(V_{f}-V_{s}\right)^{2}-4 d g\left(\rho_{s}-\rho\right) \sin \theta}{{ }_{3 \rho} C_{D_{1}}\left(V_{f_{1}}-V_{s_{1}}\right)^{2}-4 d_{1} g\left(\rho_{s_{1}}-\rho\right) \sin \theta}= \\
& \quad \frac{C_{F}\left[4 d g\left(\rho_{s}-\rho\right) \cos \theta-3 C_{L} \rho\left(V_{f}-V_{s}\right)^{2}\right]}{C_{F_{1}}\left[4 d_{1} g\left(\rho_{s_{1}}-\rho\right) \cos \theta-3 C_{L_{1} \rho}\left(V_{f_{1}}-V_{s_{1}}\right)^{2}\right]}
\end{aligned}
$$

By considering $\theta=0$, equation 9 can be simplified to

$$
\begin{aligned}
& \frac{C_{D}\left(V_{f^{-}}-V_{s}\right)^{2}}{C_{D_{1}}\left(V_{f_{1}}-V_{s_{1}}\right)^{2}}= \\
& \frac{C_{F}\left[4 d g\left(\rho_{s}-\rho\right)-3 C_{L} \rho\left(V_{f}-V_{s}\right)^{2}\right]}{C_{F_{1}}\left[4 d_{1} g\left(\rho_{s_{1}}-\rho\right)-3 C_{L_{1}} \rho\left(V_{f_{1}}-V_{s_{1}}\right)^{2}\right]}
\end{aligned}
$$

Equation 10 can be used to determine the relative velocities of rolling spheres with different densities.

Assuming the two spheres have equal diameters and therefore equal drag coefficients and equal lift coefficients and assuming equal coefficients of friction, equation 10 reduces to

$$
\frac{\left(V_{f}-V_{s}\right)^{2}}{\left(V_{f}-V_{s_{1}}\right)^{2}}=\frac{\left(\rho_{8}-\rho\right)}{\left(\rho_{s_{1}}-\rho\right)}
$$

By applying densities of materials of interest in this study: $5.0 \mathrm{~g} / \mathrm{cm}^{3}$ (gram per cubic centimeter) for $\rho_{s}$, $2.65 \mathrm{~g} / \mathrm{cm}^{3}$ for $\rho^{s_{1}}$, and $1.0 \mathrm{~g} / \mathrm{cm}^{3}$ for $\rho$, equation 11 can be expressed in dimensionless form as

$$
\frac{V_{s}}{V_{\iota_{1}}}=1.56-0.56\left(\frac{V_{t_{1}}}{V_{t}}\right)^{-1}
$$

A graph of equation 12 is shown in figure 3.

The relative velocities of spheres of the two different densities are clearly shown in figure 3 . The velocity of the denser sphere, $V_{s}$, is always less than that of the lighter sphere, $V_{s_{1}}$, unless both are equal to the fluid velocity, $V_{f}$, a condition where there is no frictional force. This condition could occur when both particles are suspended. As the velocity of the lighter particle becomes progressively smaller, the relation $V_{s} / V_{s_{1}}$ also becomes progressively smaller until a point is reached where movement of the denser sphere ceases. At this point-the point of 


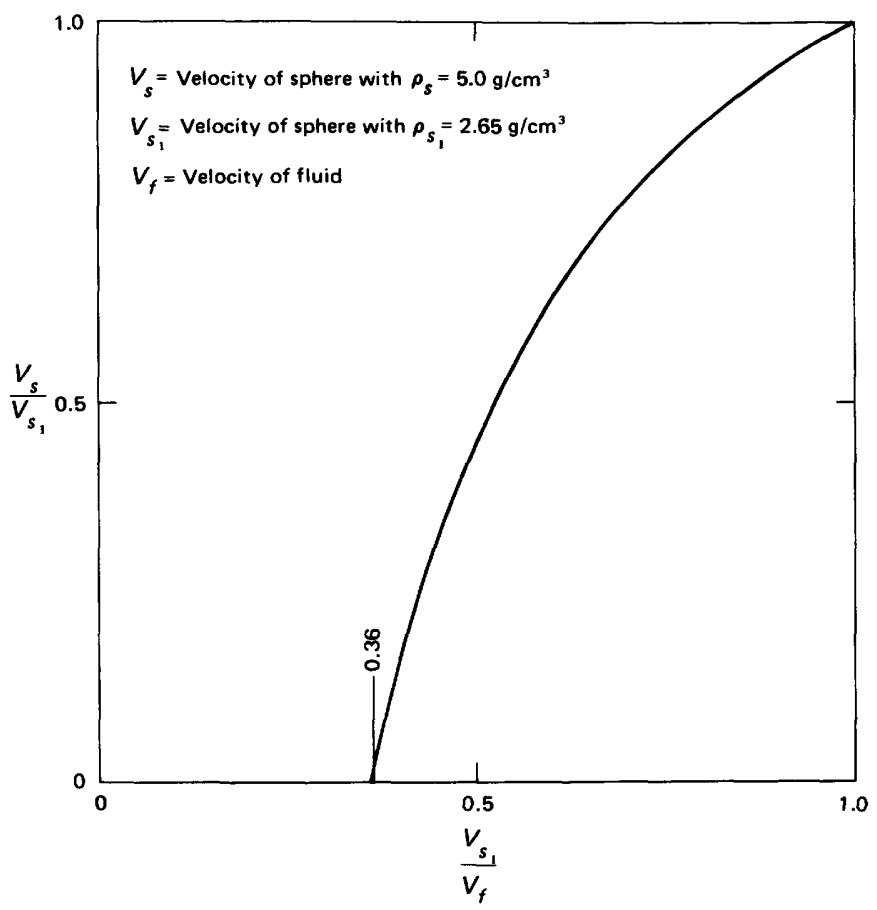

FIGURE 3.-Velocity ratios for spheres of equal size but of different densities.

incipient motion of the denser particle-the velocity of the low-density particle is 0.36 times the fluid velocity.

A second situation for which the relative velocity can be approximated is that of two spherical particles that have equal submerged weight but different densities. Substituting values for the densities of the spherical particles of $5.0 \mathrm{~g} / \mathrm{cm}^{3}$ and $2.65 \mathrm{~g} / \mathrm{cm}^{3}$, the ratio of diameters required to obtain equal submerged weights is $1: 1.34$. However, in order to derive a general velocity formula such as equation 12 the following additional conditions must be assumed:

1. For the drag force equation, a drag coefficient ratio $\left(C_{D} / C_{D_{1}}\right)$ of $1.2: 1$ is stipulated. Drag coefficients of the two spheres will differ because the spheres are of different size. The value of $1.2: 1$ was approximated from the $C_{n}$ versus Re diagram in the U.S. Inter-Agency Committee on Water Resources Report 12 (1957, p. 20) by using grain sizes similar to the experimental runs $(0.12 \mathrm{~mm}$ (millimeter) for the heavy grain and $0.163 \mathrm{~mm}$ for the light grains).

2. The lift forces for this situation are ignored.

3. Two relationships for friction will be considered. First, the coefficient of static friction is con- sidered to be the same for both spherical particles $\left(C_{F_{1}}=C_{F}\right)$. Second, the ratio of the two coefficients of friction is assumed to be equal to the resistance ratio given in figure 1. It will be assumed that the bed is composed of particles of a size equal to that of the larger particles and that these particles are arranged in a rhombic pattern. From figure 1 the value of $C_{F} / C_{F_{1}}$ is found to be 1.25 .

4. An assumption is made for this analysis that the increase in fluid velocity with distance from the bed is linear, at least up to a point where the characteristic velocity is determined, as it is in the sublayer of laminar flow. The fluid velocity is assumed to be zero at the bed surface. The fluid velocity then at the point of drag force application of the small sphere would be 0.746 of the value of the fluid velocity at the corresponding point on the larger sphere.

Accepting these assumptions, the basic equation 10 can be reduced to

$$
\frac{V_{s}}{V_{s_{1}}}=1.23-0.65\left(\frac{V_{s_{1}}}{V_{t}}\right)^{-1}
$$

for equal friction coefficients and

$$
\frac{V_{s}}{V_{s_{1}}}=1.54-1.06\left(\frac{V_{s_{1}}}{V_{f}}\right)^{-1}
$$

for a resistance ratio determined from figure 1 . Equations 13 and 14 are plotted in figure 4.

For the development of equations 10-14, the bed surface was considered horizontal; but the relations shown in figures 3 and 4 should be qualitatively similar for any given bed-form slope. The basic difference in forces affecting the grains when a slope factor is introduced is related to the effect of grain weight on the grain movement. A gravity force component parallel to the bed will act against the drag force if the local bed surface is inclined in a direction opposite to the energy slope or the stream gradient. Such restraining pull is present in grain movement up the stoss side of a dune or ripple (fig. 2). When the local bed surface is inclined in the direction of the energy slope or stream gradient, as it is on a flat bed or the lee slope of a dune, the particle weight then becomes additive to the 


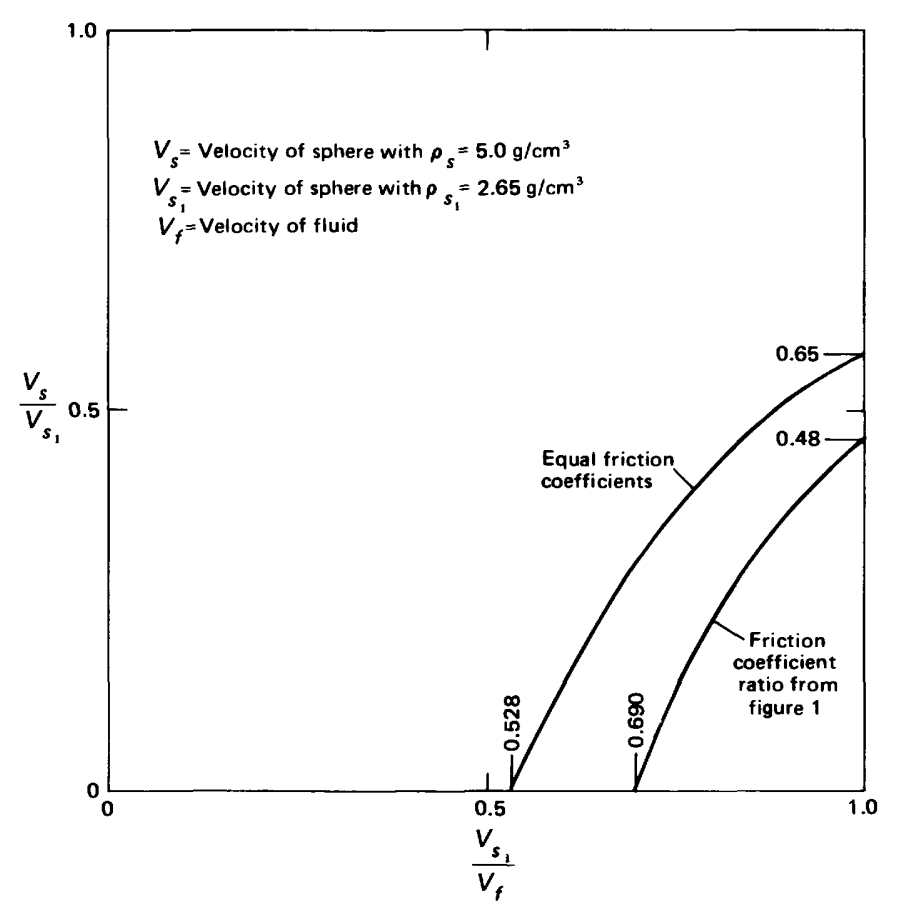

FIGURE 4.-Velocity ratios of spheres that have equal submerged weight but different densities.

drag force in influencing grain movement downstream.

In addition to the effect of gravity, frictional forces resulting from differences between size of moving particle and size of particles at the bed surface will have marked effect on the grain velocity. A coarser sand bed will provide a higher coefficient of friction than a finer sand bed for a given size of grain in movement.

The above analysis of grain movement assumes that the grains of interest are not so large or heavy that they tend to displace the underlying grains and sink into the bed during the flow. For grains that do, and they occasionally occur in the field, different methods of analysis would be required.

Grains moving along the surface of a sediment bed are continually being deposited and reentrained at a rate dependent on the local conditions of the flow. Light and heavy grains are most likely to be segregated when their velocities differ greatly. As grains of different densities slow to velocities that are much less than the fluid velocity, high-density grains will be deposited first. Before high-density grains are yet in motion, low-density grains will be entrained and moved much more readily. This type of selective deposition provides for efficient segregation by causing the accumulation of high-density grains in areas where the flow is not readily capable of transporting all the material supplied to the area. In other words, if a mixture of particles is supplied to an area where the flow is incapable of transporting the total load, the heavy particles will be selectively deposited first.

These mathematical relationships establish in a semiquantitative but simplified manner what has long been observed, that small dense grains are more resistant to surface movement than are larger lowdensity grains. Graphs similar to figures 3 and 4 can be constructed for natural materials of any density. Then, the graphs can be used to help explain why some of the bedding features observed in sediments in the natural alluvial environment are formed of materials of a particular density.

\section{SHEAR STRESS AS A DENSITY-SEGREGATION PARAMETER}

Consideration of critical shear stress, $\tau_{\mathfrak{c}}$, which is the stress exerted by the flow on the bed that is just capable of initiating grain movement, adds insight into the segregation of grains of varying densities. Shields (1936) plotted experimental results of the beginning of particle motion based on a dimensionless shear stress, $\tau_{*}$, and a particle Reynolds number, $\mathbf{R}$, where

$$
\tau_{*}=\frac{\tau_{0}}{\left(\gamma_{s}-\gamma\right) d_{s}}
$$

and

$$
\mathbf{R}_{*}=\frac{U_{*} d_{s}}{v}
$$

with $\gamma_{s}$ equal to the specific weight of the sediment grains, $\gamma$ the specific weight of the fluid, $d_{s}$ the grain diameter, $U_{*}$ is the shear velocity or $\sqrt{\tau_{0} / \rho}$ with $\rho$ the fluid density, $v$ is the kinematic viscosity of the fluid, and $\tau_{0}$ is the average shear stress at the bed.

Additional data and refinement of this plot by later workers has resulted in the generally accepted Shields diagram shown in figure 5 (A.S.C.E. Task Committee on Preparation of Sedimentation Manual, 1966, p. 297). From Shields curve (fig. 5), one can develop the relation of critical shear to grain size for grains of different densities. Grigg and 


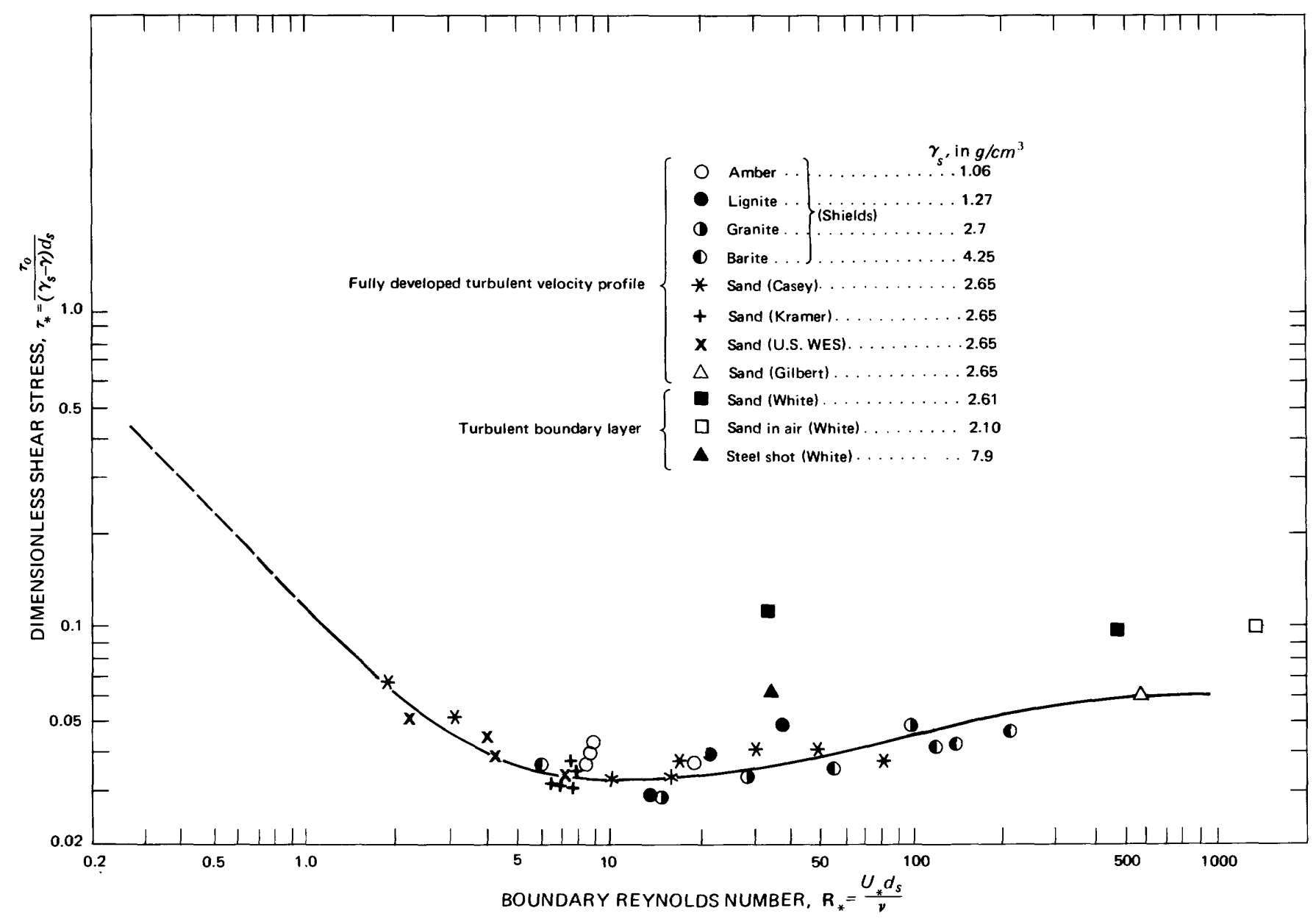

FrgURE 5.-Shields diagram showing sediment entrainment as a function of the particle Reynolds number (adapted from A.S.C.E. Task Committee on preparation of Sedimentation Manual, 1966, p. 297).

Rathbun (1969) have developed such a series of curves that show on a theoretical basis that grains of different density but equal fall velocity require different shear stress for initiation of movement. For a grain diameter below $0.1 \mathrm{~mm}$, Grigg and Rathbun $(1969$, p. 79$)$ show that critical shear is a function only of grain density, but for a grain diameter above $0.1 \mathrm{~mm}$, they show that the critical shear becomes a function of size as well.

The experimental conditions under which the Shields diagram was developed were quite different from the natural conditions that exist in an alluvial channel. Data used to develop the Shields curve were obtained from artificially flattened surfaces of sand beds that consisted of uniformly sized grains, and they were collected under fully developed turbulent flows in which shear at the bed was just large enough to initiate movement of a few grains. In contrast, large amounts of sediment are in transport at relatively high velecities on streambeds when segregation occurs, and the size distribution of the bed material is seldom uniform.

Even though Shields' (1936) work was developed to explain very small amounts of sediment motion, it gives insight into relations among moving grains. During a given flow, grains are continually being deposited and then reentrained into the flow; that is, there are always some grains at the interface that are continually subject to conditions near incipient motion. One can see, at least qualitatively, from Shields' work that the denser grains will require a much larger shear stress for movement than lighter grains of the same size.

A part of the threshold of motion problem is to determine how much sediment is in transport along the bed surface. Best known among the bed-load equations is the Einstein bed-load function (Einstein, 1950). Einstein's bed-load equations express a relation between the intensity of shear on a particle, $\psi$, and intensity of transport, $\Phi$, where 


$$
\Phi=\frac{q_{B}}{\gamma_{s}}\left[\left(\frac{\gamma}{\gamma_{s}-\gamma}\right)\left(\frac{1}{g d_{s}{ }^{3}}\right)\right]^{1 / 3}
$$

and

$$
\psi=\left(\frac{\gamma_{8}-\gamma}{\gamma}\right)\left(\frac{d_{s}}{R^{\prime} S}\right)
$$

where $q_{B}$ is the rate of transport of the bed load, in weight of total bed load per unit time and width, $g$ is the gravitational constant, $d_{s}$ is the grain diameter, $S$ is the energy slope, and $R^{\prime}$ is the hydraulic radius with respect to the particles. $\left(R^{\prime}\right.$ is based on the resistance to flow due to particle resistance as opposed to that due to the bed or streambank configuration.) The shear intensity parameter, $\psi$, of Einstein is essentially the reciprocal of Shields' dimensionless shear stress, $\tau_{*}$, and is important in determining the total transport rate of the bed load, $q_{B}$. The fact that the transport rate is a function of $\psi$ lends credence to the importance of Shields' parameter in situations other than the initiation of motion of uniformly sized grains on flattened beds.

\section{BED FORMS PRODUCED BY FLOW IN AN ALLUVIAL CHANNEL}

Shortly following initiation of movement of the bed material, bed forms start to develop. These initial forms are described by Kennedy (1963, p. 522) as "the result of scour and deposition due to the perturbation velocities induced by any protuberance on the bed." Flows in alluvial channels are classified into two flow regimes, upper and lower,

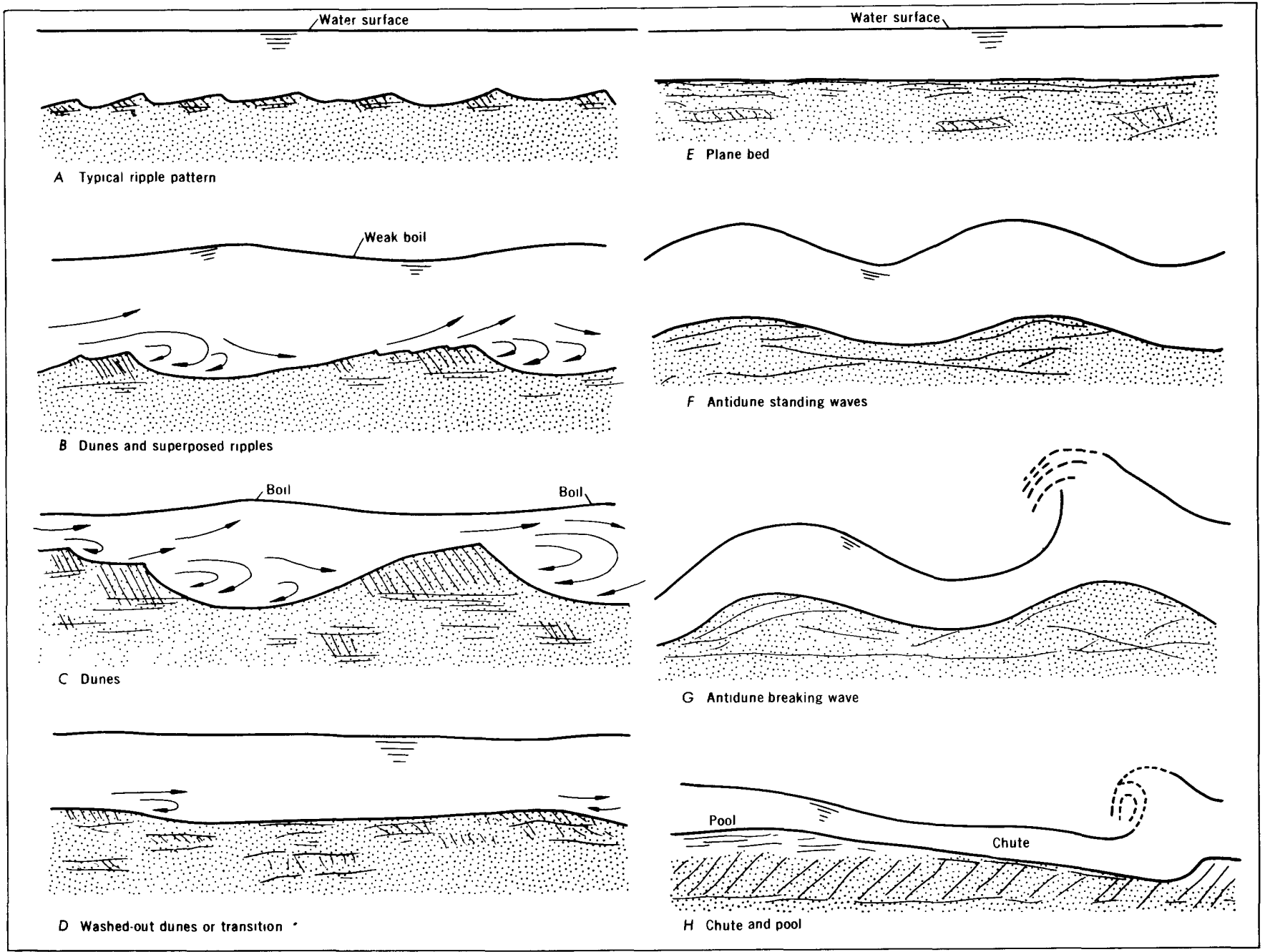

FIGURE 6.-Idealized diagram of bed forms in an alluvial channel (from Simons and Richardson, 1966, p. J5). 
TABL̇E 1.-Classification of flow regimes

[Adapted from Simons, Richardson, and Nordin (1965a, p. 36). ppm, parts per million]

\begin{tabular}{|c|c|c|c|c|c|}
\hline Flow regime & Bed form & $\begin{array}{c}\text { Bed material } \\
\text { concentrations } \\
(\mathrm{ppm})\end{array}$ & $\begin{array}{l}\text { Mode of sedi- } \\
\text { ment transport }\end{array}$ & Type of roughness & $\begin{array}{l}\text { Phase relation } \\
\text { between bed and } \\
\text { water surface }\end{array}$ \\
\hline $\begin{array}{l}\text { Lower regime } \\
\text { Transition } \\
\text { Upper regime -- }\end{array}$ & $\begin{array}{l}\text { Ripples } \\
\text { Ripples on dunes } \\
\text { Dunes } \\
\text { Washed-out dunes-- } \\
\text { Plane beds } \\
\text { Antidunes } \\
\text { Chutes and pools }\end{array}$ & $\begin{array}{c}10-200 \\
100-1,200 \\
200-2,000 \\
1,000-3,000 \\
2,000-6,000 \\
\equiv 2,000 \\
\equiv 2,000\end{array}$ & $\begin{array}{l}\text { Discrete steps } \\
- \text { do } \\
\text { Continuous } \\
\text {-do do }\end{array}$ & $\begin{array}{l}\text { Form roughness predominates } \\
\text { Variable } \\
\text { Grain roughness predominates } \\
\text { - do do }\end{array}$ & $\begin{array}{l}\text { Out of phase. } \\
\text { Do. } \\
\text { Do. } \\
\text { In phase. } \\
\text { Do. } \\
\text { Do. }\end{array}$ \\
\hline
\end{tabular}

with a transition zone between. These regimes are based on the bed configuration, mode of sediment transport, process of energy dissipation, and phase relation between the bed and water surfaces (Simons and Richardson, 1963). Relations of bed forms within these two regimes are shown in table 1 , and the bed forms are shown in figure 6 .

The A.S.C.E. Task Force on Bed Forms in Alluvial Channels $(1966$, p. 53) defines ripples as bed forms with wave lengths less than approximately 1 foot and heights less than 0.1 foot. Dunes are bed forms larger than ripples and out of phase with any water-surface gravity waves that accompany them. A flat bed is a surface devoid of form. Antidunes and chutes-and-pools develop within the upper portion of the upper flow regime but were not studied in this series of experiments. These features are described by Simons, Richardson, and Nordin (1965a, p. 40-42).

Bed forms within the lower flow regime include ripples, ripples superimposed on dunes, and dunes. In the lower regime the water-surface waves and undulations are out of phase with the bed undulations. In general, resistance to flow is high, and sediment transport is small. In natural streams, dunes, or dunes with superimposed ripples are the most common bed forms (Simons and Richardson, 1966, p. J11).

Within the transition flow the bed configuration is very erratic and may include forms common to both the upper and lower regimes. Dunes present in the transition zone will often decrease in amplitude and increase in length before the bed becomes flat (washed-out dunes) (Simons and Richardson, 1966 , p. J11).

In the upper flow regime the usual bed forms are flat beds (plane beds) or antidunes. Resistance to flow is small, and sediment transport is large. Watersurface waves in this regime are in phase with the bed surface except during the breaking of an antidune (Simons and Richardson, 1966, p. J11).
Bed forms produced by the four different experimental runs in this study were dunes in the lower flow regime, long profile dunes in the transition zone, and a flat bed in the upper flow regime. Terminology used in this report for the different surface features of dunes and the bedding structures associated with the dunes is shown in figure 7 .

\section{RELATION OF GRAIN ENTRAINMENT TO TURBULENCE}

The effect of turbulence in a given flow is an important flow characteristic in grain entrainment. Local boundary shear stress must be determined from the velocity gradient at the bed and cannot be determined from the slope-depth relationship alone. The apparent shear stress, $\tau$, in turbulent flow is expressed by Streeter (1966, p. 226) as

$$
\tau=(\mu+\eta) \frac{d U}{d Y}
$$

in which $\mu$ is the dynamic viscosity, $\eta$ is the eddy viscosity that depends on the state of the turbulent motion, and $d U / d Y$ is the velocity gradient normal to the bed. Intensity of turbulence is important, because high turbulence is indicative of large velocity fluctuations and usually indicates large velocity gradients.

McQuivey and Keefer (1969) studied the segregation of magnetite grains from quartz grains on the stoss side of ripples in a small flume and found much larger turbulent intensities over the trough area than over the crestal region of a ripple. Turbulent intensity also decreased with distance from the bed. Measurements were made with a hot-film anemometer. Differences in turbulent shear stress from ripple trough to crest and differences in shear stress required for movement of grains of different densities were considered by McQuivey and Keefer 


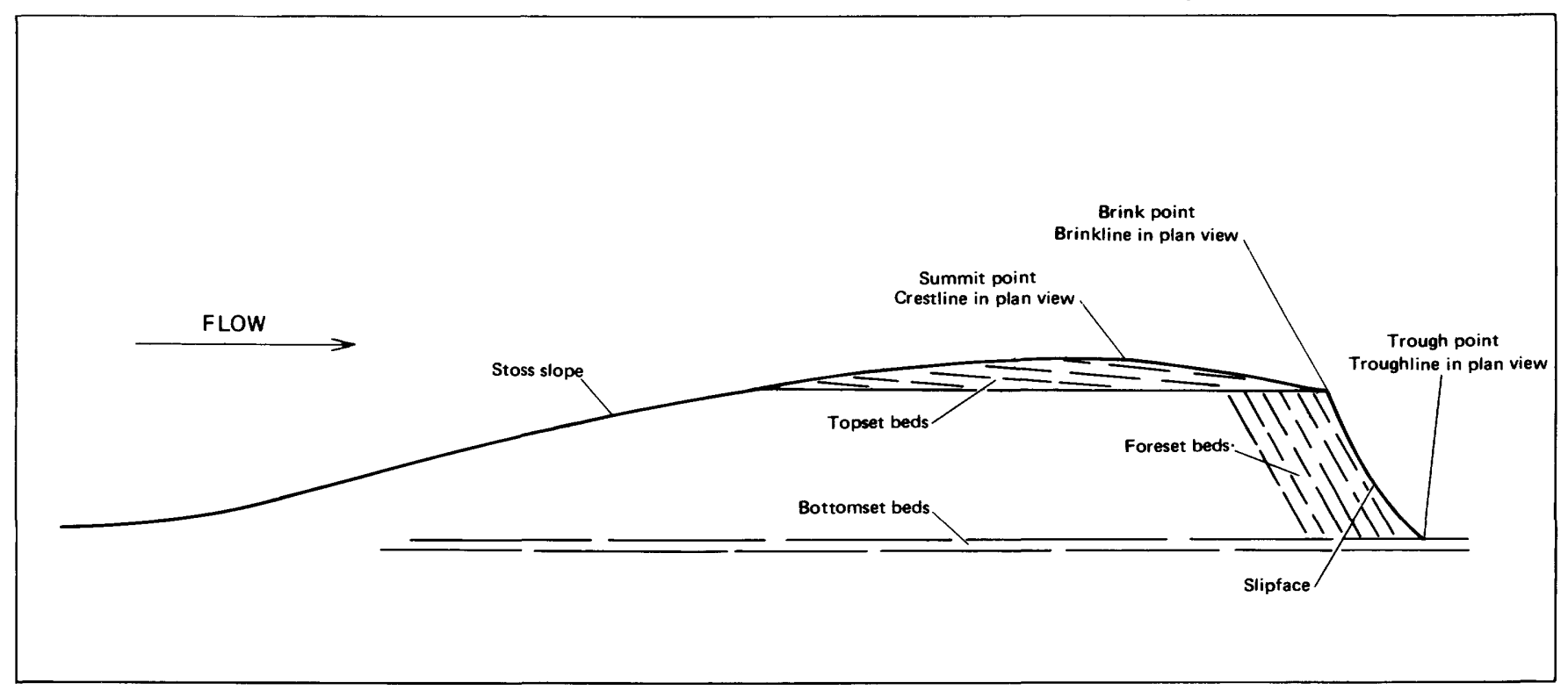

FigURE 7.-Dune profile showing dune terminology used in report ( $\times 4$ vertical exaggeration). Location terminology adapted from Allen (1968, p. 62).

as important factors in heavy-mineral segregation. Similar results of turbulence measurements are described by Raudkivi (1967, p. 206-207) for experiments conducted by Sheen (1964). Raudkivi states that turbulent intensities are greatest just downstream from the point of separation (brinkline) on a ripple, that turbulence is intense in the trough area, and that its intensity rapidly decreases downstream. Velocity and turbulence profiles were determined by McQuivey at selected locations for each of the runs of this study. These data are contained in a dissertation by Brady (1971).

\section{SUMMARY}

Theoretical conisderations of transport of grains with different densities lead to the conclusions that small dense grains are more resistant to tractive movement than larger low-density grains and that boundary shear is an important parameter in determining the rate of sediment transport.

Different bed forms are produced under different flow conditions with such common bed forms as ripples and dunes formed in the lower flow regime, flat beds formed in an upper flow regime, and washed-out dunes formed in the transition phase.

The turbulent intensity of the flow is large near the bed and decreases with distance from the bed. Much larger turbulent intensities occur in the trough regions of dune beds than on the crestal areas, and the intensity decreases rapidly downstream from the trough area toward the brinkline of a dune.
Intensity of turbulence is important because high turbulent intensities are indicative of large velocity fluctuations and usually indicate large velocity gradients. The amount of local boundary shear stress is dependent on the local velocity gradient.

\section{EXPERIMENTAL RUNS AND RESULTS OF SEDIMENT ANALYSIS}

A large recirculating water-sediment flume of rectangular cross section and dimensions of 61 meters in length, 2.44 meters in width, and 1.22 meters in depth (fig. 8) was used for the series of four experiments. The large size of the flume permits the establishment of flow conditions that approximate those in a natural channel and eliminates many of the boundary effects that are associated with smaller flumes. The slope of the flume can be changed by use of adjustable screwjacks, and water-sediment discharge can be increased to a maximum of approximately 2.5 cubic meters per second. The interior of the flume is surfaced with aluminum having an epoxy coating. A transparent plexiglass section 21.95 meters long is located midway along the left wall of the flume to allow observations to be made of sediment movement.

\section{HYDRAULIC MEASUREMENTS}

Near equilibrium conditions were established for each of the flows before sediment and hydraulic 
data were taken. Equilibrium flow is defined as flow that has established a bed configuration and slope consistent with the fluid, flow, and bed-material characteristics over the working reach of the bed (Simons and Richardson, 1966, p. 3). After equilibrium flow was established for a given experiment, measurements were made of sediment discharge, water-sediment discharge, slope of the water surface and energy grade line, depth, and water temperature. Additional hydraulic parameters were calculated from these basic data. Mean values of significant hydraulic variables are shown in table 2 .

Water-surface elevations were measured every $1.52 \mathrm{~m}$ (meters) along the centerline of the flume for several profiles. For each profile a line was fitted to the water-surface-elevation measurements and their corresponding flume stations by the method of least squares and its slope determined. The mean value of the calculated slopes was taken to be the water-surface slope for the run. By adding the local velocity head, $Q^{2} / 2 g(W D)^{2}$, where $Q$ is discharge, $W$ is channel width, $D$ is water depth, and $g$ is the gravitational constant, to the water-surface elevation at a given measurement point, the elevation of the energy grade line was obtained. The slope
TABLE 2.-Hydraulic variables and parameters of runs

\begin{tabular}{|c|c|c|c|c|c|}
\hline Run & Bed form & $\begin{array}{c}\text { Energy } \\
\text { slope } \\
\left(\times 10^{-8}\right) \\
\end{array}$ & $\begin{array}{l}\text { Men } \\
\text { dep } \\
\text { (cm }\end{array}$ & & $\begin{array}{c}\text { Water } \\
\text { discharge } \\
\text { (cu m } \\
\text { per sec) }\end{array}$ \\
\hline $\begin{array}{ll}1 & \ldots- \\
2 & --- \\
3 & --- \\
4 & ---\end{array}$ & $\begin{array}{l}\text { Dunes } \\
\text { Dunes } \\
\text { Transition } \\
\text { Flat bed }\end{array}$ & $\begin{array}{l}1.02 \\
1.06 \\
1.22 \\
1.79\end{array}$ & $\begin{array}{l}32 \\
58 \\
33 \\
52 \\
\end{array}$ & $\begin{array}{l}2.9 \\
3.5 \\
3.7 \\
2.8\end{array}$ & $\begin{array}{r}0.48 \\
1.38 \\
.73 \\
2.08 \\
\end{array}$ \\
\hline Run & Bed form & $\begin{array}{c}\text { Tempera- } \\
\text { ture } \\
\left(^{\circ} \mathrm{C}\right)\end{array}$ & $\begin{array}{c}\text { Mean } \\
\text { velocity } \\
\text { (cm per } \\
\text { sec) }\end{array}$ & $\begin{array}{l}\text { Shear } \\
\text { stress } \\
\text { (dynes } \\
\text { per } \\
\text { cm }^{2} \text { ) }\end{array}$ & $\begin{array}{l}\text { Froude } \\
\text { No. }\end{array}$ \\
\hline $\begin{array}{ll}1 & --- \\
2 & --- \\
3 & ---- \\
4 & ---\end{array}$ & $\begin{array}{l}\text { Dunes } \\
\text { Dunes } \\
\text { Transition } \\
\text { Flat bed }\end{array}$ & $\begin{array}{l}20.8 \\
20.9 \\
20.7 \\
21.0\end{array}$ & $\begin{array}{r}60 \\
97 \\
89 \\
161\end{array}$ & $\begin{array}{l}33 \\
61 \\
40 \\
93\end{array}$ & $\begin{array}{r}0.34 \\
.40 \\
.49 \\
.71\end{array}$ \\
\hline
\end{tabular}

of the energy line was determined in much the same way as the slope of the water surface.

Profiles of the bed and water surfaces along the flume centerline were recorded on chart paper by use of a sonic sounder; and from these sounder profiles, the depth of flow was determined. The mean depth of flow (table 2) for the run was determined by averaging the depth values obtained every 1.52 $\mathrm{m}$ along each profile.

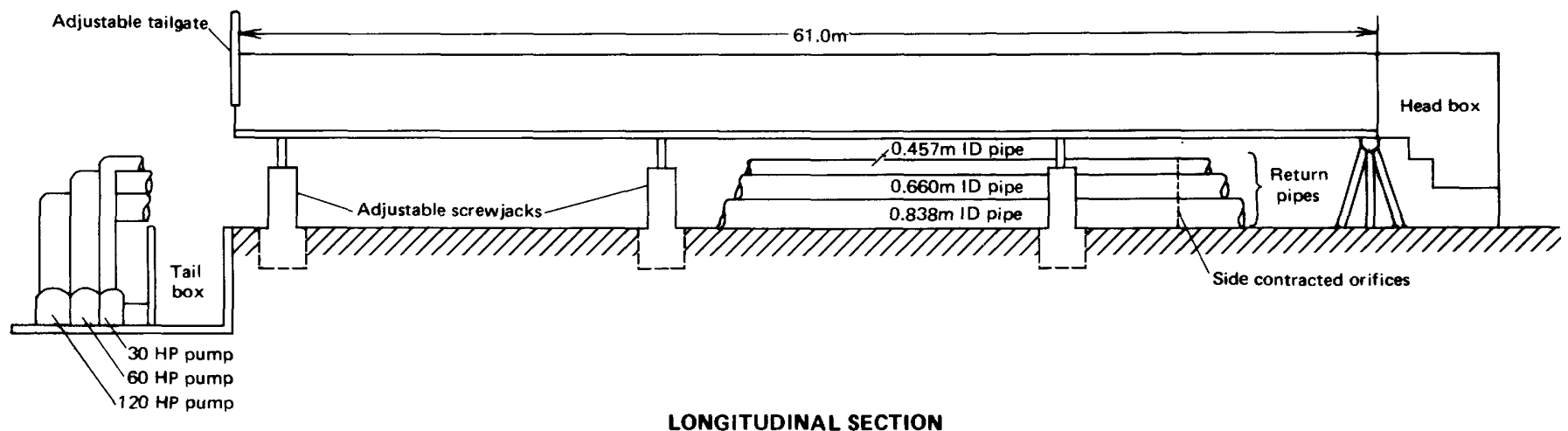

LONGITUDINAL SECTION

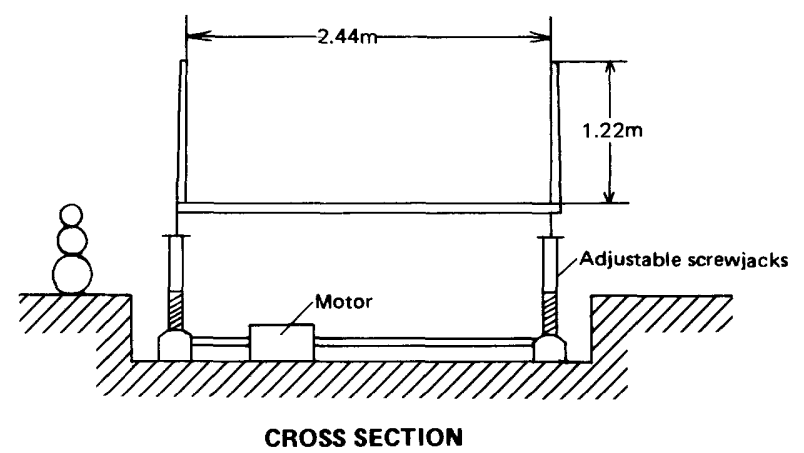

Note: Not to scale

Frgure 8.-Schematic diagram of the flume used in the four experimental runs. 
Water discharge was determined by use of waterair manometers that were connected to calibrated orifice meters located in the three return-flow pipes. Mean discharge for each run was determined from an average of four to 20 individual readings. Water temperature was held as constant as possible by use of steam and cold water. The temperature for each run had a fluctuation of less than $\pm 1^{\circ} \mathrm{C}$ (Celsius).

Mean velocity $(\bar{U})$ was calculated by use of the continuity equation

$$
\bar{U}=\frac{Q}{A}=\frac{Q}{D \times W}
$$

Any error in the mean velocity reported would be primarily due to an error in mean depth readings.

The shear stress at the bed, $\tau_{0}$, and Froude number, $\mathbf{F}$, are both calculated from the above measured variables. The shear stress is defined for a large area as

$$
\tau_{0}=\gamma D S
$$

where $\gamma$ is specific weight of water and $S$ is the energy slope. The Froude number value is a measure of the effect of gravity on the flow pattern and is defined as

$$
\mathbf{F}=\frac{\bar{U}}{\sqrt{g D}}
$$

For a Froude number less than one, a flow is defined as tranquil, because the average velocity of the flow is less than the velocity of propagation of small surface waves on the fluid. For a Froude number greater than one, the flow is defined as rapid, for the fluid velocity exceeds the velocity of movement of the small surface waves.

\section{SEDIMENT ANALYSIS}

\section{SEDIMENT CHARACTERISTICS}

Sand used in the experiments was obtained from a conveyance channel of the Rio Grande near Bernardo, N. Mex. An arkosic sand, it contains approximately 60 percent quartz, 36 percent feldspars, 3 percent rock fragments, and 1 percent accessory minerals. Heavy minerals (specific gravity $>2.95$ ) constitute 1.13 percent of the weight and 0.72 percent of the volume of the total bed-material sample. Dark opaque grains, mainly ilmenite and magnetite, amount to 0.38 percent of the bed-material sample by volume. Other heavy minerals included amphiboles, pyroxenes, garnet, zircon, tourmaline, limonite, and hematite.

Within this report, sediments referred to as opaque heavy minerals consist of ilmenite and magnetite, and those referred to as light minerals consist of the remainder of the mineral grains. These two groupings provided for maximum efficiency in recognition and description of the segregation characteristics and conditions.

\section{SIZE ANALYSES-TOTAL BED MATERIAL}

Samples for the bed-material analyses (fig. 9) were obtained from a composite sample of 10 vertical cores of the bed. Samples were taken at random locations in the flume after the water had been drained. Median size, as determined by fall diameter using visual accumulation tube (U.S. InterAgency Committee on Water Resources, 1958), was $0.286 \mathrm{~mm}$ with a geometric standard deviation, o, (A.S.C.E. Task Committee, 1962, p. 98) of 1.59, where

$$
\sigma=\frac{1}{2}\left(\frac{d_{50}}{d_{16}}+\frac{d_{84}}{d_{50}}\right) .
$$

A geometric standard deviation, hereafter referred to as sorting, with a value of 1.0 refers to a perfectly size-sorted sand, while a value of 3.5 or larger refers to a poorly size sorted sand. Sieve analysis of the bed material showed a median size of 0.285 $\mathrm{mm}$ and a sorting, $\sigma$, of 1.58 , while direct measurement of grains with conversion to the weighted sieve size (see appendix $B$ for a discussion of techniques) showed a median size of 0.287 and a sorting of 1.56 .

Weighted median size of the opaque heavy minerals as determined by microscope measurement in the bed material was $0.144 \mathrm{~mm}$ with a sorting of 1.49 (appendix $\mathrm{C}$, table 5).

The total sediment discharge was determined from a width-depth integrated sample of the watersediment mixture collected at the lower end of the flume. Size and gradation of the collected sediment was determined by use of the visual accumulation tube after each sample was dried and split to a workable size. 


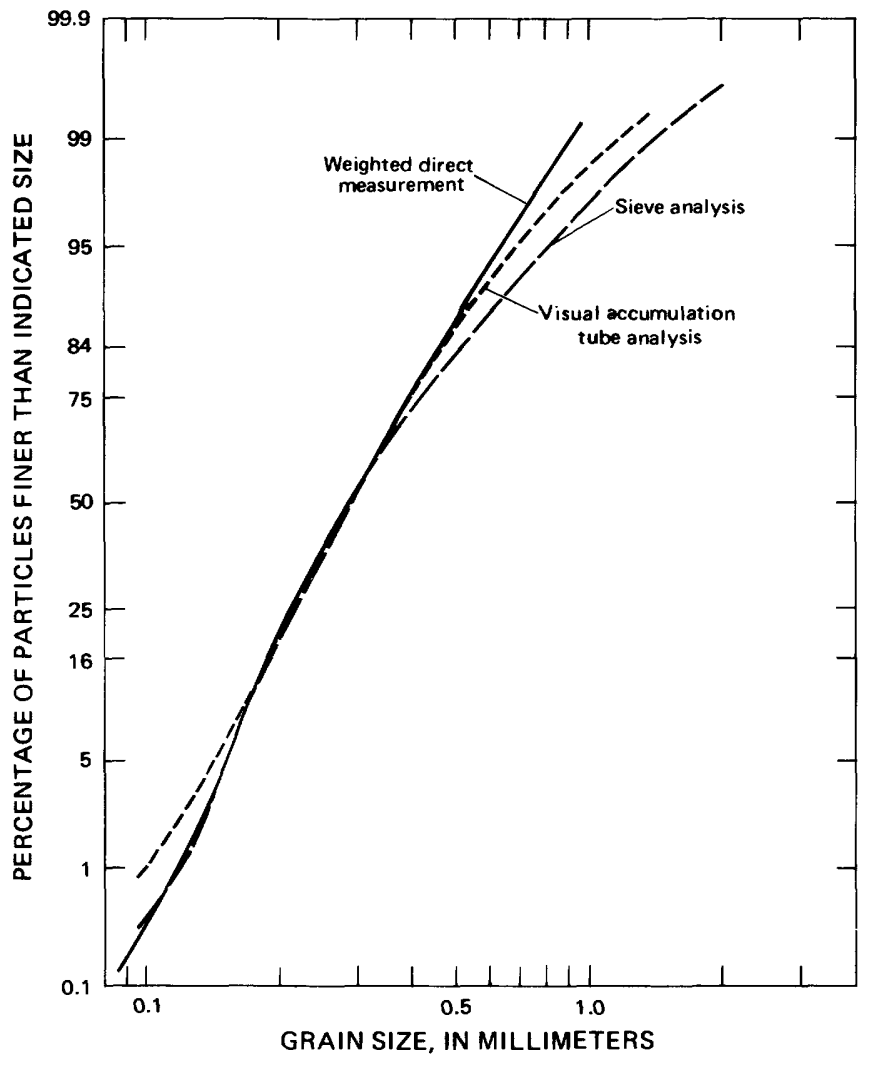

Figure 9.-Size-distribution curves for sand used in the flume. Curves plotted from analyses by visual-accumulation (VA) tube, sieves, and weighted direct measurement are shown.

\section{SIZE ANALYSES-SUSPENDED SEDIMENT}

Suspended-load samples were collected by a siphon with an inside diameter of $0.95 \mathrm{~cm}$ (centimeter). Inlet velocity at the siphon nozzle was adjusted to equal the local fluid velocity by changing the total head on the siphon. Local velocities were determined by a modified Ott velocity meter. For dune runs 1 and 2 , sediment concentration (in milligram per liter) profiles were determined at the trough, brink point, and high on the dune stoss side. Two sediment concentration profiles were measured for the transition run-one in the plane-bed reach and one high on the stoss side of one dune. One concentration profile was taken during the flat-bed run. Appendix $\mathrm{D}$ contains the concentration and size analyses for all suspended sediments analyzed.

Opaque-heavy-mineral grains were present in the suspended-sediment samples from each vertical profile in each of the four runs. Only run 2 had a volume percentage of dark opaque grains approaching that of the bed material. Each of the suspendedsediment samples from the runs show the opaque heavy minerals to be distinctly smaller than those of the bed-material samples.

Median size of the suspended opaque-heavymineral grains in each run falls below the 20th percentile size determined for the corresponding bed-material sample of opaque heavy minerals.

A more complete analysis of the suspendedsediment samples has been given by Brady (1971).

\section{SIZE ANALYSES-CORE SAMPLES}

Opaque heavy minerals and light minerals obtained from cores were studied to determine whether differences in size and sorting existed among sediments in the different runs. Studies of the opaqueheavy-mineral grains were concentrated on the darkmineral laminations of runs 2-4. Only minor accumulations of opaque heavy minerals were present in run 1 , and those were insignificant in thickness and areal distribution compared with heavy-mineral accumulations of runs $2-4$.

In addition to vertical cores mentioned previously, horizontal core samples were taken from at least two networks across and along the bed following each run. For each network, samples were obtained from the flume centerline and from 0.61 meter from each wall at 1.22 meter intervals along the flume. Total length of each sample network was selected to include the entire length of at least one bed form (average length of the networks was 6.1 meters). Small pits were dug to obtain the samples. Along the wall of each pit a can $6.5 \mathrm{~cm}$ in diameter and 12.7 $\mathrm{cm}$ in length was inserted horizontally to obtain the horizontal cores. Similar core samples were obtained from large areas of heavy-mineral segregation that were missed in the network samples.

Inasmuch as heavy-mineral accumulations developed only near the upper surfaces of the bed, it was necessary that the surface sediments be included in the sampling. Therefore, most of these samples were taken in such a way that a small space remained above the sediment surface in the can. Plaster of Paris was poured into this open area, and moisture was allowed to evaporate. A chemical soil grout (AM-9, American Cyanamid Co.) was poured into the sample and allowed to harden. Adhesive strength of the grout was controlled to permit easy removal of sand grains from selected areas. The grouted samples were sawed to remove disturbed portions of the core, and the sedimentary structures and segregation of minerals were studied in the position that they were deposited. 
Selection of cores for analysis was based on the presence of and the location in them of segregated beds of opaque heavy minerals. The method of preparation and a description of the mounting of grains from a lamina within a core sample is described in appendix B. Complete analyses of size, shape, and sorting are shown in appendix C, table $\mathbf{5}$.

In run 2, opaque-heavy-mineral samples were obtained from topset and foreset beds and from the brinklines of dunes. Samples from run 3 were obtained from topset and foreset beds, and one sample was taken from the flat-bed region. Samples from run 4 were obtained from dark-opaque laminae located at the base of and within the flat-bed region. Grain size and sorting for samples shown in table 5 (appendix C) were obtained from direct measurement of 200 individual grains per sample mount.

Size and sorting analyses were determined from grain mounts of light minerals obtained either from light-mineral laminae adjacent to or from light minerals present within opaque-heavy-mineral laminae.

Analysis of variance tests were conducted for the median size, sorting, and shape factor of opaqueheavy-mineral grains obtained from core samples from runs 2,3 , and 4 . These statistical tests are used to determine whether two or more sample means could have been obtained from populations with the same parametric mean with respect to a given variable, or whether the sample means were drawn from different populations (Sokal and Rohlf, 1969, p. 175). In this study the analysis of variance tests were conducted to determine if size and sorting of the opaque heavy minerals in the segregated layers of each run were significantly different in each run. Since the same sediment was used for each run, any significant differences in the data must be due to the effect of the different flows on the grains.

Data used for the analysis of variance tests were obtained from laminae of dark opaque minerals in the core samples (appendix C, table 5). A more complete presentation of these results has been given by Brady, (1971, p. 44).

The results of the tests on the median grain diameter and the grain-shape factor of opaqueheavy-mineral grains showed no differences among runs at the 5 percent level of significance. A significant difference, however, did exist in the sorting among runs at the 1 percent level. An a posteriori SNK test (Sokal and Rohlf, 1969, p. 239-246) of the sorting means of the three runs was conducted to determine which run was significantly different from the others. Results of the SNK show that the mean sorting value of the opaque-heavy-mineral samples in run 4 is significantly larger than the sorting values are for the other two runs at the 1 percent significance level.

The median diameter and sorting for light-mineral samples that were obtained adjacent to and within the opaque-heavy-mineral laminae also were tested by analysis of variance tests (sorting and median diameter values of the samples are listed in appendix C, table 6). The tests show that no difference in sorting of light minerals existed between runs 2-4; but, a significant difference did exist at the 5 percent level between the median diameter of the samples. Results of these tests should indicate whether a given flow had an effect on the properties of lightmineral grains that were closely associated with opaque-heavy-mineral grains that differed significantly from the effects that other flows had.

A SNK test of the mean of the sample median grain sizes for each of the three runs showed that no significant difference existed between the three runs. However, a SNK test for uneven sample sizes, such as was used for runs 2-4, does not provide sufficient sensitivity to determine which run differed significantly from the other two in its effect on sample median size.

\section{EXPERIMENTAL RESULTS}

\section{SUMMARY OF BED FORM AND OPAQUE-HEAVY-MINERAL SEGREGATING CHARACTERISTICS}

Four different flow runs were observed in this study (table 2); based on the terminology of Simons and Richardson (1966), two runs were made in the lower flow regime, one run was made in the upper flow regime, and one run in the transition regime. The bed configuration consisted of dunes (lower flow regime) in runs 1 and 2 . Transition bed forms were long profile dunes and a near flat-bed condition in run 3. Run 4 consisted entirely of a flat bed formed in the upper flow regime. Average lengths $(L)$ and heights $(H)$, measured from sonic sounder charts, and length/height ratios for the dunes of different runs are given in table 3.

$$
\text { DUNE BED FORMS (RUN 1) }
$$

Dunes in run 1 were formed by flow that produced a low shear stress at the bed surface (table 2). In profile the dunes were generally triangular in shape, with the crestline coinciding with the dune brinkline. Topset beds occurred on only a few dunes. 


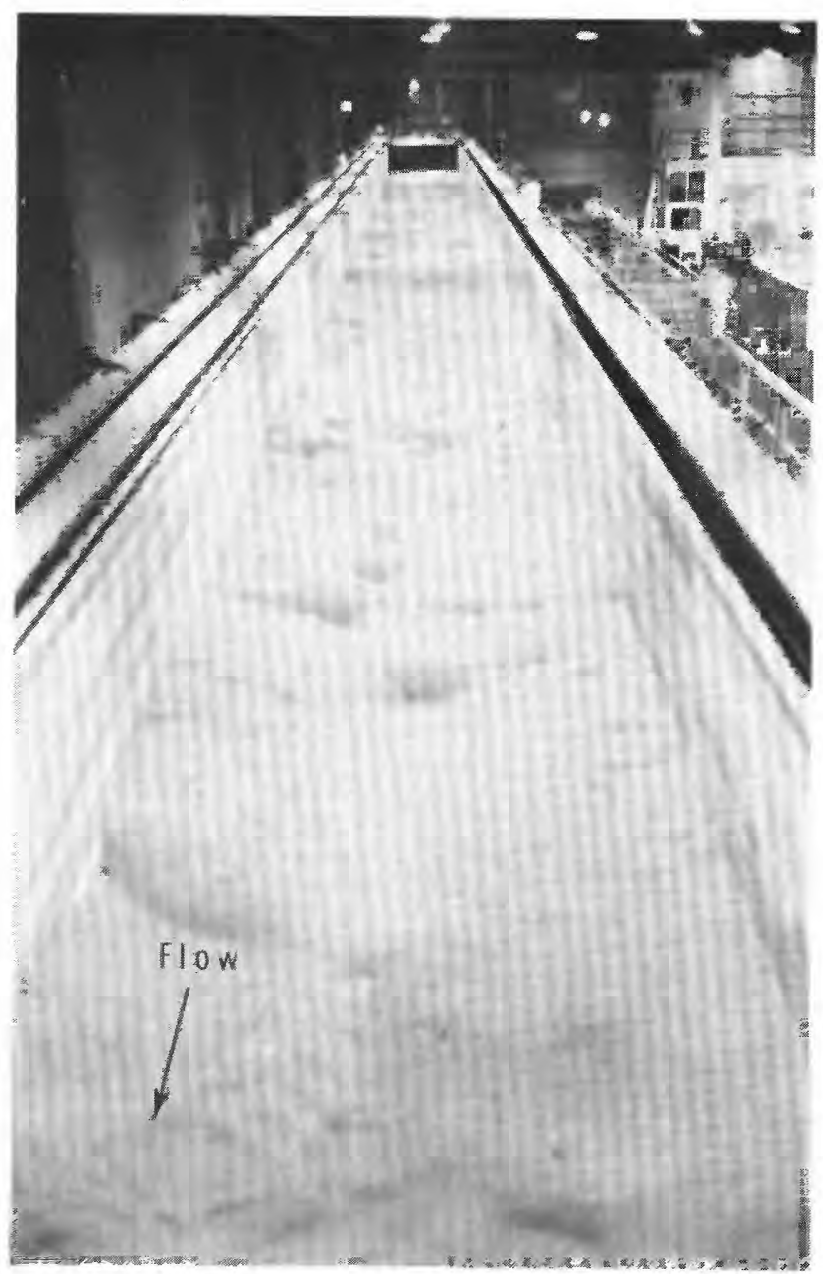

A

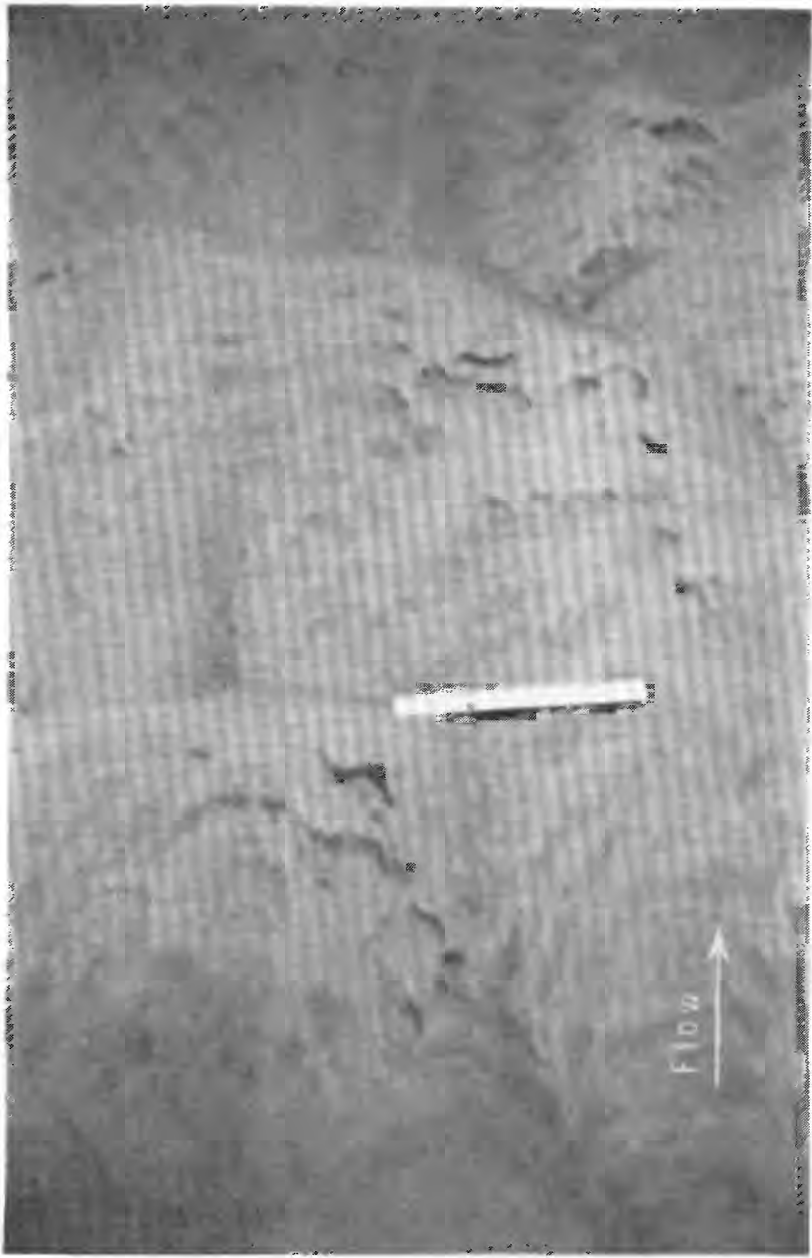

B

Figure 10.-Dune bed configuration and opaque-heavy-mineral accumulations at the bed surface following run 1. A, Dunebed configuration $B$, Stoss slopes of dunes showing small areas of accumulated opaque heavy minerals (length of rule is $30.5 \mathrm{~cm}$ ).

TABLE 3.-Mean dune size (with standard deviations) measured by sonic sounder

\begin{tabular}{|c|c|c|c|c|}
\hline Run & $\begin{array}{l}\text { Number } \\
\text { of dunes } \\
\text { measured }\end{array}$ & $\begin{array}{l}\text { Height }^{1} \\
\text { (cm) }\end{array}$ & $\begin{array}{l}\text { Length }{ }^{2} \\
\text { (meters) }\end{array}$ & $\begin{array}{c}\text { Length/height } \\
\text { ratio }\end{array}$ \\
\hline $\begin{array}{l}1-\ldots \\
2 \\
3 \\
3\end{array}$ & $\begin{array}{r}115 \\
28 \\
46\end{array}$ & $\begin{array}{l}10.2 \pm \\
30.0 \pm 13.9 \\
12.3 \pm \\
\pm\end{array}$ & $\begin{array}{l}1.63 \pm 0.66 \\
7.24 \pm 4.67 \\
5.66 \pm 2.48\end{array}$ & $\begin{array}{l}18.2 \pm \quad 8.7 \\
26.3 \pm 15.0 \\
46.6 \pm 29.6\end{array}$ \\
\hline
\end{tabular}

${ }^{1}$ Dune height, $H$, determined by maximum vertical distance between the trough point and the summit point of the dune as measured along center line of the flume.

${ }^{2}$ Dune length, $L$, was determined from the low trough point between dunes to the next trough point downstream as measured along the centerline of the flume.

The average angle of inclination of the foreset beds in run 1 was $32.4^{\circ}$, with a standard deviation of $2.3^{\circ}$. Configuration of the dunes forming the bed surface (fig. 10A) can best be described as linguoid. Rates of movement of the dunes ranged from 0.6 to 1.0 meter per hour.
Opaque heavy minerals associated with the dunes were limited to small very thin ripple-form accumulations on the stoss slopes of the dunes (fig. 10B). The small thin accumulations of opaque heavy minerals appear to develop just downstream from the reattachment point (the location where the flow impedes on the back of the downstream dune after it has passed over the upstream dune front) and migrate up the dune stoss slope. No accumulations of opaque heavy minerals were observed in the foreset beds.

\section{DUNE BED FORMS (RUN 2)}

Dunes formed by flow conditions in run 2 (table 2) were longer and higher than dunes produced by 
the other runs. Distance between brinkline and crestline commonly ranged from 25 to $110 \mathrm{~cm}$ and averaged $60 \mathrm{~cm}$. Topset beds, which are generally composed of rather fine material, were present on most dunes; they reached a total thickness of as much as $3 \mathrm{~cm}$. Foreset beds in run 2 showed an average dip of $29.2^{\circ}$ and a standard deviation of $3.1^{\circ}$. Generally the inclination angles of the foreset beds ranged from $28^{\circ}$ to $32^{\circ}$, but some low bed angles of $21^{\circ}$ to $23^{\circ}$ indicate unstable hydraulic flow during dune development. Dune fronts in run 2 were sinuous across the width of the flume (figs. 11, 12), and rates of movement of the dunes down the flume (based on successive brinkline locations) ranged from 1.5 to 3.4 meters per hour.

Accumulations of opaque heavy minerals associated with the dunes (fig. 13) were present commonly as:

1. Opaque heavy minerals on the dune stoss slopes in the form of thin ripple accumulations or very thin almost sheetlike accumulations. The thin ripple accumulations, which resembled those shown in figure $10 \mathrm{~B}$, were very common. They appear to have originated on the lower part of the dune stoss slope and to have migrated up the dune slope. Thin sheetlike accumulations of the opaque heavy minerals like

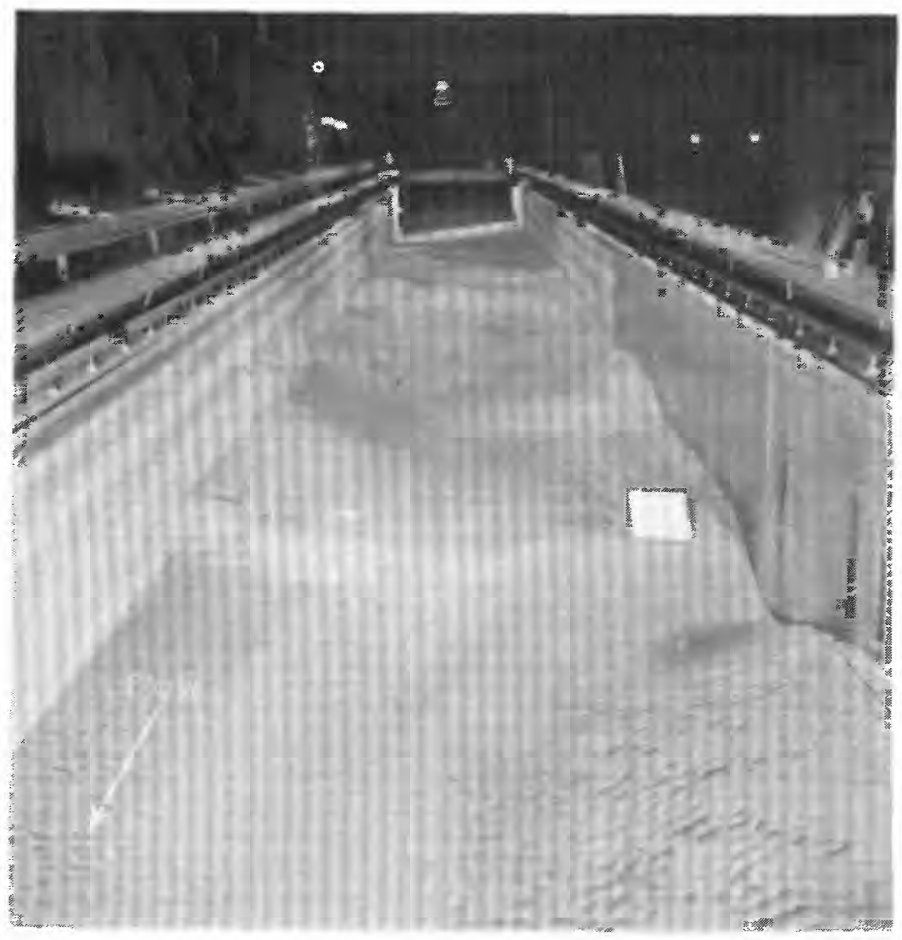

Figure 11.-Dune bed configuration (view upstream) of run 2. Figure 12 is a close view of the large dune (center of the photograph) on which the white square is located.

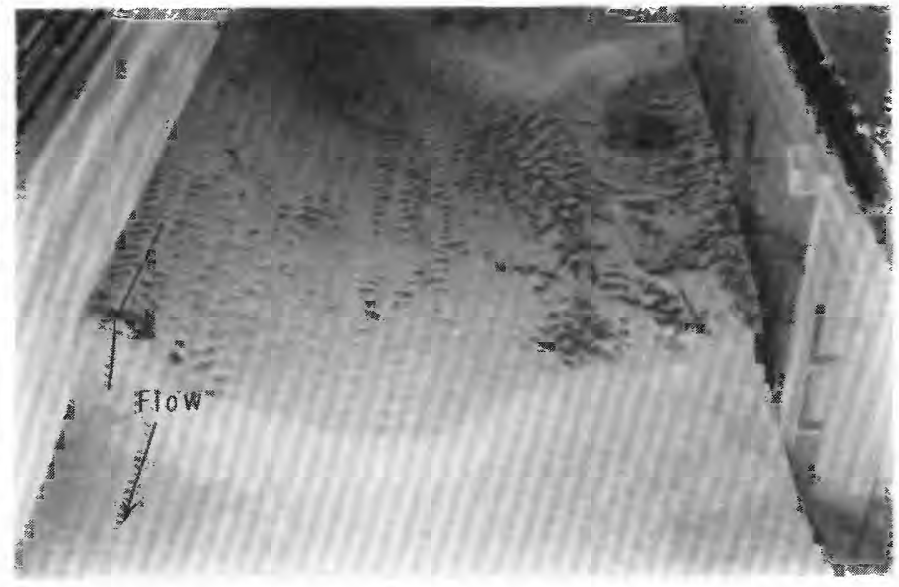

FIGURE 12.-Accumulations of dark opaque heavy minerals on the upstream sides of dunes (run 2). Location of cutaway view of dune (fig. 14) is shown by the line near the flume wall on left side of photograph. The ripple surface that is shown on the dune is due to abrupt changes in hydraulic flow that occurred when the flume was shut down at the end of the run. Segregation of the heavy minerals was not formed by shutdown of the flume.

those shown in figure 12 were present on many dune stoss slopes.

2. Thick accumulations of opaque heavy minerals associated with the dune crest area. These accumulations formed the thickest beds of opaque heavy minerals observed, and the beds were nearly 100 percent opaque heavy minerals. Observations made through the plexiglass wall of the flume during the flow showed that the opaque-heavy-mineral accumulations formed on the highest portion of the dune (in dune profile). The accumulation as a whole moved downstream at a rate approximately equal to the rate of movement of the dune. Scour occurred periodically both upstream and downstream from the heavy-mineral area. If degradation immediately downstream reached approximately $1-2 \mathrm{~cm}$ below the high point of the accumulation, large amounts of the heavy minerals were transported from the accumulation by suspended and tractive movement and redeposited as a heavy-mineral lamina along the lee slope.

3. Accumulations of opaque heavy minerals that were deposited between the dune crestline and the brinkline. These deposits, derived from the thick crest area accumulation of opaque heavy minerals, formed part of the topset beds of the dune. An example of numerous opaqueheavy-mineral laminae in the topset beds is shown in figure $14 B$. 


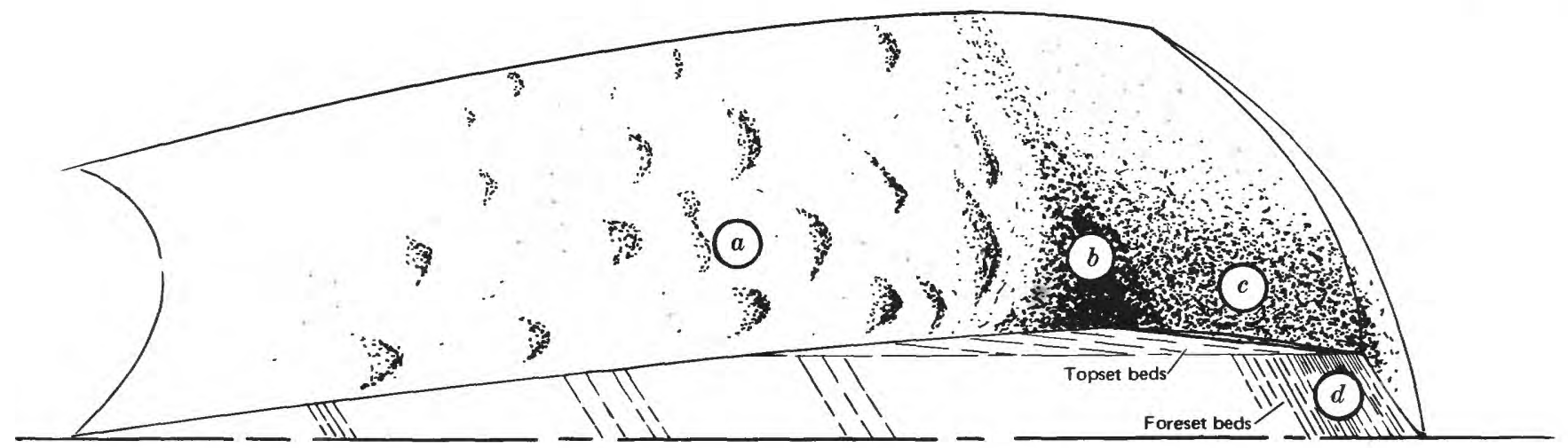

Figure 13.-Generalized view and cut-away of a dune showing structures and locations of different types of opaqueheavy-mineral accumulations: $a$, thin ripple-form accumulations on stoss slope; $b$, crestal region accumulation; $c$, region between the crestline and brinkline where accumulations occur; $d$, accumulations in foreset beds. $(\times 3$ vertical exaggeration).

4. Accumulations of opaque heavy minerals deposited at the brink point and on the slipface of the dune. These deposits formed dark laminae in the foreset beds like those shown in figure $11 \mathrm{~A}$. The concentrated opaque-heavymineral layers did not extend down the foreset beds more than $8 \mathrm{~cm}$ (total slipface length on the dunes commonly was $20-30 \mathrm{~cm}$ ), and concentration of heavy minerals decreased with increased distance down the bedding plane from the brinkline. Opaque heavy minerals were lost from the topset beds by tractive and suspended transport over the brink point.

\section{TRANSITION BED FORMS (RUN 3)}

During the run the bed forms alternated between large dunes (fig. $15 A$ and $B$ ) and a near flat-bed condition (very long profile dune). The near flatbed condition of the run differed from a true flat bed in that it did not at any time extend over the entire length of the flume. In addition, the near flat-bed condition differed from the flat bed of run 4 by having a slipface on its downstream edge as well as slight form irregularities on its surface. Dunes associated with run 3 had a much larger length-to-height ratio than the dunes of runs 1 and 2.

The distance from the crestline to the brinkline for the dunes of run 3 commonly ranged from 15 to $85 \mathrm{~cm}$, but for some dunes the distance was as much as 2.5 meters; the mean distance was $53 \mathrm{~cm}$. Topset beds of fine material were present on virtually all the dunes. Dune fronts were sinuous across the flume as shown in figure $15 A$ and $B$. Angles of inclination of foreset beds averaged $28.6^{\circ}$ with a standard deviation of $3.2^{\circ}$. Several foreset dip values of $21^{\circ}$ to $23^{\circ}$ indicated locally unstable deposition. Rates of movement of the dune fronts ranged from 2.7 to 4 meters per hour.

Opaque-heavy-mineral accumulations commonly associated with the transition bed forms can be classified as follows:

1. Thin but widespread accumulations near the base of flat beds, just above foresets formed with or as part of dunes deposited earlier.

2. Thin laminae of concentrated opaque heavy minerals within the flat beds. These laminae were usually thinner than the opaque-heavy-mineral beds at the base of the flat-bedded sediments.

3. Accumulations associated with the dune phase of the transition bed forms. They were basically the same as those associated with the dunes of run 2, namely:

a. Thin accumulations in ripple-form and sheetlike accumulations that advance up the stoss side of dunes.

b. Thick accumulations that were commonly present along the crestal region of the dune (fig. $16 A$ and $B$ ).

c. Accumulations that extended downstream from the crestline to the brinkline (fig. $17 A$ and $B$ ). In several dunes opaqueheavy-mineral segregation was observed in the foreset beds (fig. 17A).

d. Thick accumulations were often present in the topset beds. These deposits resulted from burial of surface accumulations.

BED FORMS OF MOVING FLAT-BED CONDITIONS (RUN 4)

The flow that produced the flat beds of run 4 had 


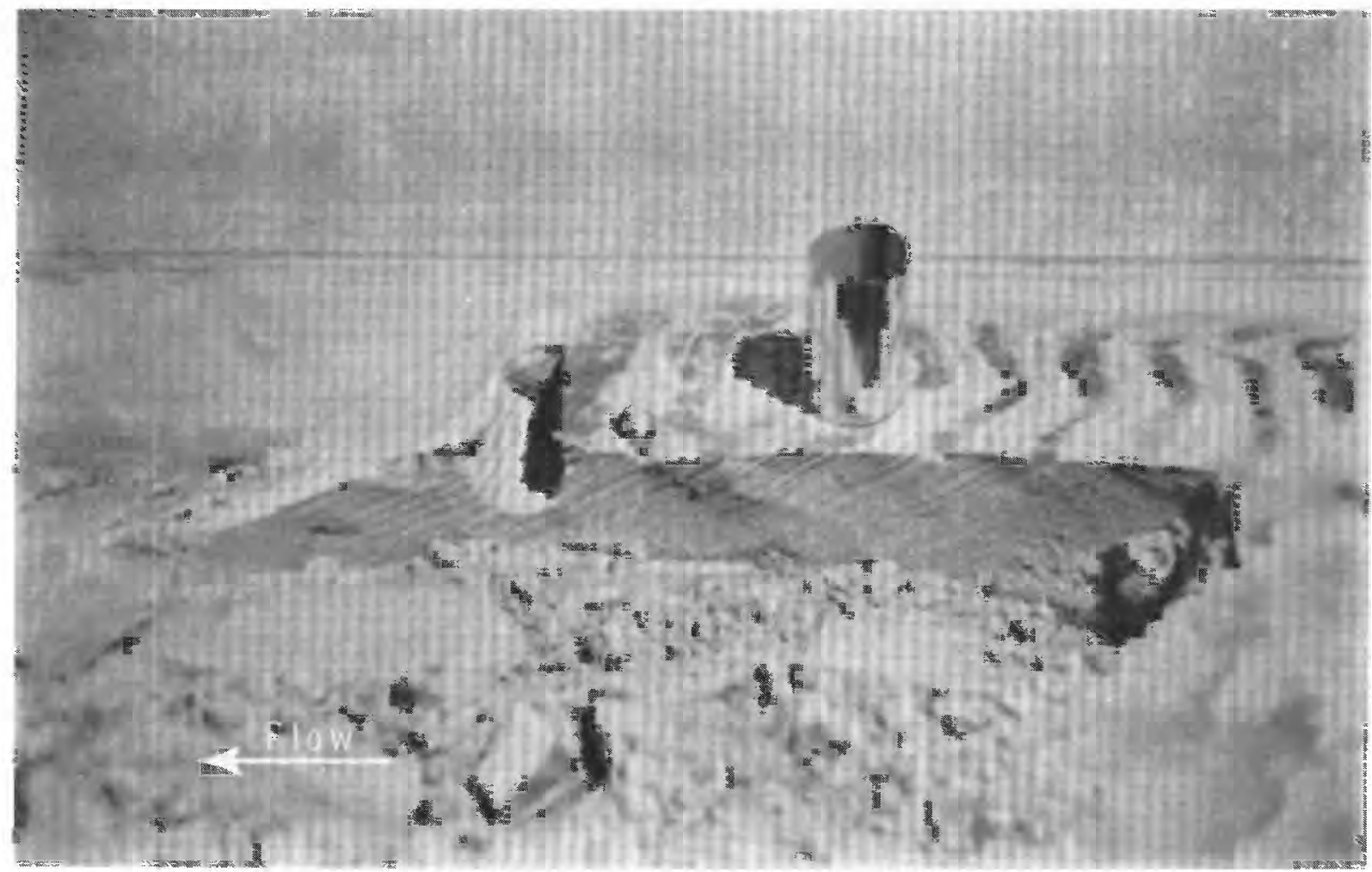

$A$

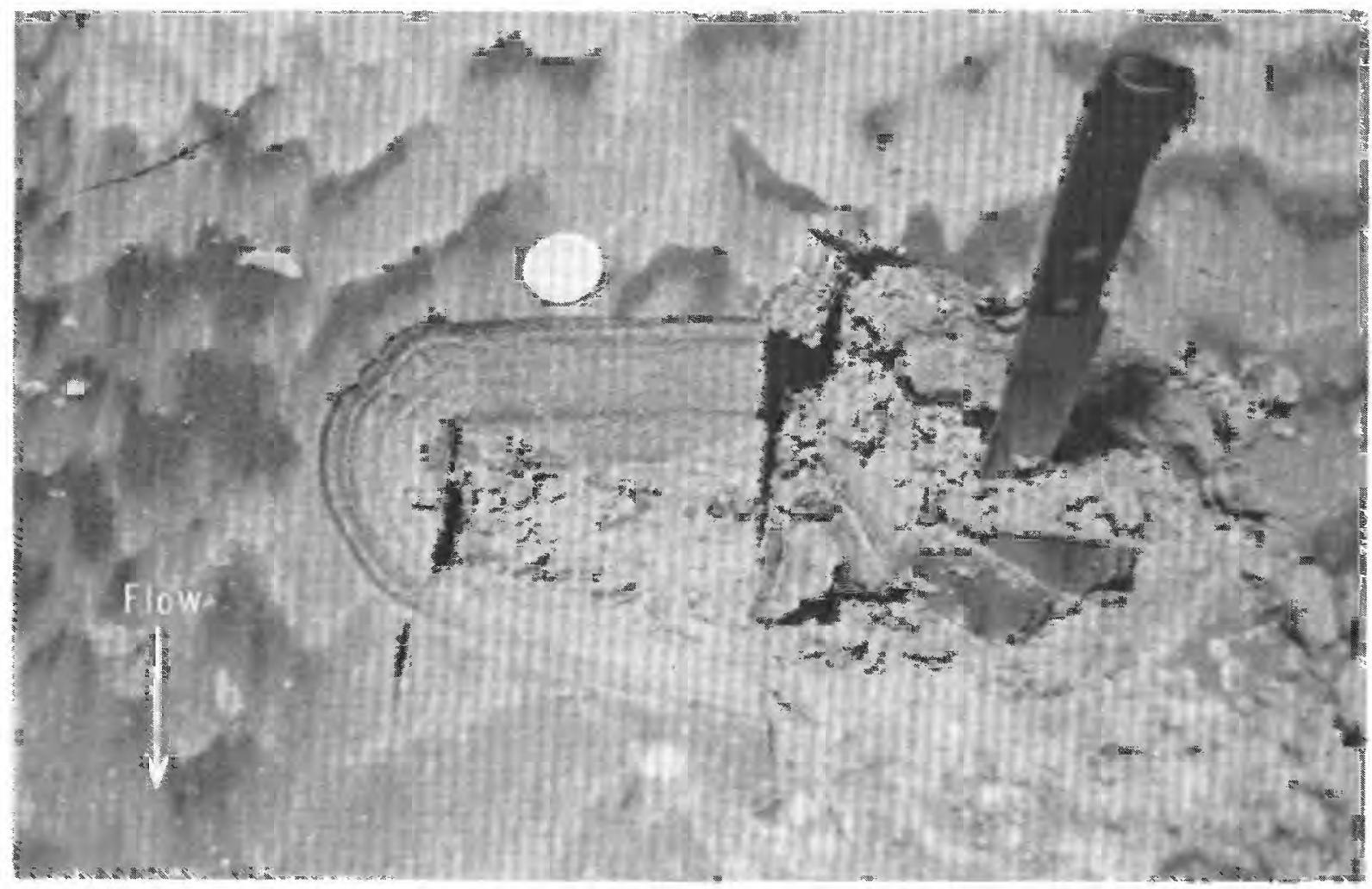

FIGURE 14.-Opaque-heavy-mineral accumulations in foreset and topset beds of dunes formed in run 2. A, Cut-away part of dune shown in figure 12 showing accumulation of opaque heavy minerals (dark beds) in the foreset beds (can diameter is $6.5 \mathrm{~cm}) ; B$, Segregation of opaque-heavy-mineral grains in topset laminations. 


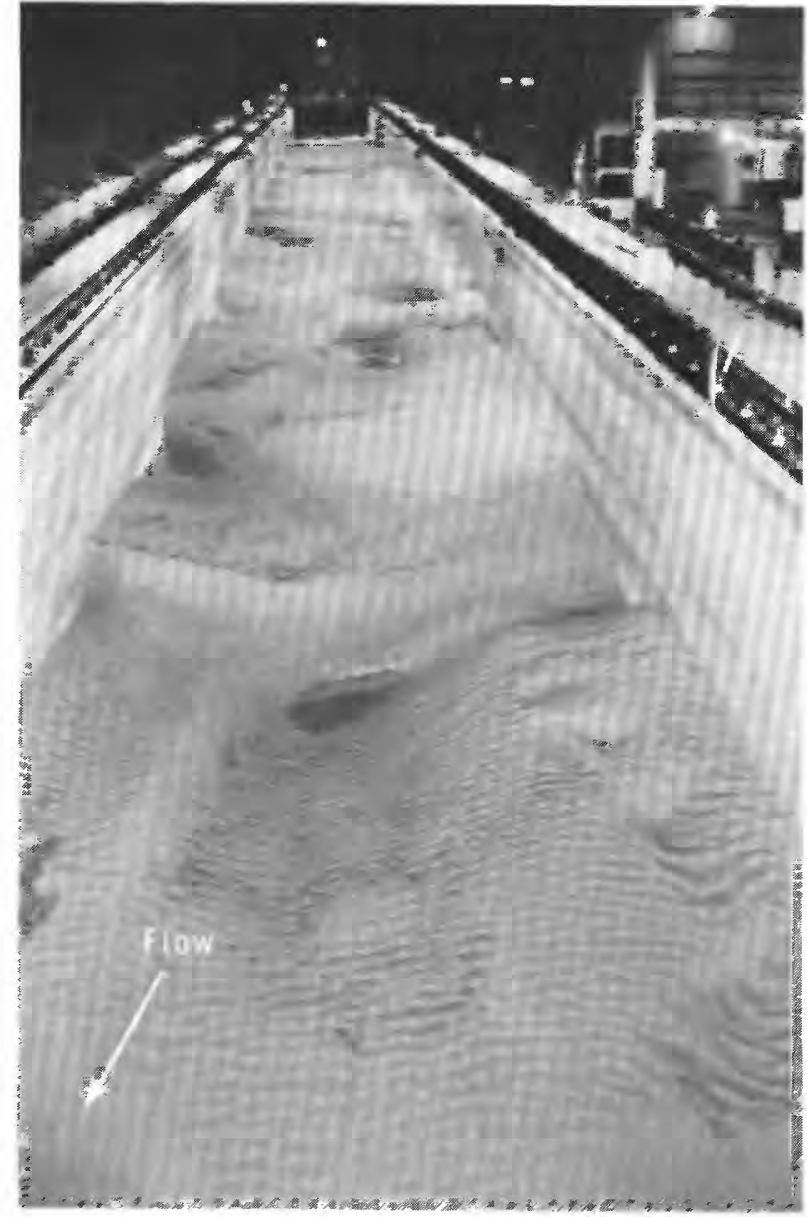

A

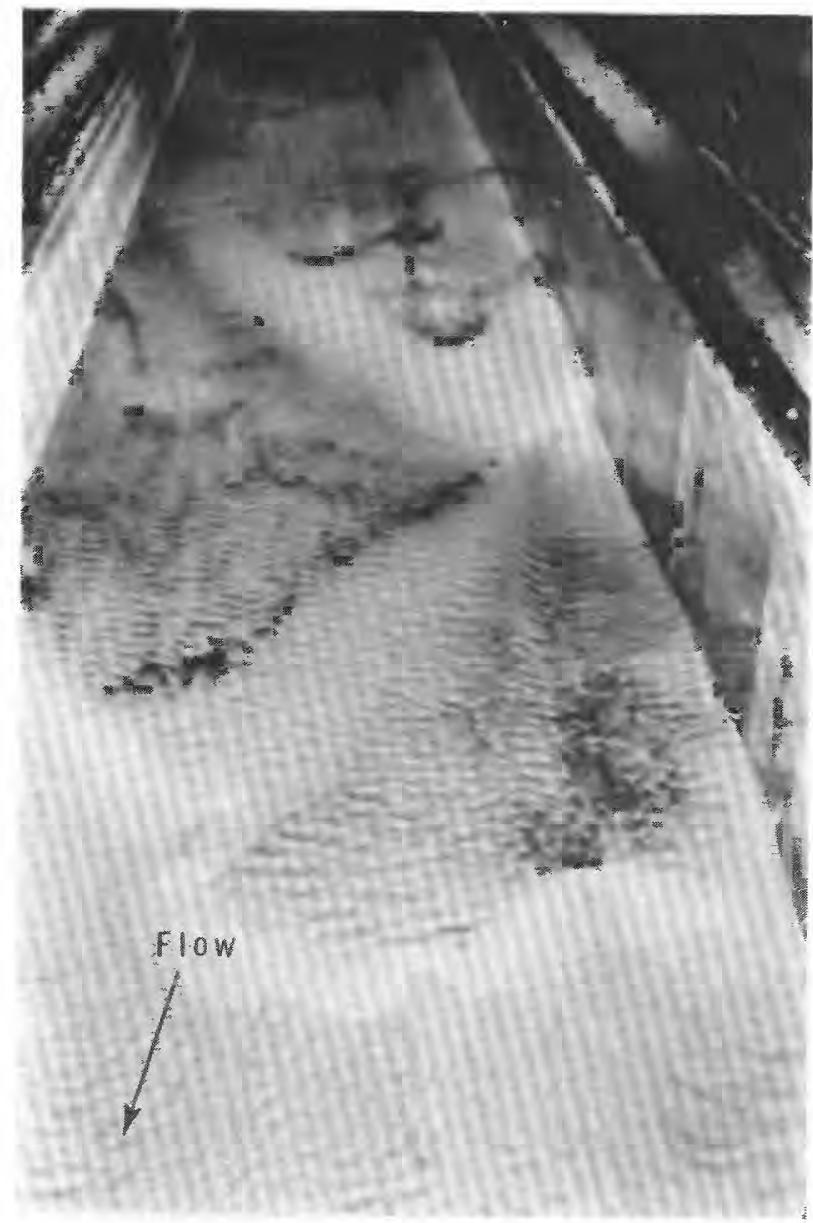

$B$

FIGURE 15.-Bed configuration and opaque-heavy-mineral accumulation at the bed surface formed during run 3 . $A$, Dune region of transition flow; $B$, Close-up view of dunes showing opaque-heavy-mineral segregation on the dune stoss slopes. Ripples present on the dunes were not present during the run but were formed as the result of abrupt changes in flow conditions during flume shutdown.

the highest shear stress and Froude number of any flow during the four runs. Under equilibrium flow the sediment bed had an essentially featureless surface (fig. 18), the bed elevation at any point departing only a few centimeters from the mean elevation. A study of bed-surface-elevation fluctuations at one location during the equilibrium flow showed a maximum fluctuation of only $1.8 \mathrm{~cm}$ during a 12 hour period. Studies by Guy, Simons, and Richardson $(1966$, p. 24,29$)$ show vertical fluctuations with time of flat-bed surfaces during several runs as ranging from 1 to $3 \mathrm{~cm}$. Bedding structures were all flat lying and covered preexisting bed forms. Generally the material in the flat lying deposits was finer than the material in the preexisting foreset beds. Total thickness of the flat beds in the run was usually less than $3 \mathrm{~cm}$.

Of the four runs studied in detail, total sediment concentrations in the total-load and suspended-load samples were by far the largest in run 4 .

Opaque-heavy-mineral accumulations were common in the flat-bed run, and accumulations of the heavy minerals were present at the base of and within the flat beds over virtually the entire flume area (fig. 19). The individual beds, however, tended to lense out within a few meters. Accumulations were often the thickest and most widespread at or near the base of the flat beds. In run 4 no opaqueheavy-mineral accumulations were present at bed surface.

\section{RELATION OF FALL VELOCITIES OF DARK OPAQUE AND LIGHT-DENSITY GRAINS}

Samples of light minerals obtained from laminae adjacent to or within laminae having a high con- 


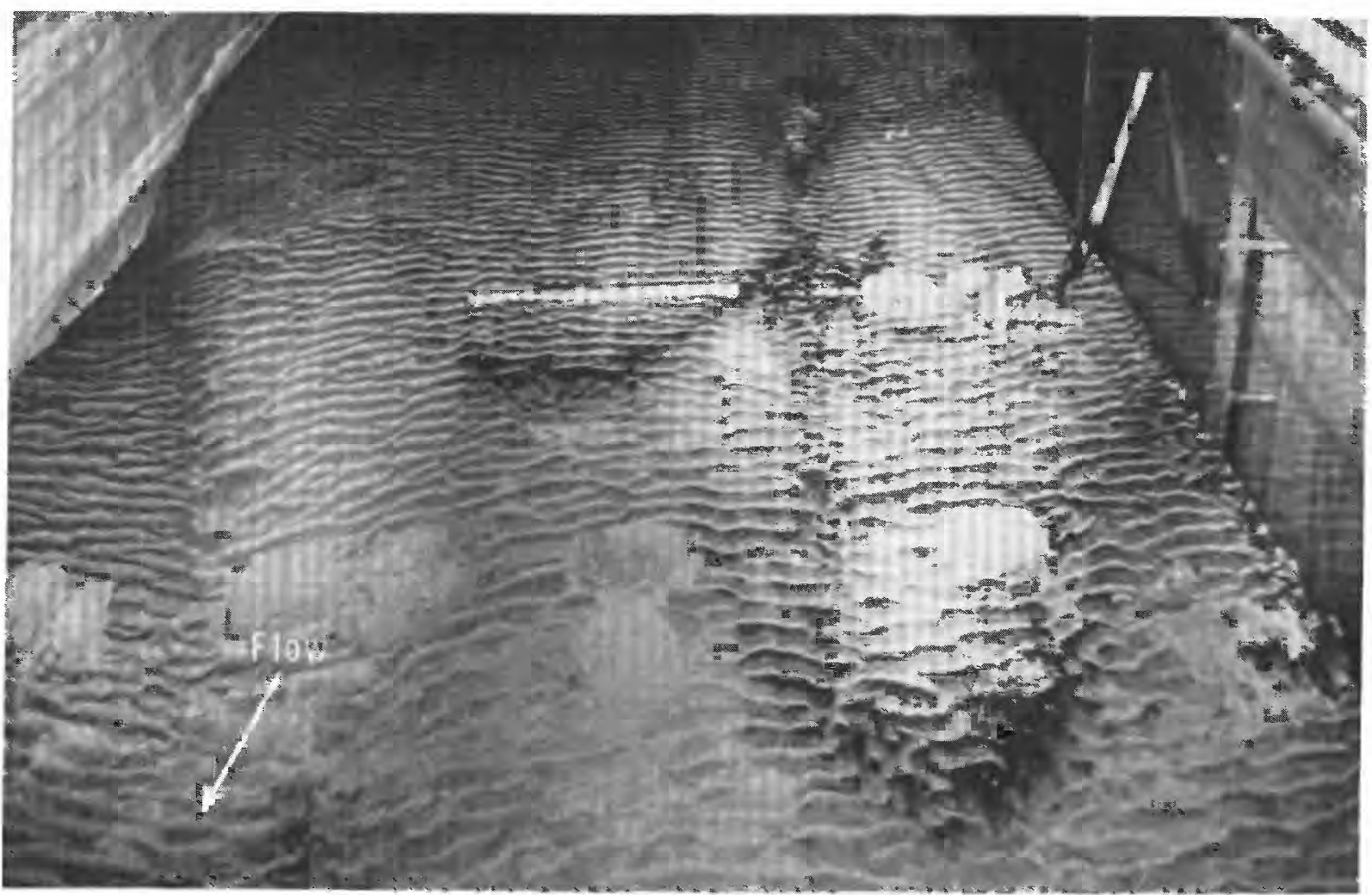

$A$

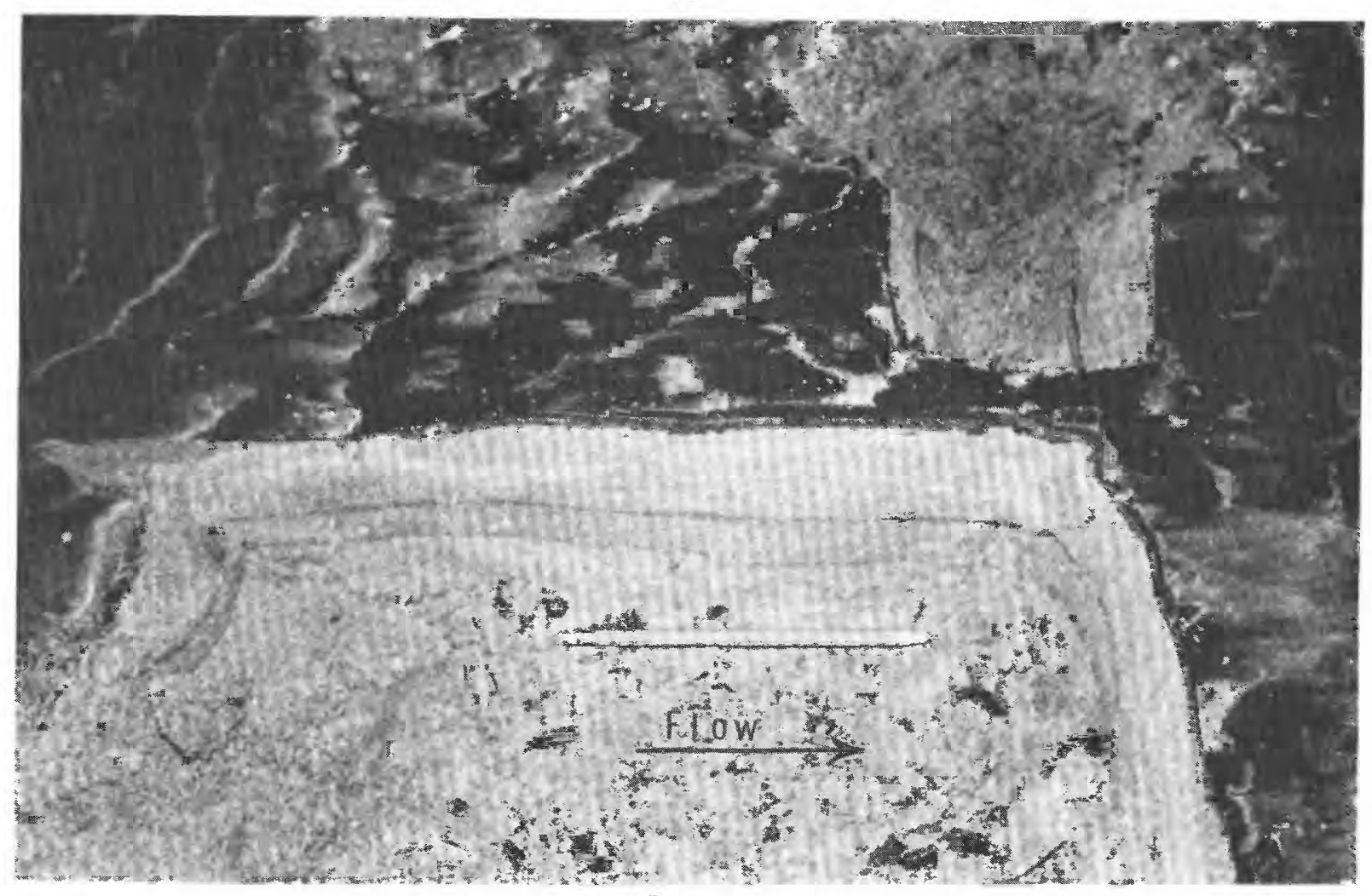

$B$

FIGURE 16.-Accumulations of opaque heavy minerals formed along the crestal region of a dune (run 3). A, Accumulation on the crestal region of a long dune in the transition flow; $B$, Exposed topset beds (located at the right side of the $71-\mathrm{cm}$ rule in top photograph) showing the thick accumulation. 


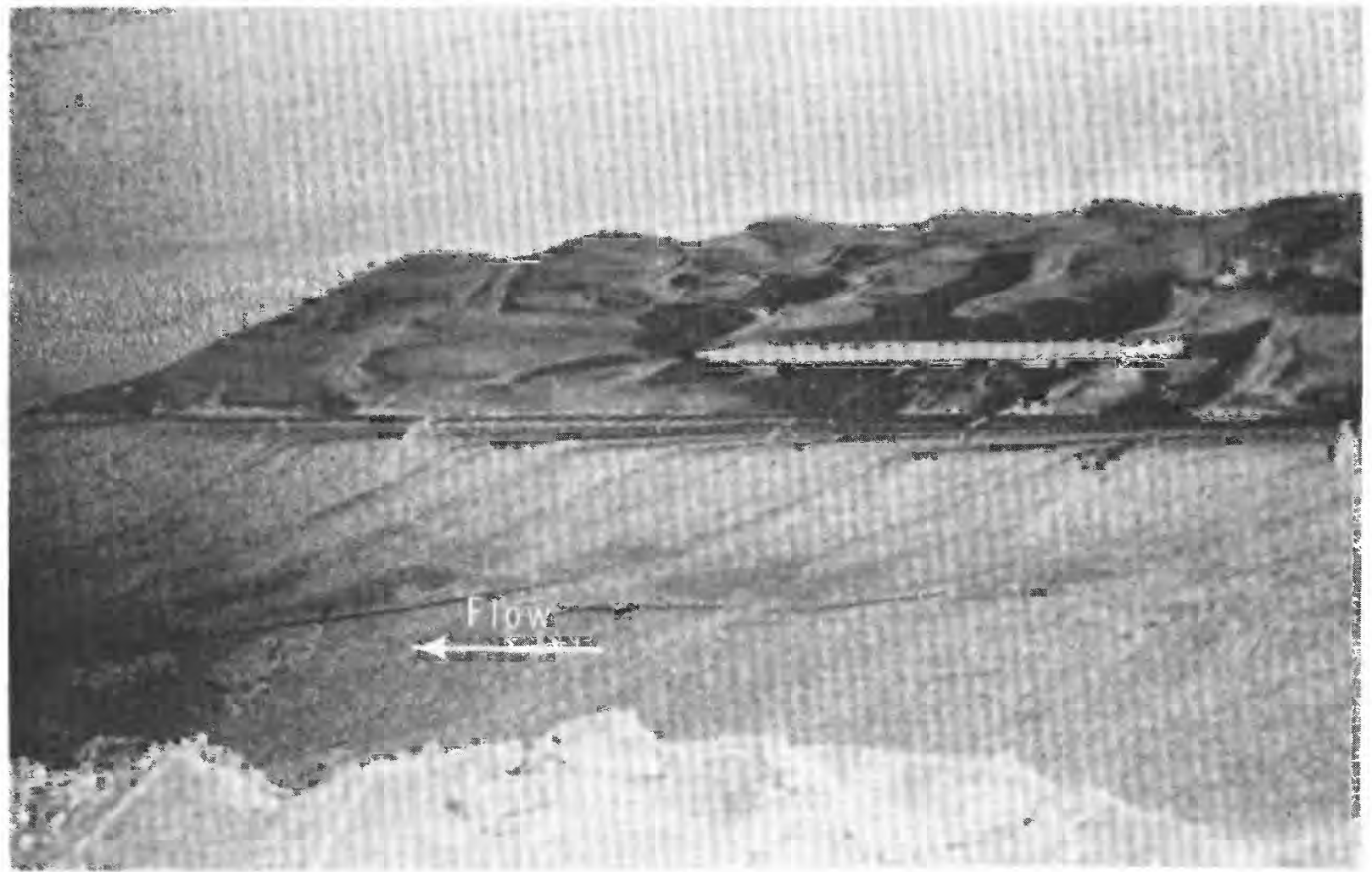

\section{$\boldsymbol{A}$}

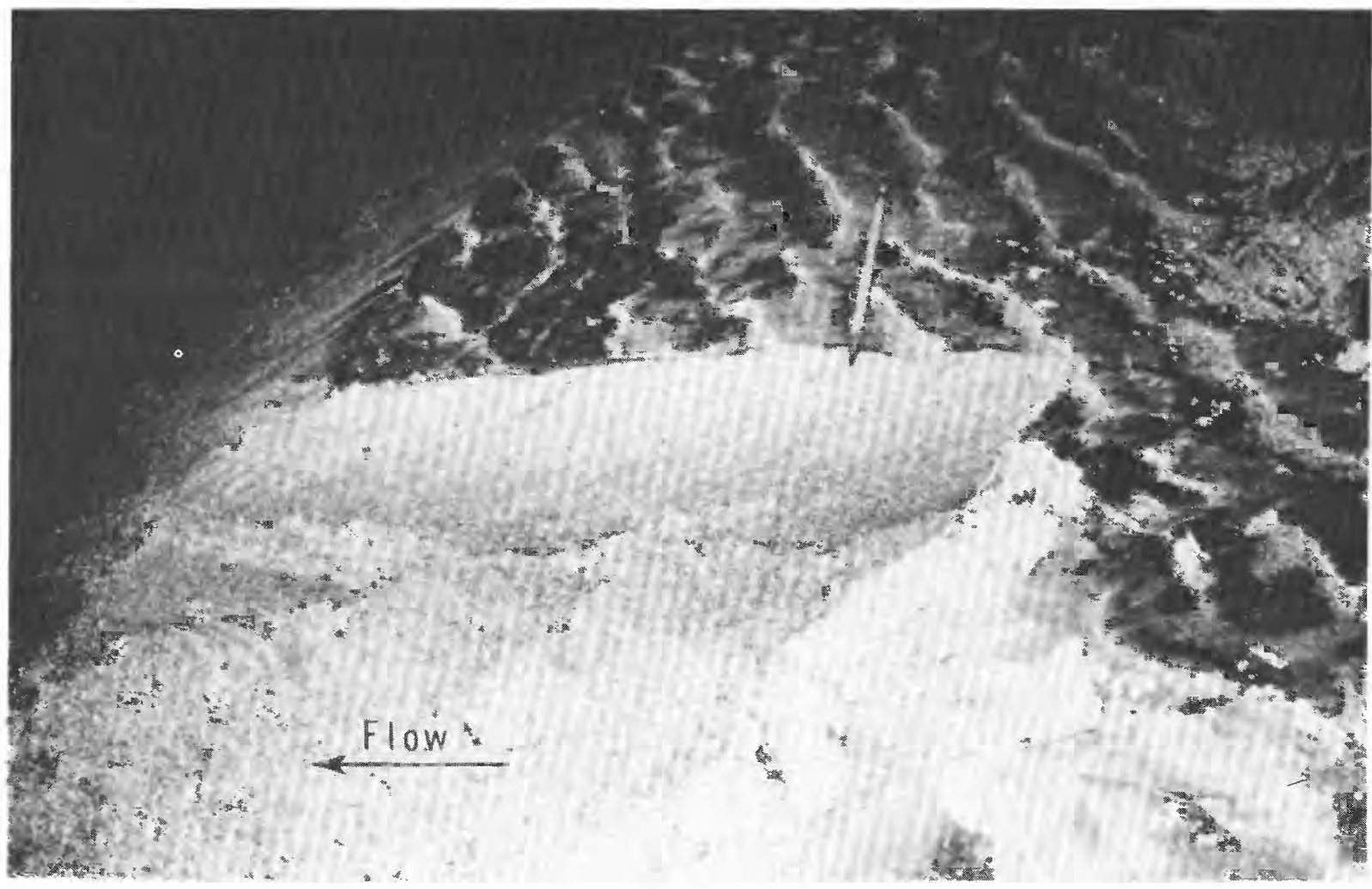

$B$

FIGURE 17.-Opaque-heavy-mineral accumulations formed in topset and foreset beds during run 3. A, Opaque heavy minerals in dark laminae of topset beds near the brinkline and in the foreset beds in laminae composed of the grains that have passed over the brink point; $B$, Foreset beds have very few opaque heavy minerals present, but a large amount of opaque heavy minerals are present in the thin topset beds. 


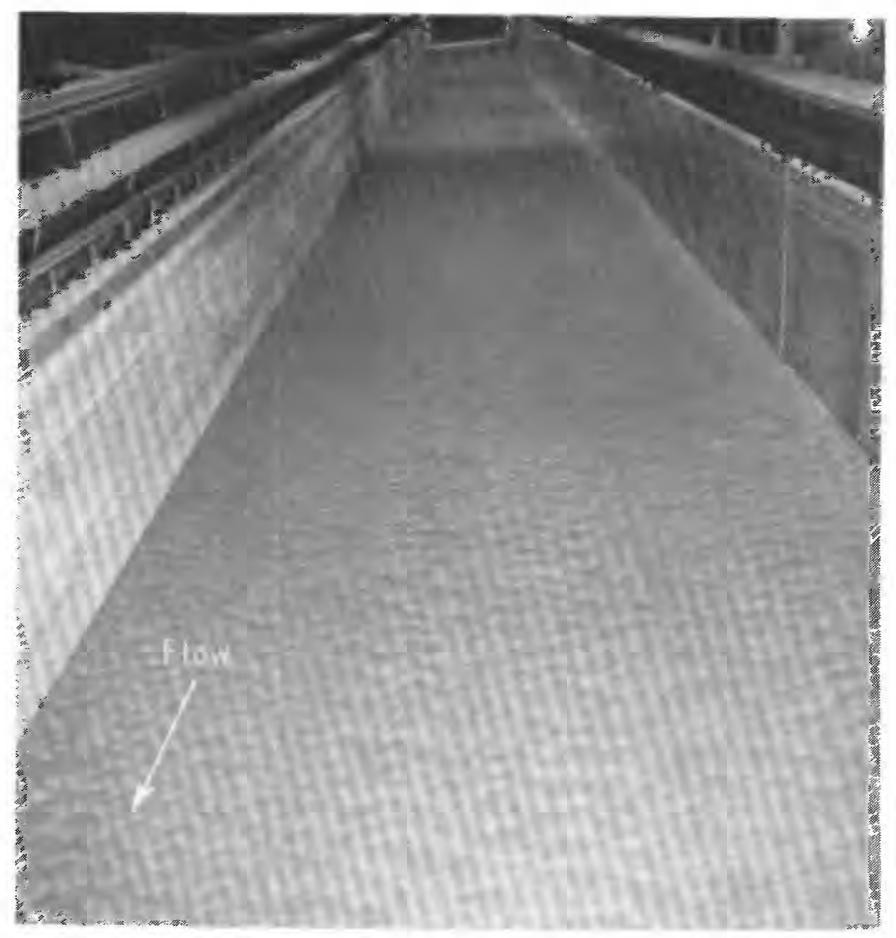

Figure 18.-Flat-bed surface formed by run 4. Ripples at the surface were due to shutdown of the flume.

centration of opaque heavy minerals were studied to examine the role fall velocities play in the association of light- and heavy-mineral grains.

To do so, a graph (fig. 20) relating sieve size to fall velocity for grains with a shape factor of 0.7 and with specific gravities of 2.65 and 5.0 was plotted from data reported by the U.S. Inter-Agency Committee on Water Resources (1957). Values of fall velocities for the $d_{16}, d_{50}$, and $d_{84}$ grain sizes were determined from figure 20 by using the samples described in tables 5 and 6 (appendix C). These fall-velocity values have been tabulated by Brady (1971, p. 112). Fall-velocity relations between opaque-heavy-mineral grains and light-mineral grains of the bed-material sample and the average of all the core samples are shown in figure 20. If one averages the range between the 16th and 84th percentiles of the opaque-heavy-mineral grains and the light-mineral grains for the sampled laminae in the core samples, 78 percent of the light mineral grains have fall velocities within the same range as 80 percent of the opaque-heavy-mineral grains. For the bed-material samples, 74 percent of the lightmineral grains had fall velocities equal to 78 percent of the opaque-heavy-mineral grains.

Median fall-velocity values of the opaque heavy minerals and the median fall velocities of light minerals sampled adjacent to (18 samples) or within (five samples) the opaque-heavy-mineral laminae have a correlation coefficient of 0.369 (fig. 21 ), a value that suggests no correlation exists. The lack of correlation for medians of fall velocities between the two mineral groups shows that the median fall velocity of one group is not a predictor of the median fall velocity of the other group despite the fact that a large number of grains have equivalent fall velocities in adjacent laminae. The lack of correlation for mean fall velocities of the opaque heavy minerals and light minerals, therefore, suggests that other grain properties were much more important for local sorting.

\section{RELATION OF GRAIN ENTRAINMENT TO CRITICAL SHEAR STRESS AND GRAIN SIZE}

By using Shields diagram (fig. 5), one can develop the relation of critical shear to grain size for grains of different densities.

Such a series of curves was developed by Grigg and Rathbun (1969, p. B79). Two curves similar to those constructed by Grigg and Rathbun are plotted in figure 22 for grains of 5.0 and 2.65 specific gravities. The range between the 16 th and 84 th percentiles of the opaque-heavy-mineral grains and the light-mineral grains of the bed material and the average values for the sampled laminae in the core samples from runs 2, 3, and 4 are plotted in figure 22 to show the relation between the critical shear stress of the two mineral groups. The large difference in critical shear indicates that quartz and feldspar grains would be entrained from sands in this study much more readily than magnetite and ilmenite grains.

Figure 22 is based directly on Shields diagram. The data on which the Shields diagram was based were obtained by laboratory experiments in which particles moved over a bed that consists of particles of the same size. How differences in size affect the moving and stationary particles has been discussed on pages 3 and 4 . By use of figure 1 , one can qualitatively adjust figure 22 so that it is more applicable to the flume situation. For example, figure 1 indicates that the resistance of a $0.1 \mathrm{~mm}$ particle resting on a bed of $0.2 \mathrm{~mm}$ particles is underestimated in figure 22 by as much as a factor of 3. Once a small magnetite or ilmenite grain is deposited on a bed of large quartz and feldspar grains, it is extremely difficult for the flow to move it again.

The resistance of a $0.4 \mathrm{~mm}$ particle resting on a bed composed of $0.2 \mathrm{~mm}$ particles is overestimated 


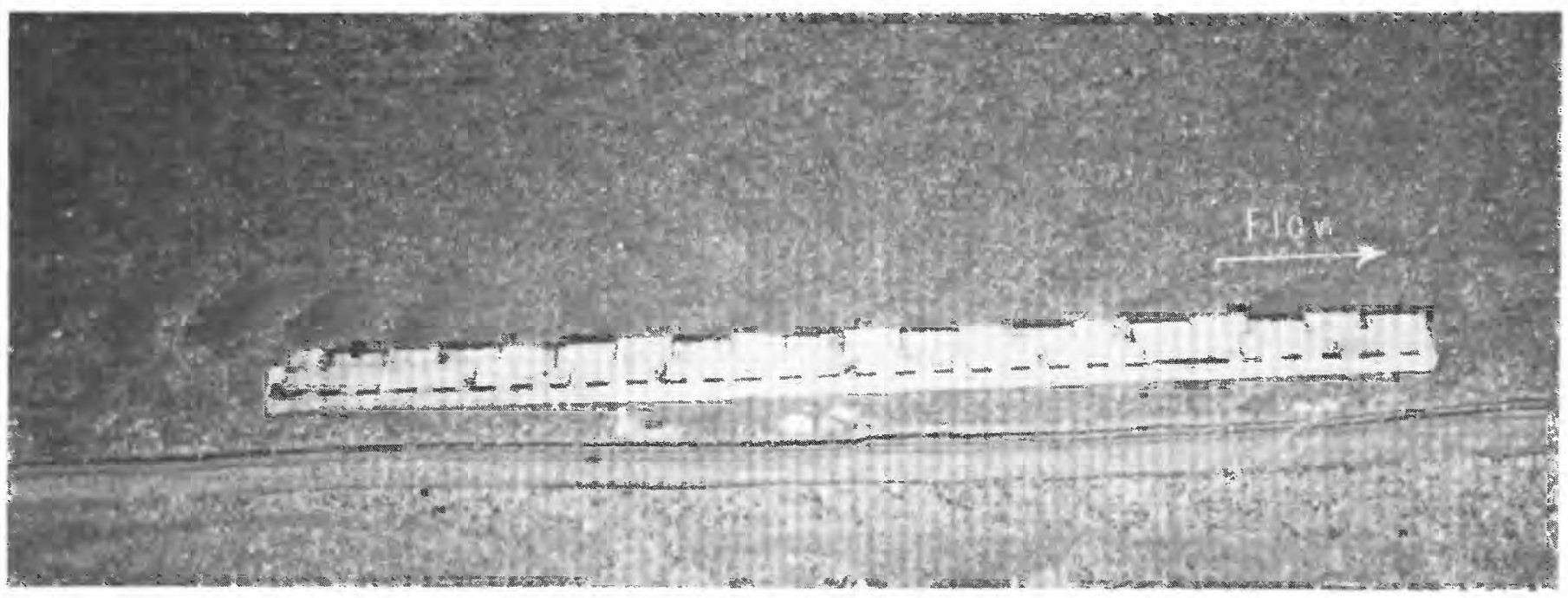

Figure 19.-Flat-bed flow deposits showing opaque-heavy-mineral layers (dark beds) within the flat-lying beds. Lower dark-mineral bed directly overlies foreset beds of an earlier run. Wavy appearance of the dark laminae in the photograph is due to an irregular cross-section cut. The rule is $71 \mathrm{~cm}$ in length.

in figure 22 by perhaps a factor of 2 . The flow will quickly remove a large quartz or feldspar particle from a bed which is composed of small dense grains.

In addition, distinct differences in physical size between grains also leads to a "hiding factor," or a shielding of the smaller grains from the flow by the larger grains. Einstein and Chien (1953) discussed the "hiding factor."

To test whether the slope of the lines in figure 22 may actually be negative when the bed is composed of a poorly sorted material in the size range of interest here, an experiment was conducted to determine what effect the sorting of the bed material might have on a particle's resistance to motion. A flat bed of quartz sand $\left(d_{50}=0.280 \mathrm{~mm}, \sigma=1.50\right)$ was placed over a 94-cm section of a flume $20 \mathrm{~cm}$ deep, $20 \mathrm{~cm}$ wide, and 10 meters long. The bed roughness for a section 6 meters long upstream from the sand bed was similar to that of the sand bed. The flow was started at a velocity insufficient to move any of the bed material, and the velocity was gradually increased. During the velocity increase the water depth was held constant at $3.5 \mathrm{~cm}$, while the slope of the water surface remained parallel to that of the bed. The velocity was increased slightly each 24 hours for 6 days. The total material transported from the test section during each day (run) was collected and sieved.

Results of this experiment (table 4) show that little sediment was eroded during the first five runs. During the last run, ripples developed, and a considerable amount of sediment was eroded, mainly producing a few isolated scour holes several millimeters deep.
The selectivity with which the flow transported a particular size fraction of the bed material can be determined by computing the ratio of the percent of that size fraction in the material transported out of the test section to the percent of the size fraction which was available for transport. This ratio will be called the transport ratio. Transport ratios which are greater than one indicate size fractions which are readily transported or which have a low resistance to motion. If a particle's resistance to motion were correctly represented by figure 22 , one would expect the transport ratio to decrease continuously with increasing particle size.

By assuming that a representative sample of the bed material was available for transport on the bed surface at the beginning of run $\mathrm{A}$, the transport ratios for each size class and run were computed from the data given in table 4. Except for run A, which did not transport any sediment larger than $0.707 \mathrm{~mm}$, the transport ratios were larger than one for all grain sizes greater than $0.35 \mathrm{~mm}$. The increase in the value of the transport ratio indicates a decrease in resistance to motion with increase in grain size in the range 0.25 to $1.0 \mathrm{~mm}$, a relationship opposite to that indicated in figure 22 .

It is suspected that some sorting of the bed material occurred at the bed surface as a result of the placement of the bed and that this sorting affected the resulting transport ratios of the smaller grain sizes during the first five runs. Therefore, no significance is attached to the transport ratios of the finer sizes for the first five runs.

Ripples were developing during run $F$, and a few scour holes were eroded several millimeters deep. 
TABLE 4.-Results of a resistance-to-motion experiment using a poorly sorted quartz bed material

\begin{tabular}{|c|c|c|c|c|c|c|c|c|c|}
\hline \multirow[b]{2}{*}{ Run } & \multicolumn{9}{|c|}{ Size, in millimeters } \\
\hline & $\begin{array}{c}0- \\
0.062\end{array}$ & $\begin{array}{l}0.062 \\
0.125\end{array}$ & $\begin{array}{l}0.125- \\
0.177\end{array}$ & $\begin{array}{l}0.177- \\
0.250\end{array}$ & $\begin{array}{l}0.250 \\
0.350\end{array}$ & $\begin{array}{l}0.350- \\
0.500\end{array}$ & $\begin{array}{l}0.500- \\
0.707\end{array}$ & $\begin{array}{c}0.707- \\
\infty\end{array}$ & Total \\
\hline \multicolumn{10}{|c|}{ Weight (in grams) of material eroded during the run } \\
\hline $\begin{array}{l}\mathrm{A} \\
\mathrm{B} \\
\mathrm{C} \\
\mathrm{D} \\
\mathbf{E}\end{array}$ & $\begin{array}{l}0.0006 \\
.0007 \\
.0016 \\
.0013 \\
.0016 \\
.000\end{array}$ & $\begin{array}{l}0.0089 \\
.0067 \\
.0110 \\
.0104 \\
.0111 \\
.019\end{array}$ & $\begin{array}{l}0.0126 \\
.0100 \\
.0147 \\
.0235 \\
.0133 \\
.594\end{array}$ & $\begin{array}{c}0.0132 \\
.0089 \\
.0109 \\
.0387 \\
.0236 \\
3.221\end{array}$ & $\begin{array}{r}0.0157 \\
.0098 \\
.0075 \\
.0528 \\
.0827 \\
8.106\end{array}$ & $\begin{array}{r}0.0285 \\
.0180 \\
.0136 \\
.0784 \\
.2505 \\
11.106\end{array}$ & $\begin{array}{r}0.0010 \\
.0109 \\
.0146 \\
.0554 \\
.2033 \\
4.085\end{array}$ & $\begin{array}{l}0 \\
.0010 \\
.0017 \\
.0012 \\
.0051 \\
.057\end{array}$ & $\begin{array}{r}0.0805 \\
.0660 \\
.0756 \\
.2617 \\
.5912 \\
27.188\end{array}$ \\
\hline Total & .006 & .067 & .668 & 3.316 & 8.275 & 11.495 & 4.370 & .066 & 28.263 \\
\hline \multicolumn{10}{|c|}{ Percent of total eroded material } \\
\hline & 0.02 & 0.24 & 2.37 & 11.7 & 29.3 & 40.6 & 15.5 & 0.23 & \\
\hline \multicolumn{10}{|c|}{ Percent of bed material } \\
\hline & 0.2 & 4.9 & 11.0 & 22.8 & 33.2 & 22.2 & 5.6 & 0.05 & \\
\hline \multicolumn{10}{|c|}{ Ratio (percent eroded/percent in bed) } \\
\hline & 0.1 & 0.05 & 0.22 & 0.52 & 0.88 & 1.8 & 2.8 & 5 & \\
\hline
\end{tabular}

Because of this erosion pattern, it is believed that the size distribution of the material which was available for transport was nearly the same as the size distribution of the total bed material and that the computed transport ratios for run $\mathrm{F}$ accurately represent the resistance to motion of the particles.

The transport ratios for run $F$ increased consistently with particle size throughout the entire range of varticle sizes. Therefore, it is concluded that the resistance to motion of sand grains decreases with increasing grain size when the transport is occurring over a poorly sorted bed. There obviously must be some maximum size above which this relation is no longer true. The data presented in table 4 indicate that this maximum size is larger than $0.1 \mathrm{~mm}$.

These results indicate, as the plot of figure 1 suggests, that figure 22 does not correctly depict the resistance to motion for particles for material being transported over a poorly sorted bed material. The resistance to motion should decrease, rather than increase, with increasing particle size for particle sizes within the range of 0.05 to $1.0 \mathrm{~mm}$.

The median size of the total load transported in these small flume experimental runs made at the point of initiation of grain movement was larger than the median size of the bed material, whereas the median size of the total-transport-load samples from the large flume runs was smaller than that of the bed material. In natural streams, total-load sam- ples almost always have smaller median sizes than does the bed material of the stream (Carl F. Nordin, oral commun., April, 1971).

Smaller particles are, of course, more easily entrained and carried in suspension by the flow, and the suspended load always has a smaller median size than does the total load. It is usually impossible to determine the size distribution of the entire suspended load so that the true size distribution of the bed load is seldom known either in the field or in the laboratory.

In addition, the median size of the bed material tends to increase with distance below the mean bed elevation for fully developed bed forms. As a consequence the coarser particles tend not to be exposed to the flow and are not available for transport as frequently as the finer particles deposited at higher elevations in the bed. Their availability would tend to account for a higher transport rate of small particles even though their resistance to motion along the bed is greater than that of larger particles.

The small flume experiment shows that a marked "hiding effect" does exist for a poorly sorted bed material, and this result is consistent with flume and field data. When small grains form only a small part of the surface material as the small opaquemineral grains did in this study prior to their concentration, the selective removal by the flow of larger less dense grains can play an important part in their segregation. 


\section{HEAVY-MINERAL TRANSPORT AND DEPOSITION IN A FLAT-BED FLOW}

Accumulations of dark opaque minerals were widespread in the flat-bed runs (run 4). The accumulations of opaque heavy minerals at the base of the flat-bedded sanas suggested that the heavy minerals were concentrated at the base of the tractive load during degradation and were the first deposited during aggradation. To test this hypothesis, a study was made of the transport of heavy minerals relative to time under equilibrium hydraulic conditions. The small recirculating water-sediment flume (20 $\mathrm{cm}$ deep, $20 \mathrm{~cm}$ wide, and $10 \mathrm{~m}$ long) was used in the experiment with a sand bed of the same Rio Grande sand that was used in the large flume runs. The sand bed was thoroughly mixed after the flow was started. Mixing of the sand provided maximum possible exposure of heavy minerals to the flow. The run, which lasted for 47 hours, was started just after the mixing of the sand.

Hydraulic conditions necessary to form the flat bed were held as constant as possible throughout the run. Average discharge for the run was 10.98 liters per second with an average water depth of $7.36 \mathrm{~cm}$. Water-surface slope was 0.0045 , and the average temperature was $16.9^{\circ} \mathrm{C}$. Total-load samples containing 80-135 grams of sediment were collected at close time intervals (15 $\mathrm{min}$ ) early in the study and at increasingly longer time intervals (up to

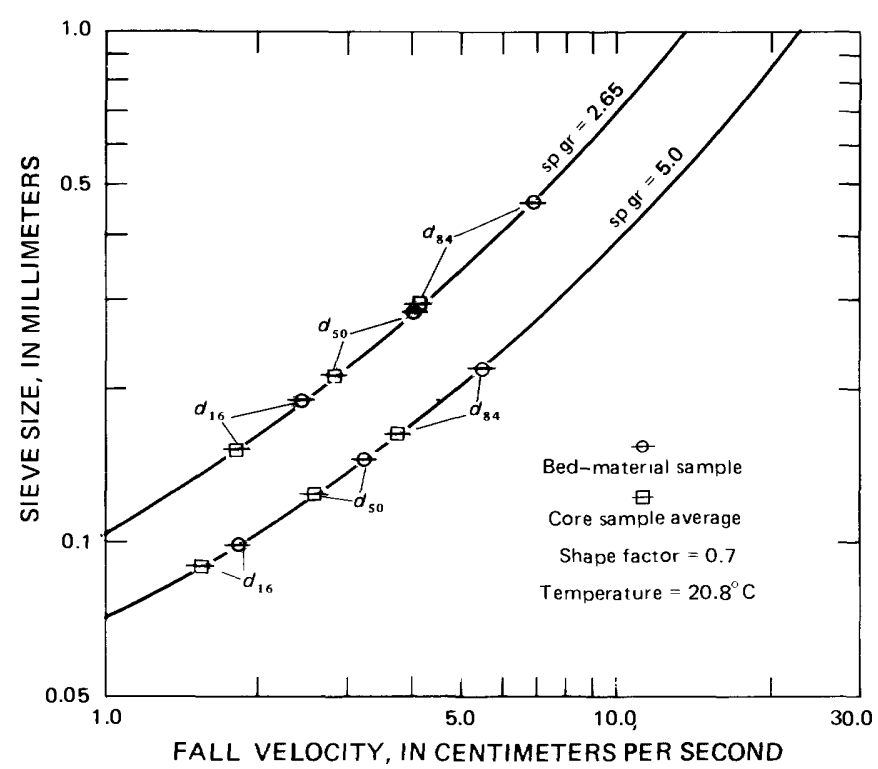

FigURE 20.-Fall-velocity relationship of light-mineral grains to opaque-heavy-mineral grains obtained from the bed-material sample and core samples of runs 2,3 , and 4 .

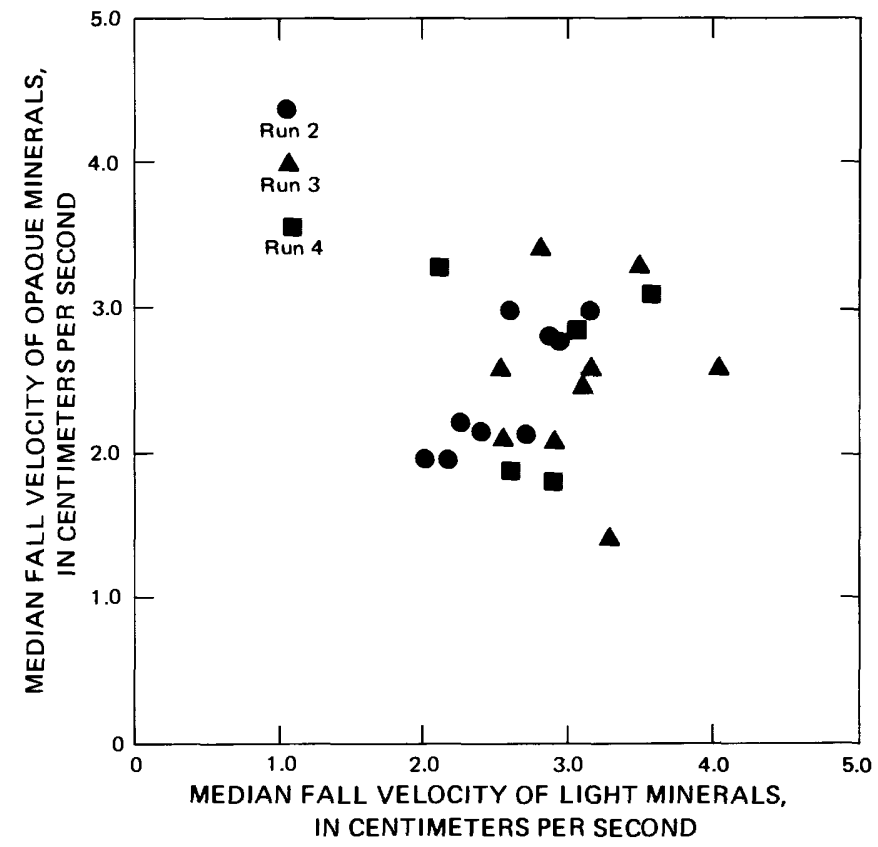

FIGURE 21.-Plot of median fall velocities of opaque-heavymineral grains and light-mineral grains.

$7 \mathrm{hr}$ ) as the study progressed. Total-load concentrations for the study averaged $2,699 \mathrm{mg} / 1$.

Sediment from the total-load sample that passed the 60 mesh $(0.25 \mathrm{~mm})$ sieve was retained for magnetite separation. Magnetite less than $0.25 \mathrm{~mm}$ was used in this study as the marker mineral because of the ease of separation of magnetite and because 88 percent of the dark-opaque-minerals of the bedmaterial sample were finer than $0.25 \mathrm{~mm}$. A strong hand magnet was used to separate the magnetite grains from the sample. The percentage of magnetite in the sand that passed the 60 mesh sieve was calculated, and the results of these percentage plots relative to time (fig. 23) confirm the hypothesis that in a flat-bed flow under equilibrium conditions there is a decreasing volume of transport of heavy minerals with increasing time of transport.

\section{DISCUSSION OF DATA}

\section{RELATIONS AMONG SEDIMENT SAMPLES}

Analysis of variance tests of median sizes and shape factors of opaque-heavy-mineral grains obtained from laminae having high concentrations of opaque heavy minerals show no significant variance at the 5 percent level among sediment samples taken from each of runs 2-4. There was, however, a significant difference at the 1 percent level in sorting 


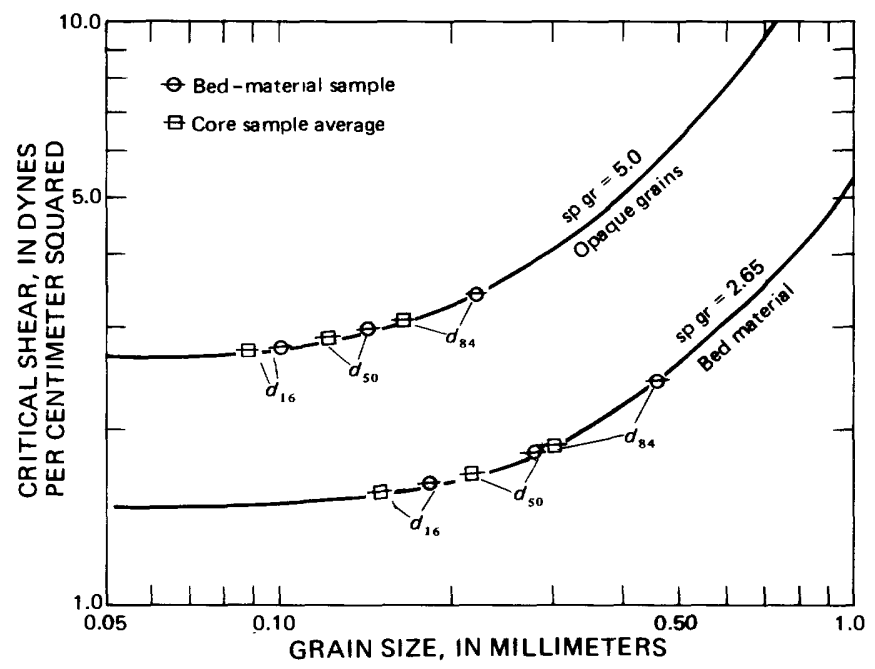

FIGURE 22.-Critical shear relationship of light minerals to opaque heavy minerals for the bed-material and core samples.

among the three runs. Among the light minerals from runs 2-4 sampled from laminae adjacent to the opaque-mineral laminae, a significant difference existed in the median size at the 5 percent level, and no significant difference (5-percent level) existed for the sorting values.

Sorting values determined for opaque-heavymineral samples from run 4 were much larger than for those from other runs. Sorting values for opaqueheavy-mineral samples of run 4 were close to those for dark opaque grains in the bed-material samples. This correlation indicates that all sizes of the high-density material in run 4 were being moved by the flow, whereas sorting of opaque heavy minerals towards finer sizes was occurring in runs 2 and 3.

Sorting is the grain distribution parameter most affected by the different hydraulic conditions. In the flat-bed flow (run 4), segregation apparently occurred first at the base of the bed load and formed a widespread layer of opaque-heavy-mineral grains. As local erosion of the bed occurred, the opaque minerals became concentrated at the base of the flow, and subsequent deposition allowed preservation of the dark laminae. For such a concentrating mechanism, the sorting would have a wide range of values and would depend on the ability of the local flow to sort the sample as to size. The smaller sorting values obtained for the dune flows shows that sorting as to size is accomplished more efficiently in the lower flow regimen.

Analysis of the critical shear stress for grain movement indicates that the larger low-density grains of the bed material require a much smaller shear for movement than the smaller, more dense grains. Relations of velocities of heavy minerals and light-density minerals (figs. 3, 4) and the critical shear relationship of opaque heavy minerals in the bed-material (figs. 1, 22) all seem to support the idea that the less dense grains are much more readily entrained and moved. In addition, the difference in size between the low-density grains and the highdensity grains leads to a "hiding effect" that can effectively shield the smaller grains from the flow.

A large percentage of the light-mineral grains and opaque-heavy-mineral grains in adjacent laminae had fall velocities in the same range. However, comparison of fall velocities of median sizes of the dark-opaque-mineral samples and light-mineral samples from the core samples showed that no correlation exists (correlation coefficient of 0.369 ) for the median values of these two groups. The light-mineral samples were obtained from within (five samples) and adjacent to (18 samples) the opaque-heavymineral laminae. All the light-mineral samples examined were taken from positions within $2 \mathrm{~mm}$ of the sampled heavy-mineral laminae. The lack of correlation and the presence of distinct segregated laminae, even though an adequate supply of both mineral groups having equal fall velocities was available, suggest that factors other than grain fall velocity were important to tha occurrence of local sorting.

Gross transfer of the sediment load, however, may be related to the fall velocities, for the fall velocities of 78 percent of the opaque-heavy-mineral grains in the bed-material samples overlap those of 74 percent of the light-mineral grains in the size distribution range between the 16 th and 84 th percentiles.

Turbulence is more intense in the trough region than on the higher portions of the stoss side or near the brink point of the dune; and, in general, turbulence is more intense near the bed. A large shear stress at the bed, caused by the turbulent eddies, is probably important in the initiating movement of the opaque heavy minerals, especially in the region of the reattachment point.

Intermittency of turbulence was not studied quantitatively, but strong turbulent eddies passing over the crestal region were observed in the flow and strong intermittent turbulence is suggested by the presence of opaque-heavy-mineral laminae in the topset beds. Strong turbulence which increases the local shear could cause a rapid movement of the opaque-heavy-mineral grains from the crestline toward the brinkline-and the low-density material could then move rapidly over the dense grains or be 
carried temporarily in suspension. With a decrease in turbulence, the heavy minerals would be deposited before the light minerals.

\section{BED FORMS AND HYDRAULIC VARIABLES}

Observations of the four runs in this study and other experimental runs made in the large flume, as well as field observations, indicate that the bed configuration is the most important single factor affecting the opaque-heavy-mineral segregation. Bed configuration, however, is not an independent variable but is dependent on a large number of hydraulic variables as shown by Simons and Richardson (1966, p. J13-J16). The most important variables affecting the bed forms are the energy slope, depth of flow, physical properties of the bed material, and velocity of flow. In flume studies, flow velocity is considered to be dependent on the energy slope and depth of flow; however, in field relations, velocity is the independent variable, and depth of flow is probably the dependent variable.

Under the flow conditions of this study there appears to have been three fundamental types of heavy-mineral segregation.

1. Thin accumulations of opaque heavy minerals covering small areas, associated with dunes without topset beds and the stoss slope of large dunes with topset beds.

2. Accumulations of opaque heavy minerals associated with topset deposits of large dunes.

3. Accumulations of opaque heavy minerals that were associated with flat-bed movement of the sediment.

The small areas of thin accumulations of opaque heavy minerals were found in association with ripples and small dunes. On larger dunes small areas of heavy-mineral accumulations formed on the dune stoss slope, commonly in the areas just downstream from the reattachment point of the flow (the location where the flow impedes on the bed after it passes over the upstream dune front). The accumulations of opaque heavy minerals moved up the stoss side of the dune as units, and additional grains were added to the migrating areas during their movement. Dark opaque-heavy-mineral accumulations generally moved as very thin ripples having very large length to height ratios (fig. 10B).

The buildup and movement of these accumulations may be described somewhat as follows. The intense turbulence associated with the reattachment point supplies both heavy and light material to the section just downstream from the reattachment point. Be- fore segregation occurs, the bed at this section consists primarily of rather coarse foreset material. This coarse bed material serves as an effective trap for the small dense particles supplied to the area (figs. 1, 22). As more and more of the dense particles are trapped and segregated at this location, a small area of the bed will become covered. Once covered, the area becomes more resistant to erosion (fig. 22 ), and the erosion of the light particles around the heavy-mineral area tends to expose the accumulation to increasingly stronger flow conditions. Finally the segregated accumulation starts to move up the stoss slope of the dune as the dense particles are eroded from the upstream edge of the accumulation, move across the relatively smooth surface of the heavy mineral area, and are deposited at the downstream edge of accumulation. All during this process large quantities of the larger less dense particles are transported over the smooth surface of the accumulation.

Large areas of opaque-heavy-mineral accumulations often were associated with topset deposits that occurred on large dunes and transition bed forms. The greatest thicknesses of accumulations of dark opaque-mineral grains were associated with this type of deposit. Three different situations associated with the topset accumulations of opaque-heavymineral grains were as follows: (1) Accumulations that occurred along the crestal region of the dunes. These opaque-heavy-mineral accumulations moved downstream with the dune if the dune maintained approximately the same shape and height. Losses from the crestal region were offset by additions of heavy minerals from upstream areas. (2) Laminae of opaque heavy minerals that occurred downstream from the crestline were found both upon and within

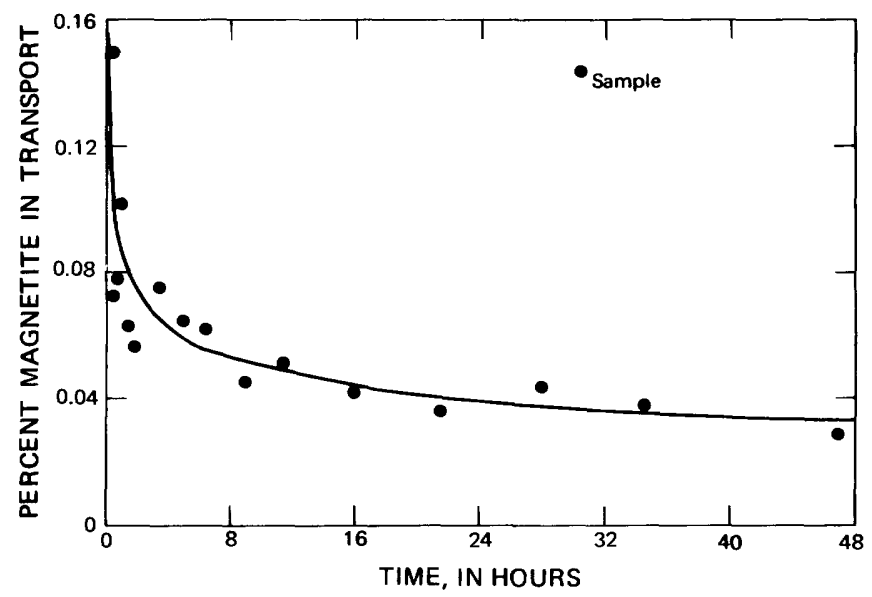

FIgURE 23.-Relation of magnetite in transport to time in $20-\mathrm{cm}$ flume and under flat-bed conditions. 
the topset beds. These heavy-mineral deposits were derived from a crestal accumulation. (3) Foreset laminae of opaque-heavy-mineral grains. The segregated opaque-heavy-mineral laminae in the foreset could be traced up slope in many cases into the topset beds. The foreset accumulations were caused by conditions similar to those that deposited the opaqueheavy-mineral laminae in the topset beds except that the heavy-mineral grains were transported in sufficient quantities past the brink point to allow some to slide down the lee slope and form the concentrated laminae in the foreset beds. A decrease in degree of concentration of opaque-heavy-mineral grains within laminae with distance down the foreset indicates a diluting of the opaque heavy minerals with low density grains or a decrease in the proportions of opaque heavy minerals transported to that point.

When accumulations of opaque heavy minerals are deposited just past the brinkline in the foreset beds, a periodicity of transport is indicated by the alternate layers of light and heavy minerals in the foreset sequence (fig. 14A). The most plausible explanation of this alternation is that strong intermittent turbulent eddies increased motion of the high-density grains and moved them past the brink point of the dune and that most of the lower density material was either carried into suspension by the increased turbulence or moved rapidly over the small, high-density grains.

The bed-surface elevation of flat-bed flow under equilibrium conditions varied randomly with time but by only a few centimeters from a mean elevation at any location. Therefore, for thick laminae of opaque heavy minerals to form in a flat-bed flow it is important that a flow condition produce a deep scour (in this study, a transition flow) prior to the flat-bed flow. Such erosion is necessary in order to expose the heavy minerals in a thick section of bed material to the flat-bed flow.

During the flat-bed run, accumulations of opaque heavy minerals occurred near the base of the tractive load. Other accumulations of opaque heavy minerals that were present within the flat beds probably also represent heavy minerals deposited in the same way as those at the base of the flat beds but subsequent to deposition of the basal accumulations. Results of the $20-\mathrm{cm}$ flume experiment show a decrease with time in the-volume of heavy-mineral grains transported in a flat-bed flow at near equilibrium conditions. This decrease in heavy-mineral transport indicates that a large percentage of the heavy minerals were deposited early during the flow and that the heavy minerals either remained at rest or were reentrained at a rate that was less than the rate of deposition.

On dunes, the thickest accumulations of opaque heavy minerals occurred in the topset bed area near the crest of the dune. Runs 2 and 3 had large dunes that had a fairly large crest-to-brink distance and topset beds that had large areas of thick heavymineral accumulation associated with them, while dunes of run 1 had a crestline corresponding to the brinkline, and no topset beds or large areas of concentrated heavy minerals.

In order to determine why the opaque heavy minerals form large accumulations near the crest of dunes, consider the expression for the rate of sediment transport as given by Simons, Richardson, and Nordin (1965b)

$$
\frac{\partial y}{\partial t}+\left(\frac{1}{1-\lambda}\right)\left(\frac{\partial q_{b}}{\partial x}\right)=0
$$

where $y=$ elevation of the bed surface, $t=$ time, $\lambda=$ porosity of the sand bed, $q_{b}=$ bed-load transport rate in volume per unit time per unit width, and $x=$ distance along the bed surface in the direction of the flow. This equation states that the rate of change of bed elevation with time (that is, the rate of deposition or erosion) is proportional to the rate of change of bed-load transport with respect to distance. From the negative ratio obtained by applying this equation to the area upstream from the crest of a dune, it is apparent that this is a region of erosion. Erosion is needed in order to keep the thin accumulations on the stoss slope of the dunes exposed to the flow so that they continue to move. However, downstream from the crest of the dune $\partial y / \partial t$ is positive, indicating that this is generally a region of deposition. Because of their large resistance to motion, dark opaque minerals are selectively deposited from the moving bed load after it passes over the crest. The net result is that the thin accumulations move up the stoss slope of the dune and are deposited just downstream from the crest. At this point the heavy minerals accumulate to rather large thicknesses, for the material is transported out of the region only by occasional bursts of extreme turbulence. Thick accumulations probably could not build up in run 1 because the crestline and brinkline were coincident; the brink point is a place where the grains can be lost to suspension and to the foreset material.

Topset beds were deposited with a small dip angle in the downstream direction (generally $4^{\circ}-6^{\circ}$ ) between the crestline and the brinkline. In general 
appearance the topset beds resembled planar beds of a flat-bed run.

The topset beds are generally composed of material which is finer than the bed material. At first, this appears to be paradoxical since, as can be seen from equation 22 , the crestal region represents the region of the flow where the transport capacity of the flow is greatest. The topset material must be selectively deposited from the moving load that passes the crest. The particles with the greatest resistance to motion should be deposited first. Thus, the segregation by the flow; that is deposit of the finer material in the topset beds and transport of the coarse material on to the brink point, indicates that the trend of the resistance to motion with increasing sieve size is opposite to that indicated in figure 22. This reverse trend can be predicted by qualitatively adjusting figure 22 using the information provided in figure 1 and the experimental results presented in table 4. Results of field experiments by Rathbun, Kennedy, and Culbertson (1971, p. I43-I45) show that up to a limiting size, the coarser material in a flat-bed flow has greater velocities than the central sizes of the grain distribution.

\section{CONCLUSIONS}

1. The type of bed configuration appears to be the most important factor affecting local segregation of heavy minerals in an open channel flow. Bed configuration, however, is not an independent variable but is dependent on a large number of hydraulic variables, the most important being energy slope, depth of flow, velocity of flow, and the physical properties of the bed material.

2. Three fundamental types of heavy-mineral accumulations were observed in this study.

a. Small areas of thin accumulations of opaque heavy minerals that were associated with the stoss side of dunes. They move as thin ripples and commonly originate in the area just downstream from the reattachment point.

b. Accumulations of opaque-heavy-mineral grains that were associated with the topset deposits of large dunes. These accumulations often formed thick deposits along and adjacent to the crestal area of the dune. Opaque-heavy-mineral segregations were also present within the topset beds, at the surface between the crestline and brinkline, and some formed deposits in the foreset beds. The segregated layers in the foreset beds were probably due to mass transport of heavy minerals from the topset area past the brinkline by strong turbulent motion.

c. Accumulations of opaque heavy minerals that were associated with the flat-bed flows. The thickest and most widespread of the flat-bed segregations of heavy minerals generally occurred at the base of the flat beds, but additional laminations of heavy minerals were present in the flat beds.

3. Among the sediment properties of size, sorting, and shape obtained for opaque heavy minerals from core samples taken from the bed, the only significant variance that occurred between runs 2, 3, and 4 was a difference in the sorting of the opaque-heavy-mineral grains.

4. Theoretical considerations indicate a distinct difference exists in the transport rates of spheres of different densities moving as bed load. The initiation of motion of grains is illustrated by the Shields diagram (fig. 5). Based on the Shields criteria, curves can be developed to show the relationship between critical shear and grain size for materials of different densities. The curves constructed clearly show that the opaque heavy minerals are much more resistant to motion than the light minerals.

5. Theoretical analysis and experimental results illustrate that the size of the particle in transport as well as the size of the bed material affects the resistance of a particle to tractive motion. For the particle sizes of interest in this study, it is found that a particle's resistance to tractive motion over a poorly sorted bed material decreases with increasing particle size at least in the size range studied.

6. Fall velocity values for median sizes of opaqueheavy-mineral grains and associated light minerals from laminae adjacent to or within the opaque-mineral laminae are not correlated. This lack of correlation and the presence of distinct segregated laminae, suggests that fall velocity alone has little or no effect on the local sorting of heavy minerals.

\section{REFERENCES}

Allen, J. R. L., 1968, Current ripples-their relation to patterns of water and sediment motion: Amsterdam, NorthHolland Publishing Co., 433 p. 
American Society of Civil Engineers, Task Committee on Preparation of Sedimentation Manual, 1962, Introduction and properties of sediment; Am. Soc. Civil Engineers Proc., v. 88, no. HY4, p. 77-107.

1966, Sedimentation transportation mechanics: Initiation of motion: Am. Soc. Civil Engineers Jour., v. 92, no. HY2, p. 291-314.

American Society of Civil Engineers, Task Force on Bed Forms in Alluvial Channels, 1966, Nomenclature for bed forms in alluvial channels: Am. Soc. Civil Engineers Proc., v. 92, no. HY3, p. 51-64.

Bagnold, R. A., 1966, An approach to the transport problem irom general physics: U. S. Geol. Survey Prof. Paper 422-I, $37 \mathrm{p}$.

Brady, L. L., 1971, An experimental study in a large flume of heavy mineral segregation under alluvial flow conditions: Ph.D. dissert., Lawrence, Kans., Univ. Kansas, $115 \mathrm{p}$.

Coleman, N. L., 1967, A theoretical and experimental study of drag and lift forces acting on a sphere resting on a hypothetical streambed: Internat. Assoc. Hydraulic Research Cong., 12th, Proc., Fort Collins, Colo. U.S.A., v. 3 , p. $185-192$.

Corey, A. T., 1949, Influence of shape on the fall velocity of sand grains: M.S. thesis, Fort Collius, Colo., Colorado State Univ., $102 \mathrm{p}$.

Daily, J. W., and Harleman, D. R. F., 1966, Fluid dynamics: Reading, Mass., Addison-Wesley Publishing Co., $454 \mathrm{p}$.

Einstein, H. A., 1950, The bed load function for sediment transportation in open channel flows: U.S. Dept. Agriculture Tech. Bull. 1026, $70 \mathrm{p}$.

Einstein, H. A., and Chien, N., 1953, Transport of sediment mixtures with large ranges of grain sizes: Berkeley, Calif., Univ. California Inst. Engineering Research, $49 \mathrm{p}$.

El-Sammi, E. A., 1949, Hydrodynamic forces on particles in the surface of a stream bed: Ph.D. dissert., Berkeley, Calif. Univ. California.

Grigg, N. S., and Rathbun, R. E., 1969, Hydraulic equivalence of minerals with consideration of the reentrainment process, in Geological Survey research 1969; U.S. Geol. Survey Prof. Paper 650-B, p. B77-B80.

Guy, H. P., Simons, D. B., and Richardson, E. V., 1966, Summary of alluvial channel data from flume experiments: U.S. Geol. Survey Prof. Paper 462-I, 96 p.

Henderson, F. M., 1966, Open channel flow: New York, The MacMillan Co., 522 p.

Ippen, A. T., and Verma, R. P., 1955, Motion of particles on bed of a turbulent stream: Am. Soc. Civil Engineers Trans., v. 120, p. 921-939.

Kennedy, J. F., 1963, The mechanics of dunes and antidunes in erodible-bed channels: Fluid Mechanics Jour., v. 16, p. 521-544.

Lane, E. W., 1947, Report of the Subcommittee on Sediment Terminology: American Geophysical Union Trans., v. 28, p. $936-938$.

McQuivey, R. S., and Keefer, T. N., 1969, The relation of magnetite over ripples in Geological Survey research 1969: U.S. Geol. Survey Prof. Paper 650-D, p. D244D247.

Rathbun, R. E., Kennedy, V. C., and Culbertson, J. K., 1971, Transport and dispersion of fluorescent tracer particles for the flat-bed condition, Rio Grande Conveyance Channel, near Bernardo, New Mexico: U.S. Geol. Survey Prof. Paper 562-I, 56 p.

Raudkivi, A. J., 1967, Loose boundary hydraulics: Oxford, Pergamon Press, 331 p.

Richardson, E. V., and McQuivey, R. S., 1968, Measurement of turbulence in water: Am. Soc. Civil Engineers Proc., v. 94, no. HY2, p. 411-430.

Rittenhouse, G., 1943, Transportation and deposition of heavy minerals: Geol. Soc. American Bull., v. 54, p. 1725-1780.

Rubey, W. W., 1933, The size distribution of heavy minerals within a waterlaid sandstone: Jour. Sed. Petrology, v. 3, p. 3-29.

Schultz, E. F., Wilde, R. H., and Albertson, M. L., 1954, Influence of shape on the fall velocity of sedimentary particles: U.S. Army Corps of Engineers, Missouri River Div., Sediment Ser., no. 5, 161 p.

Sears, F. W., and Zemansky, M. W., 1963, University physics, [3d ed.], pt. 1: Reading, Mass., Addison-Wesley Publishing Co., 548 p.

Sheen, S. J., 1964, Turbulence over a sand ripple: M.S. thesis, New Zealand, Univ. Auckland.

Shields, A., 1936, Anwendung der Ahnlichkeitsmechanik und der Turbulenzforschung auf die Geschiebebewegung: Mitteilungen der Press. Versuch anst. f. Wasserbau u. Schiffbau., Berlin, no. 26, 26 p.; Application of similarity principles and turbulence research to bed load movement-translated to English by W. P. Ott and J. C. van Uchelen, U.S. Dept. Agriculture, Soil Conservation Service Coop Lab., Calif. Inst. Technology, Pasadena, $21 \mathrm{p}$.

Simons, D. B., and Richardson, E. V., 1963, Forms of bed roughness in alluvial channels: Am. Soc. Civil Engineers Trans., v. 128, p. 284-302.

1966, Resistance to flow in alluvial channels: U.S. Geol. Survey Prof. Paper 422-J, 61 p.

Simons, D. B., Richardson, E. V., and Nordin, C. F., Jr., 1965a, Forms generated by flow in alluvial channels: Soc. Econ. Paleontologists and Mineralogists Spec. Pub. 12, p. 34-52.

1965b, Bed load equations for ripples and dunes: U.S. Geol. Survey Prof. Paper 462-H, 9 p.

Sokal, R. R., and Rohlf, F. J., 1969, Biometry: San Francisco, W. H. Freeman and Co., 776 p.

Streeter, V. L., 1966, Fluid Mechanics, 4th ed.: New York, McGraw-Hill Book Co., 705 p.

Tourtelot, H. A., 1968, Hydraulic equivalence of grains of quartz and heavier minerals, and implications for the study of placers: U.S. Geol. Survey Prof. Paper 594-F, $13 \mathrm{p}$.

U.S. Inter-Agency Committee on Water Resources, 1957, Some fundamentals of particle size analysis, Report 12 of A study of methods used in measurement and analysis of sediment loads in streams: Washington, U.S. Govt. Printing Office, $55 \mathrm{p}$.

1958, Operator's manual on the visual-accumulation-tube method for sedimentation analysis of sands, Report $\mathrm{K}$ of $\mathrm{A}$ study of methods used in measurement and analysis of sediment loads in streams: $30 \mathrm{p}$.

Watters, G. Z., and Rao, M. V. P., 1971, Hydrodynamic effects of seepage on bed particles: Am. Soc. Civil Engineers Proc., v. 97, no. HY3, p. 421-439. 


\section{APPENDIX}




\section{A. SYMBOLS AND NOMENCLATURE}

\section{Symbol Definition}

$A$ Area, such as the cross-sectional area of the flume.

$A_{s} \quad$ Projected area of a sphere.

a Longest diameter of a grain with three mutually perpendicular axes.

$b$ Intermediate diameter of a grain with three mutually perpendicular axes.

$C_{D} \quad$ Coefficient of drag for a sediment particle. The coefficient of drag varies with the particle geometry, relation of particle shape to flow, and the Reynolds number of the flow.

$C_{F} \quad$ Coefficient of friction for a sediment particle. The coefficient of friction depends primarily on the nature of the particle surface and the surface of the material with which it is in contact.

$C_{L} \quad$ Coefficient of lift for a sediment particle. The coefficient of lift depends on the shape of the particle, relation of particle shape to flow, and the Reynolds number of the flow.

$C_{R} \quad$ Coefficient of static resistance of a sediment particle. The coefficient of static resistance depends on the shape and size of the particle and the arrangement, size, and shape of the bed particles.

Shortest diameter of a grain with three mutually perpendicular axes.

$D \quad$ Flow depth.

d Diameter of a spherical particle.

$d_{B} \quad$ Diameter of spheres making up bed material.

$d_{m} \quad$ Diameter of a sphere resting on the bed.

$d_{s}$ Diameter of a grain-equal to sieve diameter or approximately equal to $b$ diameter of a particle.

$F_{D} \quad$ Hydrodynamic drag force-force exerted by the flow on the particle parallel to the relative motion of the flow.

$F_{F} \quad$ Frictional force-resistance to motion between two bodies in contact.

$F_{G} \quad$ Gravity force.

$F_{L} \quad$ Hydrodynamic lift force-the force component produced by the flow on a particle that is perpendicular to the direction of the flow and opposite to the gravity force.

$F_{N} \quad$ Resultant force normal to the bed surface.

F Froude number $=\bar{U} / \sqrt{g D}$-a ratio of inertial forces to gravitational forces.

$g \quad$ Gravitational constant $\left(980 \mathrm{~cm}\right.$ per $\left.\sec ^{2}\right)$.

$H$ Dune height-vertical distance from trough point to crest point.

$k \quad$ Ratio $d_{m}$ to $d_{B}$.

$L \quad$ Dune length-measured from trough of a given dune to trough point of the next dune upstream.

$n \quad$ Number count of a given size in grain-size analysis.

$Q \quad$ Fluid discharge (cubic meter per sec).

$q_{B} \quad$ Bed-load discharge-weight of sediment carried in bed load per unit width per unit of time.

$q_{b} \quad$ Bed-load discharge-volume per unit width per unit time.

Re Reynolds number $=\frac{\bar{U} D}{v}-\mathbf{a}$ ratio of inertial forces to viscous forces for the mean flow.

R* Particle Reynolds number $=U_{*} d / v-$ a ratio of in-
Symbol

Definition

ertial forces to viscous forces relative to a particle.

$R^{\prime} \quad$ Hydraulic radius a channel would have if the resistance to flow were limited to grain roughness (no resistance due to bed-form or streambank roughness). This term can be stated in terms of the average flow depth, $D$, with corrections for bed-form roughness.

$S \quad$ Energy slope of the fluid.

$t$ Time.

$U \quad$ Fluid velocity.

$\bar{U} \quad$ Mean fluid velocity.

$U_{*} \quad$ Shear velocity $=\sqrt{\tau_{0} / \rho}$. The shear velocity is not a real velocity but is related to the real velocity which would give rise to shear stress $\tau_{0}$ (Henderson, 1966, p. 412).

$V$ Velocity of flow at a representative distance from the bed.

$V_{0} \quad$ Relative velocity of flow past a body.

$V$. Velocity of translation of a particle.

$W \quad$ Channel width.

$x \quad$ Distance along bed surface.

$Y \quad$ Elevation of the bed surface.

$y \quad$ Height above the bed surface.

$\gamma \quad$ Specific weight of water.

$\gamma_{s} \quad$ Specific weight of a sediment grain.

$\eta \quad$ Eddy viscosity that depends on the state of turbulent motion.

Angle between the bed and horizontal line.

Porosity of the bed.

Dynamic viscosity of the fluid.

Kinematic viscosity of the fluid $=\frac{\mu}{\rho}-$ a ratio of viscosity to mass density.

$\rho \quad$ Mass density of water.

$\rho_{s} \quad$ Mass density of a particle.

$\sigma$ Geometric standard deviation of a sediment size distribution.

$$
\sigma=\frac{1}{2}\left(\frac{d_{50}}{d_{10}}+\frac{d_{84}}{d_{50}}\right)
$$

Shear stress in the fluid. For turbulent flow

$$
\tau=(\mu+\eta) \frac{d U}{d Y}
$$

and for laminar flow

$$
\tau=\mu \frac{d U}{d Y}
$$

$\tau_{0} \quad$ Average shear stress at the bed $=\gamma D S$-force per unit area acting on the bed in the direction of flow.

$\tau_{0}$ Critical shear stress for sediment particles-the minimum amount of shear stress necessary to start movement of particles at the bed.

$\tau$ Dimensionless shear stress (Shields entrainment function) $=$

$$
\frac{\tau_{0}}{\left(\gamma_{s}^{-} \gamma\right) d_{s}}
$$

$\phi \quad$ Einstein's intensity of bed-load transport.

$\psi \quad$ Einstein's intensity of shear on a particle. 


\section{B. GRAIN-MOUNT PREPARATION AND RELATIONSHIP OF DIRECT GRAIN MEASUREMENTS TO SIEVE-SIZE EQUIVALENTS}

Preparation of grain mounts-Grain mounts for size analyses were prepared for the bed-material sample, core samples and many of the suspendedsediment samples studied. Where loose sample grains were used, as they were from the bed-material sample, the sample was reduced by a microsplitter to the desired size. For samples of opaque-heavymineral grains and light-mineral grains that were obtained from selected laminations or areas of a grouted core, the material was removed by use of a blunted dissecting needle. Both types of samples were prepared by distributing the grains as evenly as possible onto a petrographic slide that had previously been covered with alcohol. The grains, in settling through the alcohol, oriented themselves with their shortest axis ( $c$ axis) perpendicular to the slide. Measurement of 500 grains for shape factor analysis showed that this orientation occurred for 88 percent of the grains. Those grains with the $c$ axis lying parallel to the slide usually had a $c$ axis length very similar to the intermediate axis ( $b$ axis) length.

When the alcohol evaporated, a residue remained that caused the grains to adhere to the slide. After grain shape studies were made, Lakeside 70 and a cover glass were applied for permanent mounting and grain-size measurement.

Sieve-analysis equivalent of direct measurementMounted mineral grains were measured directly by use of a petrographic microscope with a calibrated eyepiece that was divided into units of 12.1 microns. For most samples, intermediate axes ( $b$ axis) were measured in units of 200 grains per slide. Where more than 200 measurements were used for a given sample, additional slides were made.

If an abundance of material was available, as it was for the bed-material sample, grains were selected by an equal-interval point-count method. A pattern of evenly spaced intervals was made by use of a modified stage micrometer mounted on the microscope. If a grain was present under the stage stop, that grain was measured. A stage interval was selected that was large enough to prevent repetition of individual grain measurements.

Slides made from samples with limited amounts of material (samples from grouted cores) were analyzed by a line-measurement technique. In the line method, horizontal traverses were made over the slide at equal intervals and the $b$ axis was measured for each grain of the particular mineral being studied that the line crossed.

The probability that a grain will be measured by the point method is in direct proportion to its projected area on the slide, and the probability that a grain will be "hit" by the line method is in direct proportion to its diameter as measured perpendicular to the traverse line. Neither of these methods, however, allows for differences in the thickness of the grains perpendicular to the slide.

Opaque heavy minerals and light minerals were studied separately, and both groups had mean shape factors (appendix C) of near equant shape (0.680.75 shape factor); therefore, a relation between measured size and sieve equivalence was determined.

In order to make the direct measurements equivalent to the size equivalents determined by sieving, a common measuring factor was used. The best common standard for such a relation was the nominal grain diameter defined as the diameter of a sphere that has the same volume as the particle (Lane, 1947, p. 937). The U.S. Inter-Agency Committee on Water Resources (1957, p. 31, 33-35) developed graphs from extensive studies that show the relation of the intermediate axes of grains to their nominal diameters and the sieve-size equivalents of grains to their nominal diameters for various shape factors. Based on the graphs of the U.S. Inter-Agency Committee on Water Resources (1957, figs. 4,5 ), the sieve diameter equivalent of the grains is 0.85 times the value of the direct intermediate axis measurement (using a shape factor of 0.7 ) for the grain sizes in this study.

Besides adjustments to convert $b$ axis to sievesize measurement, other factors had to be considered in conversion of direct measurement to the weight frequencies of a sieve analysis; these factors include adjusting for different grain thicknesses and assuring that a certain size grain occurred in the measurement in its correct proportion relative to the total grain-size population. Differences in grain thicknesses were corrected by multiplying the $b$ size frequency count by the $b$-axis diameter. To compute a weight frequency distribution from direct measurement, the following manipulations of the direct $b$-axis measurements were made.

1. For the line method, the size frequency was determined by taking the percentage of each size from the sum of the sizes determined by $\Sigma n b^{2}$, where $n$ is the $b$-axis frequency and $b$ is the $b$-axis size.

2. For the point-count method, the size frequency 
was determined by taking the percentage of each size from the sum of the sizes determined by $\Sigma n b$.

Cumulative curves were plotted with the weighted percentages as the ordinate and with the $b$-axis values multiplied by 0.85 , the correction factor, on the abscissa.

A check of the 0.85 conversion factor was made by using the bed-material sample. The results showed close agreement to a sieve analysis of the same material except on the large-grain-size end (fig. 9). Direct measurement of the $b$ axis of 1,000 grains showed a weighted median value of 0.338 $\mathrm{mm}$ and a sorting $(\sigma)$ of 1.56. A sieved sample of the same bed material gave a median value of $0.285 \mathrm{~mm}$ and a sorting of 1.58 . The sorting values of the sieved sample and of the weighted direct measurements were similar. Applying the correction factor of 0.85 to the median diameter of 0.338 $\mathrm{mm}$ determined by direct measurement gives a corrected value of $0.289 \mathrm{~mm}$, which is in good agreement with the median diameter of $0.285 \mathrm{~mm}$ determined from sieve data.

Values stated in the text of this study for a given grain-size measurement are the sieve-size equivalent values determined by the method just described and by the use of 0.85 as the size conversion factor.

\section{ANALYSES OF OPAQUE-HEAVY-MINERAL GRAINS AND LIGHT-MINERAL GRAINS FROM CORE SAMPLES (RUNS 2-4)}

Data on size and sorting shown for each of the samples in tables 5 and 6 were determined from direct measurement of 200 individual grains using techniques described in appendix $B$. The bedmaterial size analyses, however, were based on 1,000 measurements.

Twenty grain measurements per sample were made for determination of mean shape factor. The shape factor used in this report was originally defined by Corey (1949) as

$$
\text { S.F. }=\frac{c}{\sqrt{a b}}
$$

for three mutually perpendicular axes of the grains, where $a=$ maximum diameter of the grain,

$b=$ intermediate diameter of the grain, and

$c=$ smallest diameter of the grain.

One advantage in the use of the Corey shape factor over other shape factors is the extensive experimental data available on sediment analysis by Schultz, Wilde, and Albertson (1954) and a summarization by the U.S. Inter-Agency Committee on Water Resources (1957) of the work in which the Corey shape factor was used. Discussion of the (Text continues on p. 37.)

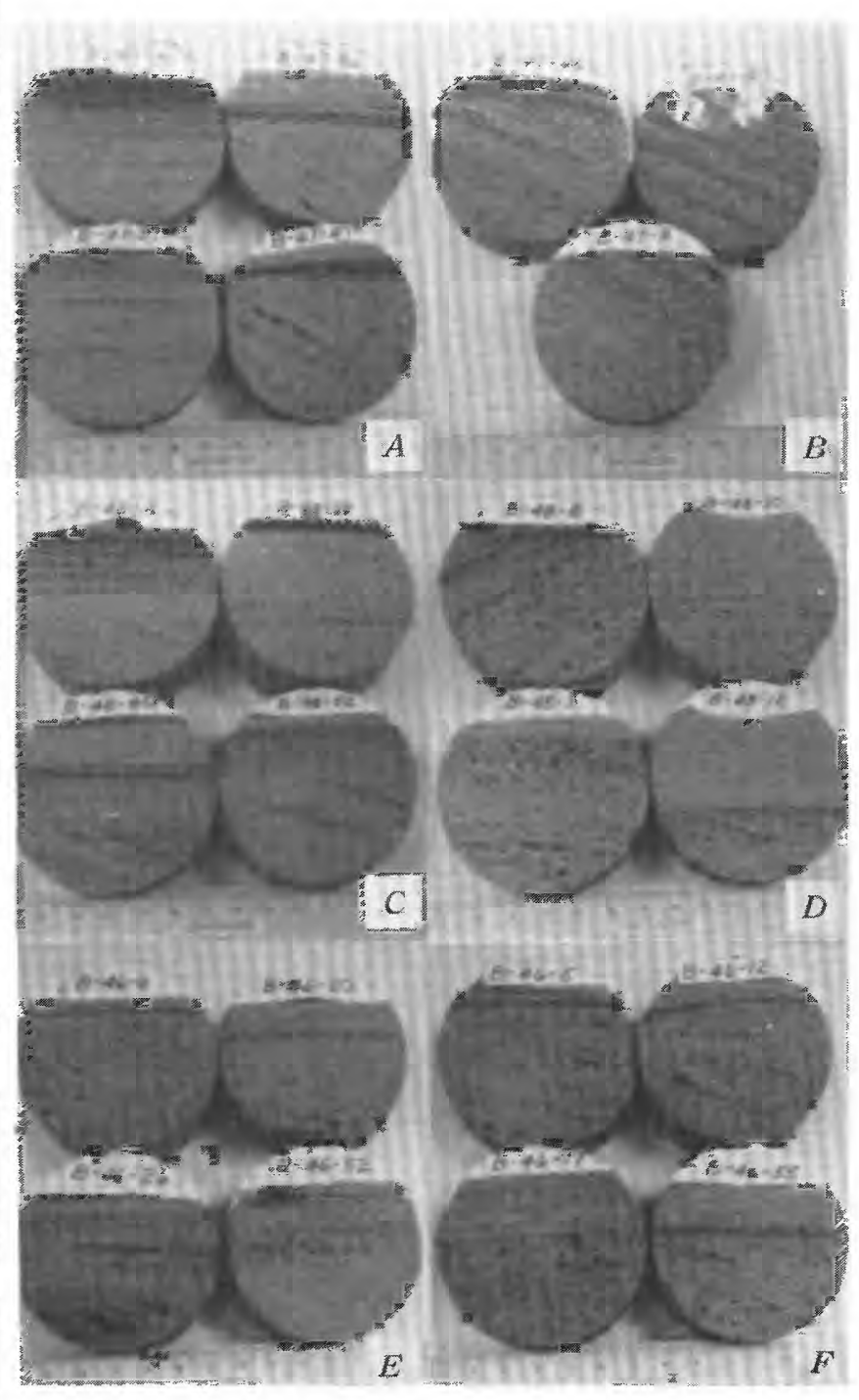

FIGURE 24.-Sections of core samples showing opaque-heavymineral beds. $A$, Run 2-topset beds (sample B-47-X was obtained from a crestal accumulation) ; $B$, Run 2 -foreset beds; $C$, Run 3-topset beds; $D$, Run 3-foreset beds (sample B-48-B) and flat bed area (samples B-48-3, 10, and 12) ; $E$, Run 4-within the flat bed deposits; $F$, Run 4-at the base of the flat beds. 
TABLE 5.-Size analyses of opaque heavy minerals from core samples

\begin{tabular}{|c|c|c|c|c|c|c|}
\hline \multirow[b]{2}{*}{ Sample } & \multicolumn{3}{|c|}{ Median } & \multirow[b]{2}{*}{$\begin{array}{l}\text { Sorting } \\
(\sigma)\end{array}$} & \multirow[b]{2}{*}{$\begin{array}{l}\text { Shape } \\
\text { factor }\end{array}$} & \multirow[b]{2}{*}{ Description of location in bed 1} \\
\hline & $\left(\begin{array}{c}d_{50} \\
(\mathrm{~mm})\end{array}\right.$ & $\begin{array}{c}d_{16} \\
(\mathrm{~mm})\end{array}$ & $\underset{(\mathrm{mm})}{d 84}$ & & & \\
\hline
\end{tabular}

Representative sample of bed material

\begin{tabular}{lllllll}
\hline Bed Material & $-\ldots$ & 0.144 & 0.099 & 0.220 & 1.49 & 0.684 \\
\hline
\end{tabular}

Run 2

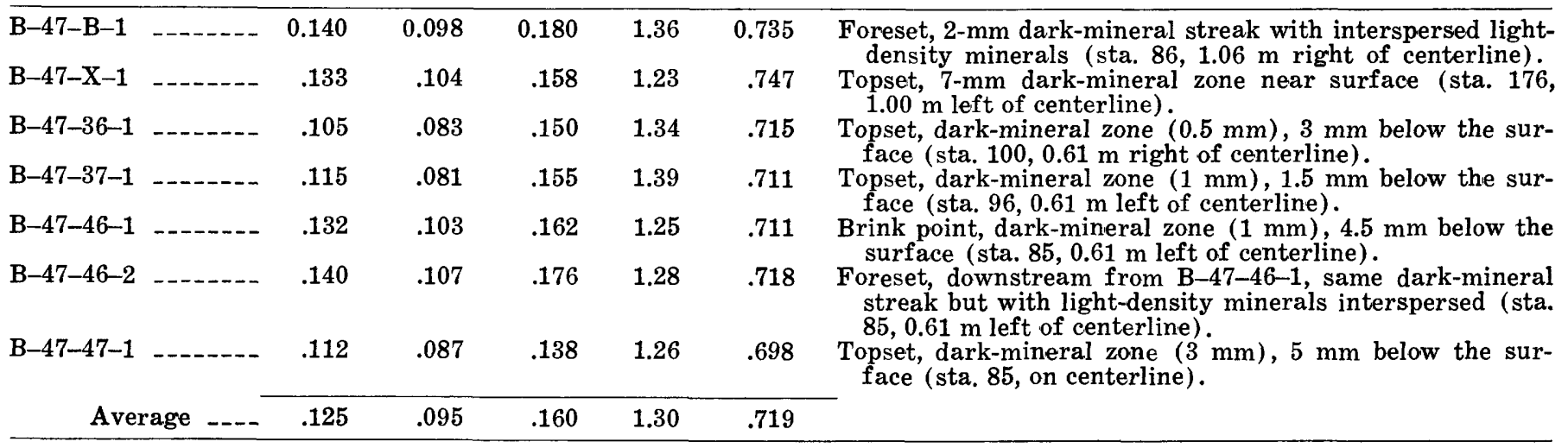

Run 3

\begin{tabular}{|c|c|c|c|c|c|c|c|}
\hline B-48-A-1 & $-1-1-$ & .126 & .101 & .154 & 1.23 & .754 & $\begin{array}{l}\text { Topset, thickest laminae in zone, } 1.5 \mathrm{~mm} \text { thick of several } \\
\text { thin dark-mineral laminations; } 5 \mathrm{~mm} \text { from surface (sta. } \\
98,1.07 \mathrm{~m} \text { right of centerline). }\end{array}$ \\
\hline B-48-B-1 & - - & .154 & .102 & .198 & 1.40 & .744 & $\begin{array}{l}\text { Topset (near brink point), dark-mineral zone }(1 \mathrm{~mm}) \text { at } \\
\text { base of topset } 3 \mathrm{~mm} \text { from surface (sta. } 114,0.79 \mathrm{~m} \text { left } \\
\text { of centerline). }\end{array}$ \\
\hline B-48-B-2 & 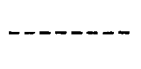 & .150 & .115 & .192 & $1.29^{\circ}$ & .769 & $\begin{array}{l}\text { Foreset, } 2 \text {-mm dark-mineral zone with interspersed light- } \\
\text { density minerals (sta. 114.2, } 0.79 \mathrm{~m} \text { left of centerline). }\end{array}$ \\
\hline B-48-10-1 & $\ldots$ & .087 & .063 & .111 & 1.33 & .724 & $\begin{array}{l}\text { Flat Bed, dark-mineral zone }(0.5 \mathrm{~mm}) 35 \mathrm{~mm} \text { from the } \\
\text { surface (sta. } 18,0.61 \mathrm{~m} \text { left of centerline). }\end{array}$ \\
\hline B-48-40-1 & & .122 & .088 & .154 & 1.32 & .723 & $\begin{array}{l}\text { Topset, uppermost dark-mineral laminae }(0.5 \mathrm{~mm}) \text { in } \\
\text { dark-mineral zone } 17 \mathrm{~mm} \text { from surface (sta. } 90,0.61 \mathrm{~m} \\
\text { left of centerline). }\end{array}$ \\
\hline B-48-52-1 & $---1-$ & .110 & .082 & .145 & 1.33 & .751 & $\begin{array}{l}\text { Topset, dark-mineral zone }(0.5-1 \mathrm{~mm}) 4 \mathrm{~mm} \text { below the } \\
\text { surface ( } \mathrm{sta} .74,0.61 \mathrm{~m} \text { left of centerline). }\end{array}$ \\
\hline \multicolumn{2}{|c|}{ Average } & .125 & .093 & .159 & 1.31 & .741 & \\
\hline
\end{tabular}

Run 4

\begin{tabular}{|c|c|c|c|c|c|c|}
\hline B-46-5-1 & .144 & .102 & .218 & 1.46 & .744 & $\begin{array}{l}\text { Dark-mineral zone }(1.5 \mathrm{~mm}) \text { at base of flat-bed sands, } 6 \\
\mathrm{~mm} \text { from surface (sta. } 176 \text {, on centerline). }\end{array}$ \\
\hline$B-46-12-1 \quad-\cdots$ & .100 & .076 & .120 & 1.26 & .715 & $\begin{array}{l}\text { Dark-mineral zone ( } 1 \mathrm{~mm} \text { ) at base of flat-lying sand, } 8 \\
\mathrm{~mm} \text { from surface (sta. } 168,0.61 \mathrm{~m} \text { right of centerline). }\end{array}$ \\
\hline$B-46-20-1 \quad \ldots$ & .135 & .095 & .173 & 1.35 & .693 & $\begin{array}{l}\text { Dark-mineral zone }(0.5 \mathrm{~mm}) \text { interbedded with light-den- } \\
\text { sity, flat-lying sand, } 11 \mathrm{~mm} \text { from surface (sta. 110, on } \\
\text { centerline). }\end{array}$ \\
\hline B-46-20-2 & .103 & .070 & .150 & 1.47 & .748 & $\begin{array}{l}\text { Mixed dark-mineral and light-density minerals zone (1.5 } \\
\mathrm{mm} \text { ) just below sample } \mathrm{B}-46-20-1 \text {. Taken } 20 \mathrm{~mm} \text { above } \\
\text { base of flat-bed sand (sta. 110, on centerline). }\end{array}$ \\
\hline$B-46-52-1 \quad \ldots$ & .150 & .082 & .205 & 1.59 & .781 & $\begin{array}{l}\text { Zone of dark minerals with interspersed light-density } \\
\text { minerals ( } 1 \mathrm{~mm}), 16 \mathrm{~mm} \text { below surface, } 35 \mathrm{~mm} \text { above } \\
\text { base of flat-bedded sands (sta. } 130 \text {, on centerline). }\end{array}$ \\
\hline
\end{tabular}


TABLE 5.-Size analyses of opaque heavy minerals from core samples-Continued

\begin{tabular}{|c|c|c|c|c|c|c|}
\hline \multirow[b]{2}{*}{ Sample } & \multicolumn{3}{|c|}{ Median } & \multirow[b]{2}{*}{$\begin{array}{l}\text { Sorting } \\
(\sigma)\end{array}$} & \multirow[b]{2}{*}{$\begin{array}{l}\text { Shape } \\
\text { factor }\end{array}$} & \multirow[b]{2}{*}{ Description of location in bed 1} \\
\hline & $\begin{array}{c}d_{50} \\
(\mathrm{~mm})\end{array}$ & $\begin{array}{c}d_{18} \\
(\mathrm{~mm})\end{array}$ & $\begin{array}{c}d_{54} \\
(\mathrm{~mm})\end{array}$ & & & \\
\hline $\bar{B}-46-55-1$ & .135 & .086 & .173 & 1.43 & .757 & $\begin{array}{l}\text { Dark-mineral zone with interbedded light-density grains } \\
\text { (zone is } 2.5 \mathrm{~mm} \text { thick) at base of flat-bedded material, } \\
15 \mathrm{~mm} \text { from surface (sta. 155, on centerline). }\end{array}$ \\
\hline
\end{tabular}

Runs 2-4

$\begin{array}{llllll}\text { Average --- } & .127 & .091 & .165 & 1.35 & .735\end{array}$

1 Stations along the flume are designated in feet $(1 \mathrm{ft}=0.3048 \mathrm{~m}$ ) downstream from the headbox. (Example: the distance between sta. 100 and sta. 110 is $10 \mathrm{ft}(3.05 \mathrm{~m})$.

TABLE 6.-Size analyses of light minerals associated with opaque heavy minerals in the core sample

\begin{tabular}{|c|c|c|c|c|}
\hline \multirow[b]{2}{*}{ Sample } & \multicolumn{2}{|c|}{ Median } & & \multirow[b]{2}{*}{ Description of location in bed 1} \\
\hline & $\begin{array}{c}d_{50} \\
(\mathrm{~mm})\end{array}$ & $\begin{array}{c}d_{16} \\
(\mathrm{~mm})\end{array}$ & $\begin{array}{c}\text { Sorting } \\
(\sigma)\end{array}$ & \\
\hline
\end{tabular}

Representative sample of bed material

\begin{tabular}{llllll}
\hline Bed material & $\ldots$ & 0.287 & 0.190 & 0.462 & 1.56 \\
\hline
\end{tabular}

\section{Run 2}

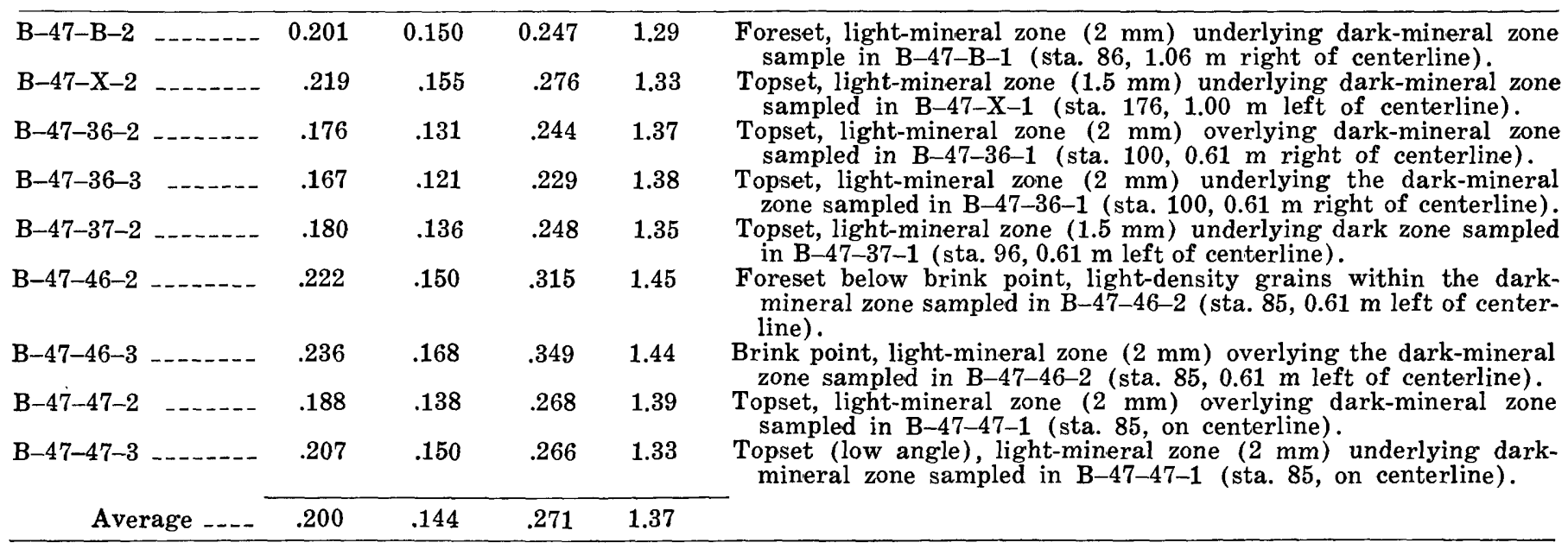

Run 3

\begin{tabular}{|c|c|c|c|c|c|c|}
\hline B-48-A-2 & $---\cdots$ & 0.236 & 0.170 & 0.309 & 1.35 & $\begin{array}{l}\text { Topset, light-mineral zone }(2 \mathrm{~mm}) \text { underlying the dark-mineral } \\
\text { zone sampled in B-48-A-1 (sta. } 98,1.07 \mathrm{~m} \text { right of centerline). }\end{array}$ \\
\hline B-48-B-2 & - & .254 & .183 & .343 & 1.37 & $\begin{array}{l}\text { Foreset, light-density minerals from within the zone where dark } \\
\text { minerals were sampled in B-48-B-2 (sta. 114, } 0.79 \mathrm{~m} \text { left of } \\
\text { centerline). }\end{array}$ \\
\hline B-48-B-4 & $\ldots$ & .212 & .151 & .280 & 1.36 & $\begin{array}{l}\text { Topset (near brink point), light-mineral zone }(1.5 \mathrm{~mm} \text { ) overlying } \\
\text { the dark-mineral zone sampled in B-48-B-1 (sta. 114, } 0.79 \mathrm{~m} \\
\text { left of centerline). }\end{array}$ \\
\hline
\end{tabular}


TABLE 6.-Size analyses of light minerals associated with opaque heavy minerals in the core sample-Continued

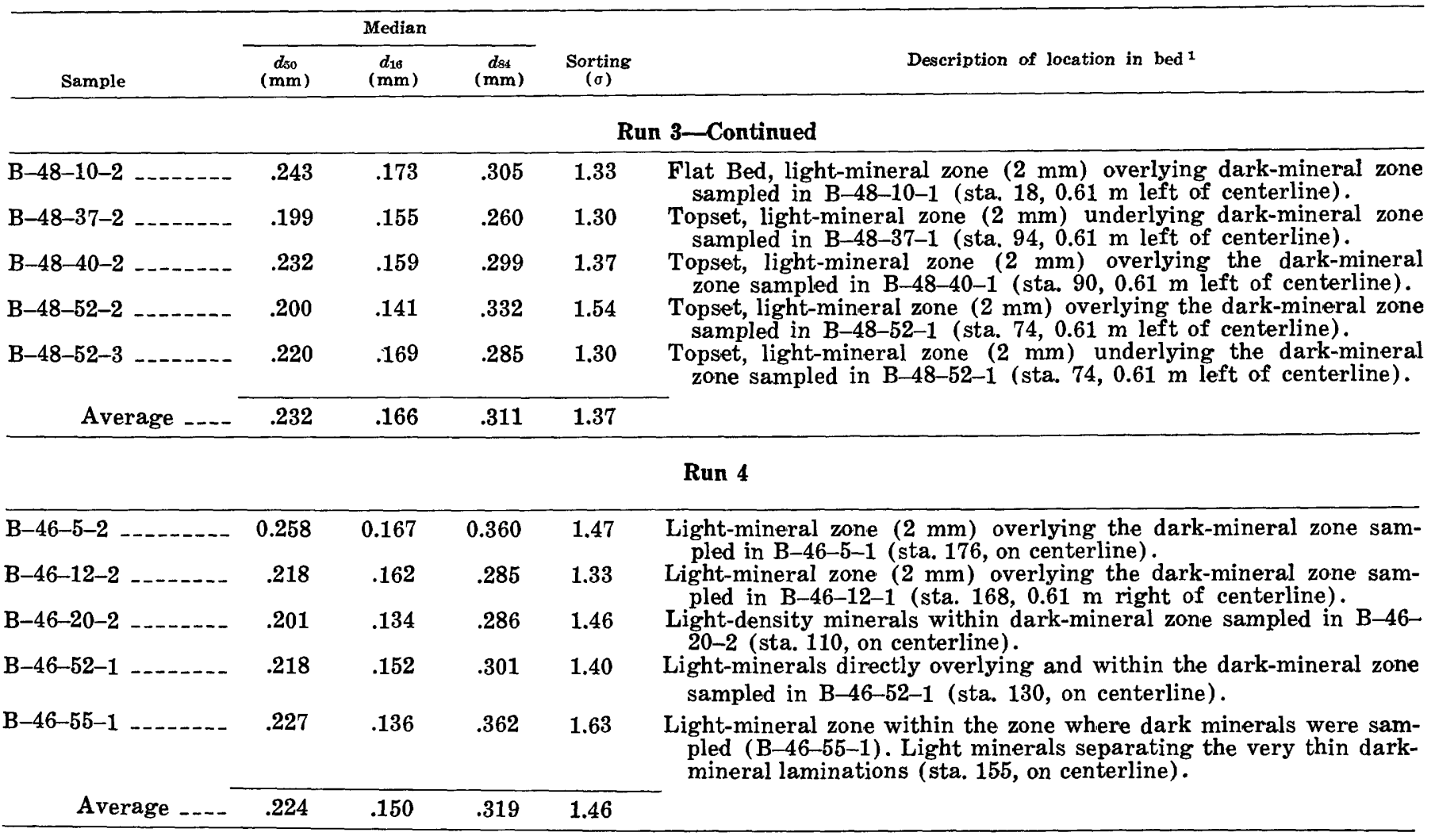

Runs 2-4

$\begin{array}{lllll}\text { Average -.-- } & 0.218 & 0.154 & 0.297 & 1.40\end{array}$

1 Stations along the flume are expressed in feet $(0.3048 \mathrm{~m})$ in a down stream direction.

Corey shape factor's relation to other shape factors is presented by Tourtelot (1968, p. F4-F7).

Measurements of the shape factor determined for the bed-material sample of opaque heavy minerals and of light minerals were each based on 60 shape factor measurements, 20 measurements on each of three grain mount slides.

For identifying the numbers in tables 5 and 6 , the following criteria should be used:

$$
\mathrm{B}-47-\mathrm{B}-1
$$
(1)
(2)
(3) (4)

1. The "B" refers to a "bed" sample as opposed to a "S" for suspended sample (appendix D).

2. The " 47 " refers to a continuous flume experiment series run number. The following numbers are the designated run numbers for this study:

$$
\begin{aligned}
& 45=\text { Run } 1 \\
& 47=\text { Run } 2
\end{aligned}
$$

$$
\begin{aligned}
& 48=\text { Run } 3 \\
& 46=\text { Run } 4
\end{aligned}
$$

3. The " $B$ " used in the example is a selected core sample. All letters in the third position designate selected samples, while numbers indicate core samples obtained in the established sample network. Numbers and letters used are usually consecutive except for " $X$ " used in run 2.

4. The " 1 " in the fourth position designates the grain mount number made from the particular core sample.

Examples of horizontal core samples obtained from the bed including the cores from which the bed sample of light mineral and opaque heavy mineral grains were obtained are shown in figure 24. (See p. 34.) 


\section{SEDIMENT CONCENTRATION AND SIZE ANALYSES OF SUSPENDED-SEDIMENT SAMPLES}

TABLE 7.-Size analyses and concentration of suspended-sediment samples

\begin{tabular}{|c|c|c|c|c|c|c|c|}
\hline \multirow[b]{2}{*}{ Run } & \multirow[b]{2}{*}{ Location } & \multirow{2}{*}{$\begin{array}{c}\text { Height } \\
\text { above bed } \\
\text { (cm) }\end{array}$} & \multirow{2}{*}{$\begin{array}{c}\text { Concentration } \\
(\mathrm{mg} / 1)\end{array}$} & \multicolumn{3}{|c|}{ Size 1} & \multirow{2}{*}{$\underset{(\sigma)}{\text { Sorting }}$} \\
\hline & & & & $\begin{array}{c}d_{50} \\
(\mathrm{~mm})\end{array}$ & $\begin{array}{c}d_{16} \\
(\mathrm{~mm})\end{array}$ & $\begin{array}{c}d_{84} \\
(\mathrm{~mm})\end{array}$ & \\
\hline \multirow[t]{11}{*}{$1 \ldots$} & Trough & 33.6 & 122 & 0.146 & 0.116 & 0.184 & 1.26 \\
\hline & & 18.3 & 236 & .186 & .154 & .225 & 1.21 \\
\hline & & 9.2 & 475 & .172 & .132 & .215 & 1.28 \\
\hline & & 3.1 & 501 & .172 & .134 & .217 & 1.28 \\
\hline & Brink point & 24.4 & 66 & .158 & .127 & .200 & 1.25 \\
\hline & & 18.3 & 130 & .143 & .108 & .179 & 1.25 \\
\hline & & 9.2 & 117 & .148 & .116 & .187 & 1.27 \\
\hline & & 3.1 & 290 & .165 & .128 & .212 & 1.29 \\
\hline & Stoss side & 18.3 & 291 & .174 & .140 & .207 & 1.22 \\
\hline & & 9.2 & 234 & .174 & .140 & .216 & 1.24 \\
\hline & & 3.1 & 343 & .177 & .146 & .224 & 1.24 \\
\hline \multirow[t]{12}{*}{$2 \ldots \ldots$} & Trough & 42.7 & 458 & .138 & .104 & .172 & 1.29 \\
\hline & & 30.5 & 2304 & .187 & .146 & .230 & 1.26 \\
\hline & & 24.4 & 1554 & .173 & .123 & .209 & 1.31 \\
\hline & & 9.2 & 2022 & .186 & .128 & .244 & 1.38 \\
\hline & Brink point & 36.6 & 176 & .127 & .092 & .157 & 1.31 \\
\hline & & 18.3 & 256 & .138 & .101 & .184 & 1.35 \\
\hline & & 12.2 & 345 & .140 & .103 & .183 & 1.33 \\
\hline & & 3.1 & 551 & .145 & .110 & .184 & 1.29 \\
\hline & Stoss side & 33.6 & 391 & .140 & 107 & .176 & 1.28 \\
\hline & & 21.4 & 513 & .157 & .116 & .205 & 1.33 \\
\hline & & 9.2 & 569 & .146 & .107 & .190 & 1.33 \\
\hline & & 3.1 & 763 & .150 & .120 & .188 & 1.25 \\
\hline \multirow{8}{*}{$3 \ldots$} & Stoss side & 33.6 & 59 & .130 & .102 & .165 & 1.27 \\
\hline & & 18.3 & 328 & .155 & .117 & .212 & 1.35 \\
\hline & & 9.2 & 279 & .144 & .112 & .184 & 1.28 \\
\hline & & 3.1 & 618 & .146 & .115 & .184 & 1.26 \\
\hline & Flat bed & 27.5 & 25 & .116 & .090 & .159 & 1.33 \\
\hline & & 21.4 & 39 & .119 & .096 & .150 & 1.25 \\
\hline & & 12.2 & 218 & .134 & .105 & .160 & 1.24 \\
\hline & & 7.6 & 974 & .172 & .133 & .220 & 1.29 \\
\hline \multirow[t]{4}{*}{$4-\ldots$} & Flat bed & 33.6 & 512 & .123 & .088 & .156 & 1.33 \\
\hline & & 21.4 & 940 & .136 & .099 & .168 & 1.30 \\
\hline & & 9.2 & 2103 & .151 & .110 & .195 & 1.33 \\
\hline & & 3.1 & 6477 & .183 & .133 & .226 & 1.31 \\
\hline
\end{tabular}

\footnotetext{
${ }^{1}$ Size determined by VA-tube sedimentation analysis.
} 
Sediment Transport in Alluvial Channels, I $966-$ i 972

GEOLOGICAL S URVEY PROFESIONAL PAPER 562

This volume was published

as separate chapters $A-K$ 
UNITED STATES DEPARTMENT OF THE INTERIOR

ROGERS C. B. MORTON, Secretary

GEOLOGICAL SURVEY

V. E. McKelvey, Director 


\section{CONTENTS}

[Letters designate the separately published chapters]

(A) Sediment transport in Cache Creek drainage basin in the Coast Ranges west of Sacramento, California, by Lawrence K. Lustig and Robert D. Busch.

(B) Flume experiments on the transport of a coarse sand, by Garnett P. Williams.

(C) The behavior of large particles falling in quiescent liquids, by G. E. Stringham, D. B. Simons, and H. P. Guy.

(D) Response of a laboratory alluvial channel to changes of hydraulic and sedimenttransport variables, by R. E. Rathbun, H. P. Guy, and E. V. Richardson.

(E) Fluorescent sand as a tracer of fluvial sediment, by Vance C. Kennedy and Dorothy L. Kouba.

(F) Statistical properties of dune profiles, by Carl F. Nordin, Jr.

(G) Field measurement of the initiation of large bed particle motion in Blue Creek near Klamath, California, by E. J. Helley.

(H) Flume width and water depth effects in sediment-transport experiments, by Garnett P. Williams.

(I) Transport and dispersion of fluorescent tracer particles for the flat-bed condition, Rio Grande conveyance channel near Bernardo, N. Mex., by R. E. Rathbun, V. C. Kennedy, and J. K. Culbertson.

(J) Summary of alluvial-channel data from Rio Grande conveyance channel, New Mexico, 1965-69, by J. K. Culbertson, C. H. Scott, and and J. P. Bennett.

(K) An experimental study of heavy mineral segregation under alluvial-flow condiditions, by Lawrence L. Brady and Harvey E. Jobson. 